\begin{abstract}
Recent concerns regarding global warming and energy security have accelerated research and developmental efforts to produce biofuels from agricultural and forestry residues, and energy crops. Anaerobic digestion is a promising process for producing biogas-biofuel from biomass feedstocks. However, there is a need for new reactor designs and operating considerations to process fibrous biomass feedstocks. In this research project, the multiphase flow behavior of biomass particles was investigated. The objective was accomplished through both simulation and experimentation. The simulations included both particle-level and bulk flow simulations.
\end{abstract}

Successful computational fluid dynamics (CFD) simulation of multiphase flow in the digester is dependent on the accuracy of constitutive models which describe (1) the particle phase stress due to particle interactions, (2) the particle phase dissipation due to inelastic interactions between particles and (3) the drag force between the fibres and the digester fluid. Discrete Element Method (DEM) simulations of Homogeneous Cooling Systems (HCS) were used to develop a particle phase dissipation rate model for non-spherical particle systems that was incorporated in a two-fluid CFD multiphase flow model framework. Two types of frictionless, elongated particle models were compared in the HCS simulations: glued-sphere and true cylinder. A new model for drag for elongated fibres was developed which depends on Reynolds number, solids fraction, and fibre aspect ratio. Schulze shear test results could be used to calibrate particle-particle friction for DEM simulations.

Several experimental measurements were taken for biomass particles like olive pulp, orange peels, wheat straw, semolina, and wheat grains. Using a compression tester, the breakage force, breakage energy, yield force, elastic stiffness and Young's modulus were measured.

Measurements were made in a shear tester to determine unconfined yield stress, major principal stress, effective angle of internal friction and internal friction angle. A liquid fludized bed system was used to determine critical velocity of fluidization for these materials. Transport measurements for pneumatic conveying were also assessed.

Anaerobic digestion experiments were conducted using orange peel waste, olive pulp and wheat straw. Orange peel waste and olive pulp could be anaerobically digested to produce high methane yields. Wheat straw was not digestible. In a packed bed reactor, anaerobic digestion was not initiated above bulk densities of $100 \mathrm{~kg} / \mathrm{m}^{3}$ for peel waste and $75 \mathrm{~kg} / \mathrm{m}^{3}$ for olive pulp. Interestingly, after the digestion has been initiated and balanced methanogenesis established, the decomposing biomass could be packed to higher densities and successfully digested. These observations provided useful insights for high throughput reactor designs. Another outcome from this project was the development of low cost devices to measure methane content of biogas for off-line (US\$37), field (US\$50), and online (US\$107) applications. 


\section{Collaboration}

Professor Kalmans laboratory possesses unique solids handling and characterization facilities not available to the US collaborators. Kevin Buettner, $\mathrm{PhD}$ student on this project spend some time in Professor Kalman's laboratory during the first year of project. He conducted particle characterization experiments with the equipment available there. The data collected was used in modeling work. Additionally, observations from experimental work helped in incorporating modifications to model. In addition, he also assisted Professor Kalman's laboratory in setting up and shaking down the pneumatic conveying experimental test rig. Data collected from this rig is presented in the report. Particle characterization data from Dr. Kalman's experiments were used to validate the parameter values estimated from DEM and CFD model simulations. 
BARD Final Report US-4877-15

\title{
Investigation of particulate flow behavior in a continuous, high solids, leach-bed biogasification system
}

\author{
Pullammanappallil, P.C. University of Florida Board of Trustees \\ Kalman, H. Ben-Gurion University of the Negev \\ Curtis, J. University of Florida Board of Trustees
}

\section{Main Scientific Achievements}

Recent concerns regarding global warming and energy security have accelerated research and developmental efforts to produce biofuels from agricultural and forestry residues, and energy crops. Anaerobic digestion is a promising process for producing biogas-biofuel from biomass feedstocks. Anaerobic digestion is a biochemical process in which the concerted action of a mixed culture of microorganisms convert organic compounds (like carbohydrates, proteins and fats) to biogas under anaerobic conditions. Anaerobic digesters are commonly implemented in farms to process various types of manure and biogas used as an energy source on site. However, biogas can also be produced from agricultural residues (like sugarbeet tops and tailings, olive processing waste, hay, straw etc.) and energy crops (example sorghum, sugar beets, grasses etc.) which would enhance the energy production in farm. However, an operational issue with high-solids digestion is the removal of digested residue as it tends to pack at the bottom of the vessel. These problems arise due to the fact that the design of these systems does not account for the flow properties of the three-phase system (gas, liquid, biomass particles) within the digester. Therefore, there is a need for new reactor designs and operating considerations to process fibrous biomass feed-stocks. In order to develop better tools for new reactor designs for fibrous biomass feed-stocks the project was divided to three parts:

1. Anaerobic digestion experiments with reactors using fibrous biomass.

2. Developing CFD-DEM models for fibrous and flexible particles to be used later to design new reactors.

3. Characterization of biomass particles to be used later with CFD-DEM simulations.

For the purposes of evaluating anaerobic digestion of organic materials, two anaerobic digesters were assembled. Biogasification experiments were carried out using orange peels, olive pulp and 
wheat straw. Experiments with different bulk densities were carried out with the orange peels. It was found that only when bulk densities were at or below $100 \mathrm{~kg} / \mathrm{m}^{3}$, balanced decomposition was initiated and the material was successfully digested. It appeared that a low bulk density was required to initiate decomposition, however once balance methanogenesis has been established, the biomass undergoes successful digestion at higher bulk densities. The olive pulp had to be bulked to around $75 \mathrm{~kg} / \mathrm{m}^{3}$ before it could be successfully digested. Like with peel waste, after onset of balanced decomposition, the biomass could be bulked to around $250 \mathrm{~kg} / \mathrm{m}^{3}$ for continued digestion. These observations provided useful insights for high throughput reactor designs. Wheat straw could not be successfully digested even at very low bulk density.

As a by-product of the research an inexpensive, portable device for off-line measurement of methane content of biogas samples was constructed. The off-line design was assembled for a cost of only US\$37, a field version assembled for under US\$50, automatic and on-line device online device was about \$107 as compared to measurement devices like gas chromatographs that cost thousands of dollars. It should be emphasized that such a device is required for any future research with anaerobic digesters or even for the purpose of controlling such a device operation on farms. The Discrete Element Method (DEM) was developed for flexible fibres, such as biomass, in both the wet and dry state incorporated in a two-fluid CFD multiphase flow model framework. In the DEM simulations, a flexible fibre is formed in an innovative way by connecting a number of spheres in a line using deformable virtual bonds. A number of parameters had to be defined for the use of the simulation, such as developing a new model for drag for elongated fibres, which depends on Reynolds number, solids fraction, and fibre aspect ratio. In addition, Schulze shear test results could be used to calibrate particle-particle friction for DEM simulations. The developed model can be used for a number of applications including new reactor designs and optimization.

Using the computational simulations, the effects of several key fibre properties on flexible, dry particle bulk flow behavior were explored and some scientific achievements were gained. It was found that the angle of internal friction initially increases with the fibre-fibre friction coefficient and then asymptotes to an upper limit. An increase in fibre bending modulus can lead to a reduction in the fibre volume fraction and bulk density, but the fibre bending modulus shows no effect on the fibre shear stress with the same normal stress and fibre-fibre friction coefficient. In addition, the elastic modulus that determines the fibre-fibre contact stiffness does not affect the fibre shear stress either. When the fibre volume fraction approaches the maximum packing density, the fibre- 
fibre friction coefficient can be a more dominant factor than the liquid bridge force in determining the fibre solid-phase shear stress.

In addition, the angles of repose of dry and wet flexible and rigid fibres were simulated, and the DEM simulation results are in good agreement with these experimental results. In the shear flow of wet fibres, significant agglomeration is observed. The size of the largest agglomerate in the fibre flow was found to depend on a Bond number, which is proportional to liquid surface tension and inversely proportional to the square of the shear strain rate. The scientific benefit of developing such a tool is huge and much is remains to be revealed in the future.

Several experimental measurements and characterizations were taken for biomass particles like olive pulp, orange peels, wheat straw, semolina, and wheat grains. Using a compression tester, the breakage force, breakage energy, yield force, elastic stiffness and Young's modulus were measured. Measurements were made in a shear tester to determine unconfined yield stress, major principal stress, effective angle of internal friction and internal friction angle. A liquid fludized bed system was used to determine critical velocity of fluidization for these materials. Transport measurements for pneumatic conveying were also assessed.

This part of the research applied, in one hand, known techniques (developed mainly for minerals) to characterize biomass particles. But, in other hand it also developed new techniques for the purpose of use with new design of new reactors and with appropriate CFD-DEM simulations. The bending tests were developed in the frame of this project to enable measuring of elastic and strength properties for elongated particles, such as wheat straws. Another innovative characterization methods developed here is the use of the Jenike Shear Tester totally immersed in liquid. In this way internal and wall friction coefficients for particles in liquid can be measured at the first time.

\section{Agricultural and/or economic impacts of the research findings}

It is too early to be able to evaluate the full potential of the research findings. However, new methods of characterization as well as new simulation models for fibers have a significant contribution to the scientific community. This is obviously leading to economic impacts. All of these tools enable to design new and optimum reactors to use agricultural residues for energy savings. There is no doubt that developing of cheap and reliable methane content of biogas samples measurement devices have a significant economic impact on the field. 


\section{Investigation of particulate flow behavior in a continuous, high solids, leach-bed biogasification Ssystem Pratap C Pullammanappallil ${ }^{1}$, Haim Kalman ${ }^{2}$ and Jennifer Curtis ${ }^{1}$} 1. University of Florida 2. Ben-Gurion University of the Negev

\section{ABSTRACT}

Recent concerns regarding global warming and energy security have accelerated research and developmental efforts to produce biofuels from agricultural and forestry residues, and energy crops. Anaerobic digestion is a promising process for producing biogas-biofuel from biomass feedstocks. However, there is a need for new reactor designs and operating considerations to process fibrous biomass feedstocks. In this research project, the multiphase flow behavior of biomass particles was investigated. The objective was accomplished through both simulation and experimentation. The simulations included both particle-level and bulk flow simulations.

Successful computational fluid dynamics (CFD) simulation of multiphase flow in the digester is dependent on the accuracy of constitutive models which describe (1) the particle phase stress due to particle interactions, (2) the particle phase dissipation due to inelastic interactions between particles and (3) the drag force between the fibres and the digester fluid. Discrete Element Method (DEM) simulations of Homogeneous Cooling Systems (HCS) were used to develop a particle phase dissipation rate model for non-spherical particle systems that was incorporated in a two-fluid CFD multiphase flow model framework. Two types of frictionless, elongated particle models were compared in the HCS simulations: glued-sphere and true cylinder. A new model for drag for elongated fibres was developed which depends on Reynolds number, solids fraction, and fibre aspect ratio. Schulze shear test results could be used to calibrate particle-particle friction for DEM simulations.

Several experimental measurements were taken for biomass particles like olive pulp, orange peels, wheat straw, semolina, and wheat grains. Using a compression tester, the breakage force, breakage energy, yield force, elastic stiffness and Young's modulus were measured.

Measurements were made in a shear tester to determine unconfined yield stress, major principal stress, effective angle of internal friction and internal friction angle. A liquid fludized bed system was used to determine critical velocity of fluidization for these materials. Transport measurements for pneumatic conveying were also assessed.

Anaerobic digestion experiments were conducted using orange peel waste, olive pulp and wheat straw. Orange peel waste and olive pulp could be anaerobically digested to produce high methane yields. Wheat straw was not digestible. In a packed bed reactor, anaerobic digestion was not initiated above bulk densities of $100 \mathrm{~kg} / \mathrm{m}^{3}$ for peel waste and $75 \mathrm{~kg} / \mathrm{m}^{3}$ for olive pulp. Interestingly, after the digestion has been initiated and balanced methanogenesis established, the decomposing biomass could be packed to higher densities and successfully digested. These observations provided useful insights for high throughput reactor designs. Another outcome from this project was the development of low cost devices to measure methane content of biogas for off-line (US\$37), field (US\$50), and online (US\$107) applications. 


\section{INTRODUCTION}

Recent concerns regarding global warming and energy security have accelerated research and developmental efforts to produce biofuels from agricultural and forestry residues, and energy crops. Production of biofuels, whether liquid or gas, from such agricultural or forestry feedstock, requires the processing of fibrous biomass in a reactor. Typical approach has been to process the material in a slurry form in a stirred reactor. For example, enzymatic saccharification of biomass as a pretreatment step to ethanol fermentation is carried out in agitated vessels. In order to provide agitation, the solids content in the slurry cannot exceed a certain concentration (about $12 \%$ ), which then limits the product yield. Instead, processing of material in unagitated reactors would be advantageous as higher concentrations of solids could be handled. This proposal addresses the production of biogas (60\% methane and rest carbon dioxide) from organic wastes and energy crops in an anaerobic digester. Anaerobic digestion is a biochemical process in which the concerted action of a mixed culture of microorganisms convert organic compounds (like carbohydrates, proteins and fats) to biogas under anaerobic conditions. Anaerobic digesters are commonly implemented in farms to process various types of manure and biogas used as an energy source on site. However, biogas can also be produced from agricultural residues (like sugarbeet tops and tailings, olive processing waste, hay, straw etc.) and energy crops (example sorghum, sugar beets, grasses etc.) which would enhance the energy production in farm.

Biogasification of biomass can be carried out in unagitated, high-solids, leach-bed anaerobic digesters. The leach-bed, high-solids digesters have several advantages over other anaerobic digestion systems as they (1) do not require addition of large quantities of water as the digestion is carried out at $35 \%$ solids content, (2) do not involve pumping of solids/slurry during digestion, and (3) do not require agitation of digester contents which contrary to conventional wisdom guarantees rapid and stable start-up and operation of anaerobic digestion. However, an operational issue with high-solids digestion is the removal of digested residue as it tends to pack at the bottom of the vessel. There are several commercial high-solids anaerobic digestion installations in Europe, where operators frequently encounter this problem. These problems arise due to the fact that the design of these systems does not account for the flow properties of the three-phase system (gas, liquid, biomass particles) within the digester. A batch digestion process is attractive because as the one-off charge of feedstock is degraded, the mass that has to be 
removed is reduced and the whole digester content can be emptied by opening up the vessel completely. However, batch processing is inefficient as considerable digester volume is unused. As the biomass feedstock is degraded, it also compacts leading to unused space within the digester. Compaction of solids results in lower permeability which can cause liquid channeling, gas accumulation within the bed that expels liquid, and dead zones where volatile organic acids accumulate causing the $\mathrm{pH}$ to drop. This in turn retards the kinetics of the reactions, slowing down the product formation rates. In addition, difficulties in removing digested residue often arise, as the residue tends to pack in the vessel. Continuous digestion systems, on the other hand, overcome this problem as empty volume is replenished with fresh feedstock. Another digester operational issue occurs when the bed of biomass within the digester compacts and floats to the top when it becomes buoyant due to the gas entrapped within the bed. Therefore, high solids digesters need to incorporate features for bulking as well as continuous removal of gas and introduction of leachate to the biomass bed. In this research project, the flow behavior of fibrous particles was investigated through simulations and experiments.

\section{Task 1: DEM Simulation of Biomass}

The Discrete Element Method (DEM) has been utilized to simulate the stress-controlled shear flows of fibrous particles, in which the shear flow of the material is driven by the relative movement between two parallel plates and a constant normal stress is applied to the material by one of the plates. A typical stress-controlled shear flow is the granular material flow in a Schulze shear cell test. As a result, the DEM simulations of stress-controlled shear flows of fibrous particles were calibrated and validated with the Schulze shear cell tests. For the first series of DEM simulations, cut, flexible fishing wires of aspect ratio 9 were used. The shear flow simulations and experiments were performed with various normal stresses in order to explore the dependence of the yield shear stress on the pressure applied to compress the material. Using the DEM simulations, the parametric studies were conducted to examine the effects of particle-particle friction, fibre bending stiffness, and particle aspect ratio on the yield shear stress. The influence of moisture was also investigated by performing the DEM simulations and Schultz shear cell tests of the wet fibrous particles (i.e. the wetted cut fishing wires). It was found that in the dense flows, the effect of cohesion, which is caused by the moisture, is minimal compared to the effect of particle-particle friction. 
Then the Discrete Element Method (DEM) was utilized to simulate stress-controlled shear flows of wheat straw. Measured shear stress in a Schulze ring shear cell test, given a constant normal stress, was compared to shear stress predictions via DEM. The comparisons provided a validation for the DEM model for fibres. The wheat straw had a moisture content of $9.6 \%$, diameter of $2.8 \mathrm{~mm}$, and an aspect ratio was 5 . A glued sphere model was used to describe the elongated fibres in the DEM simulations. DEM simulations with rough fibres, formed from non-overlapping spheres, shows: i) a large difference between peak and steady-state stresses and ii) a fluctuating steady state. Simulation results (shown in Fig 1 at $10 \mathrm{KPa}$ normal stress) were improved by reducing shear rate and using a smooth particle (overlapping spheres) model. Simulations were also performed to assess the sensitivity of shear stress predictions to domain size, particle bending modulus, and particle friction. It was found that Schulze shear test results can be used to calibrate particle-particle friction for DEM simulations.
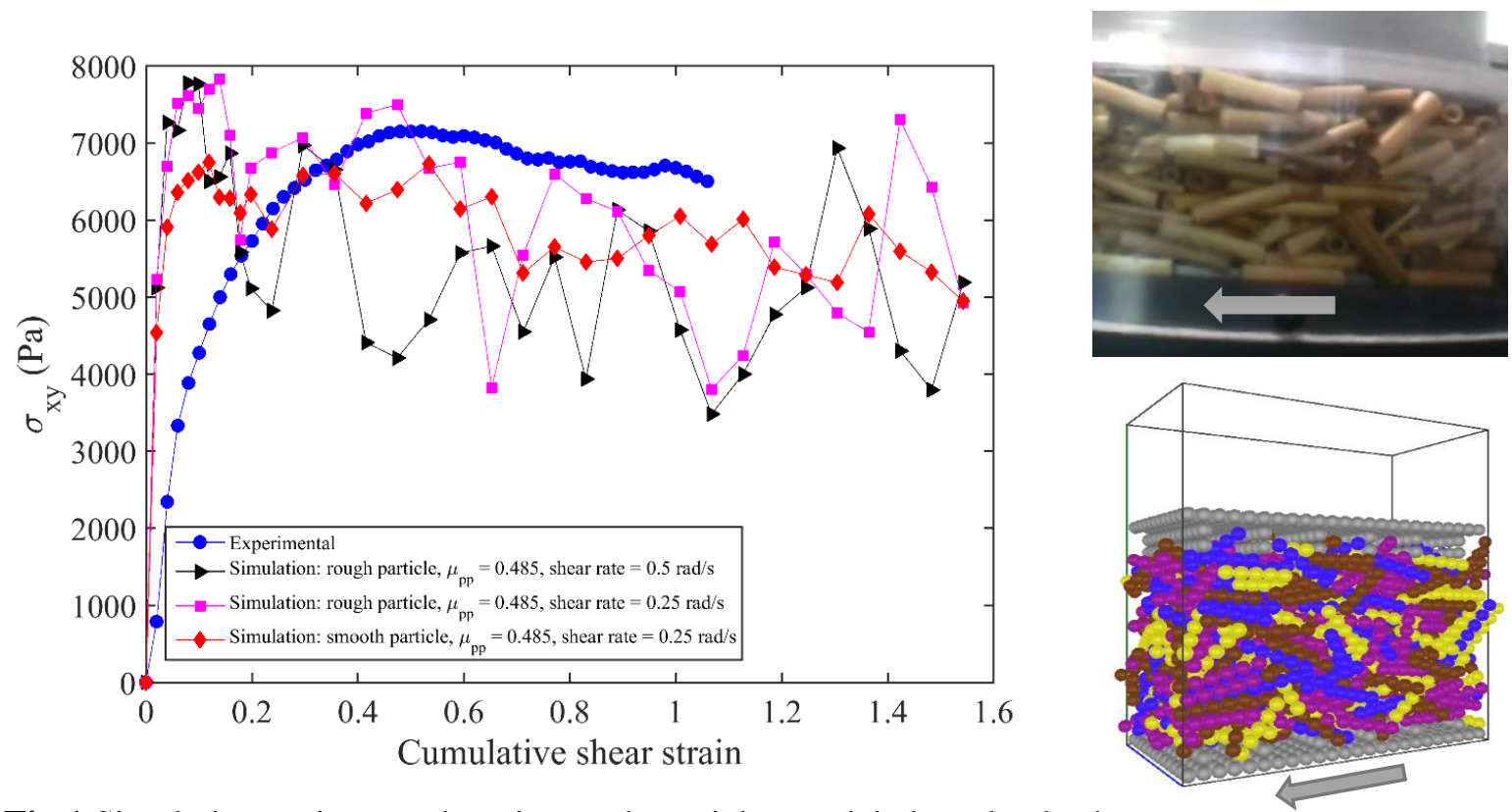

Fig.1 Simulations using rough and smooth particles modeled as glued sphere

The Discrete Element Method (DEM) was developed for flexible fibres, such as biomass, in both the wet and dry state. The DEM simulations were validated via experimental measurements of shear stress in a ring shear cell with both flexible and rigid particles. In addition, the angles of repose of dry and wet flexible and rigid fibres were simulated, and the DEM simulation results are in good agreement with these experimental results.

In the DEM simulations, a flexible fibre is formed by connecting a number of spheres in a line using deformable virtual bonds. Using the computational simulations, the effects of several key 
fibre properties on flexible, dry particle bulk flow behavior were explored. It was found that the angle of internal friction initially increases with the fibre-fibre friction coefficient and then asymptotes to an upper limit. An increase in fibre bending modulus can lead to a reduction in the fibre volume fraction and bulk density, but the fibre bending modulus shows no effect on the fibre shear stress with the same normal stress and fibre-fibre friction coefficient. In addition, the elastic modulus that determines the fibre-fibre contact stiffness does not affect the fibre shear stress either. Both the contact damping coefficient, which determines the kinetic energy loss in fibre-fibre collisions, and the bond damping coefficient, which determines the kinetic energy loss in fibre deformation and vibration, have limited impact on the fibre shear flow behavior in the shear tester due to the combined effects of frequent fibre-fibre and fibre-wall contacts and the continuous energy input from the moving lower wall of the annular shear cell.

In the shear flow of wet fibres, significant agglomeration is observed. The size of the largest agglomerate in the fibre flow was found to depend on a Bond number, which is proportional to liquid surface tension and inversely proportional to the square of the shear strain rate. This Bond number reflects the relative importance of the liquid-bridge force to the fibre's inertial force, with a larger Bond number leading to a larger agglomerate. As fibre aspect ratio $(A R)$ increases, the size of the largest agglomerate increases, while the coordination number in the largest agglomerate initially decreases and then increases when $A R$ is greater than four. A larger agglomerate with a larger coordination number is more likely to form for more flexible fibres with a smaller bond elastic modulus due to better connectivity between the more flexible fibres. Liquid viscous force resists pulling of liquid bridges and separation of contacting fibres, and therefore it facilitates larger agglomerate formation. The effect of liquid viscous force is more significant at larger shear strain rates. The fibre-phase shear stress was increased due to the presence of liquid bridges in moderately dense flows. As the fibre volume fraction increases, the effect of fibre-fibre friction coefficient increases sharply. When the fibre volume fraction approaches the maximum packing density, the fibre-fibre friction coefficient can be a more dominant factor than the liquid bridge force in determining the fibre solid-phase shear stress. 


\section{Task 2: Characterization and Flow Experimentation with Biomass - Validation of Simulations}

Five types of experimental tests are to be conducted as will be described later. Figure 2 shows overview of the tested materials. The three materials selected for the main characterization are: olive pulp, orange peel and wheat straw. However, a number of additional bio-materials were partially tested.

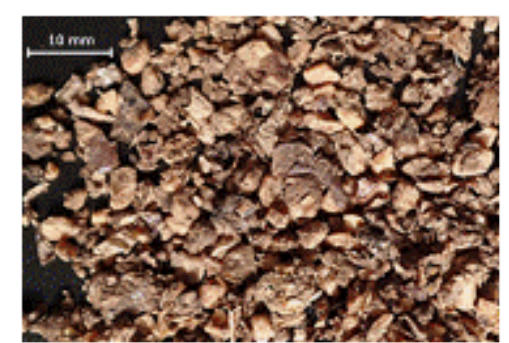

Olive Pulp

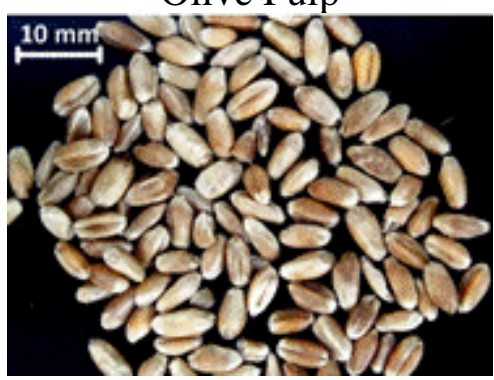

Wheat Grains

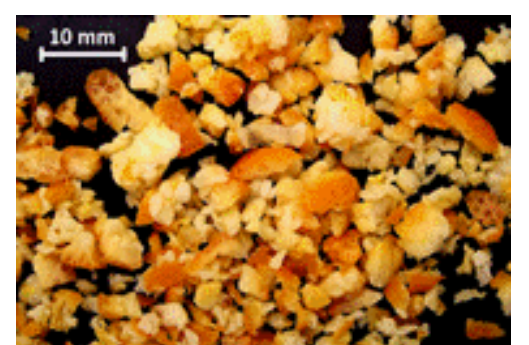

Orange Peels

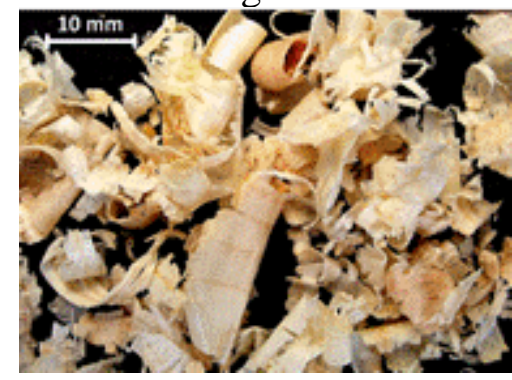

Wood Flake

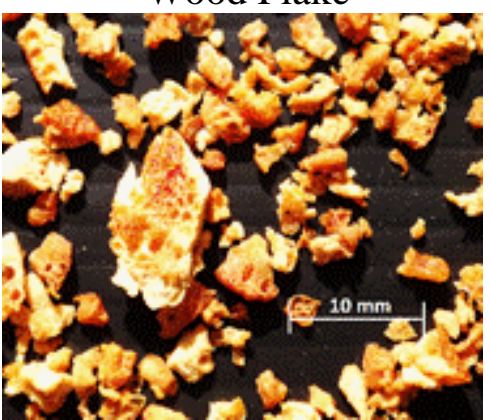

Dry Orange Peels

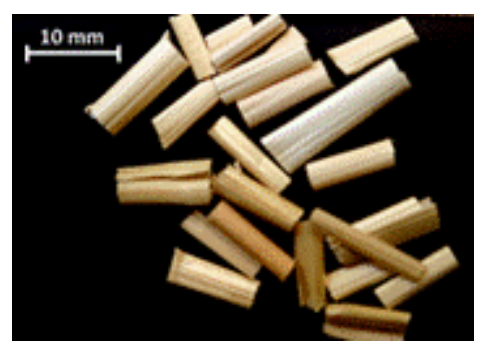

Wheat Straw

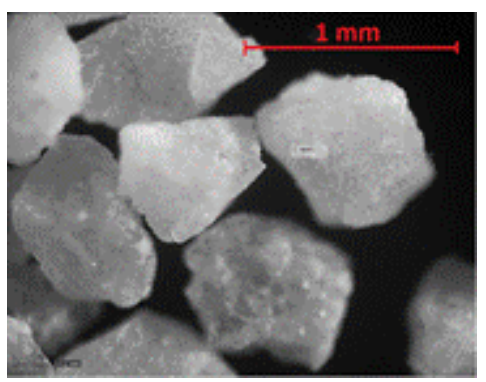

Semolina

Fig. 2: The materials tested in this part.

\section{a. Particle Characterization of Biomass}

This part is mainly concern with particle compression to measure breakage force and energy, elastic stiffness, yield force and Young's apparent modulus. Although we planned to test three materials only, we tested much more variations related to particle size and the straw aspect ratio. All measurements were conducted in both air and water. Some tests were also conducted at elevated temperatures. The tests were conducted with an in-house device developed earlier and by 
a predefined procedure [1-6]. However, before the compression results, let us present basic characterization of the material in Table 1 and an example of size distribution in Fig. 3.

Table 1: Different physical Properties of the Materials

\begin{tabular}{|c|c|c|c|c|c|c|c|}
\hline Materials & $\begin{array}{c}\mathrm{d}_{50} * \\
(\mathrm{~mm})\end{array}$ & $\begin{array}{c}\rho_{\mathbf{p}} \\
\left(\mathbf{k g} / \mathbf{m}^{3}\right)\end{array}$ & $\begin{array}{c}\rho_{\mathrm{b}}{ }^{*} \\
\left(\mathrm{~kg} / \mathrm{m}^{3}\right)\end{array}$ & $\mathrm{d}_{90} / \mathrm{d}_{10} *$ & $\begin{array}{l}\text { distribution } \\
\text { width }\end{array}$ & Ar [-] & $\begin{array}{c}\text { Moisture } \\
\text { content } \\
(\%)\end{array}$ \\
\hline Semolina & 0.6 & 1810 & 860 & 1.5 & & $1.4 \times 10^{4}$ & 8.8 \\
\hline Olive pulp & 1.56 & 1480 & 526 & 13.5 & broad & $2.02 \times 10^{5}$ & 11.9 \\
\hline Wheat & 3.5 & 1500 & 1033 & 1.4-3.5 & medium & $2.31 \times 10^{6}$ & 11.4 \\
\hline Orange peels & 2.77 & 1438 & 323 & 2.85 & medium & $1.1 \times 10^{6}$ & 9 \\
\hline
\end{tabular}

$* \mathrm{~d}_{50}$ : median particle size

* $\rho_{\mathrm{b}}$ : free bulk density

$* \mathrm{~d}_{90} / \mathrm{d}_{10}$ : ratio of particle size above $90 \%$ and below $10 \%$ by weight

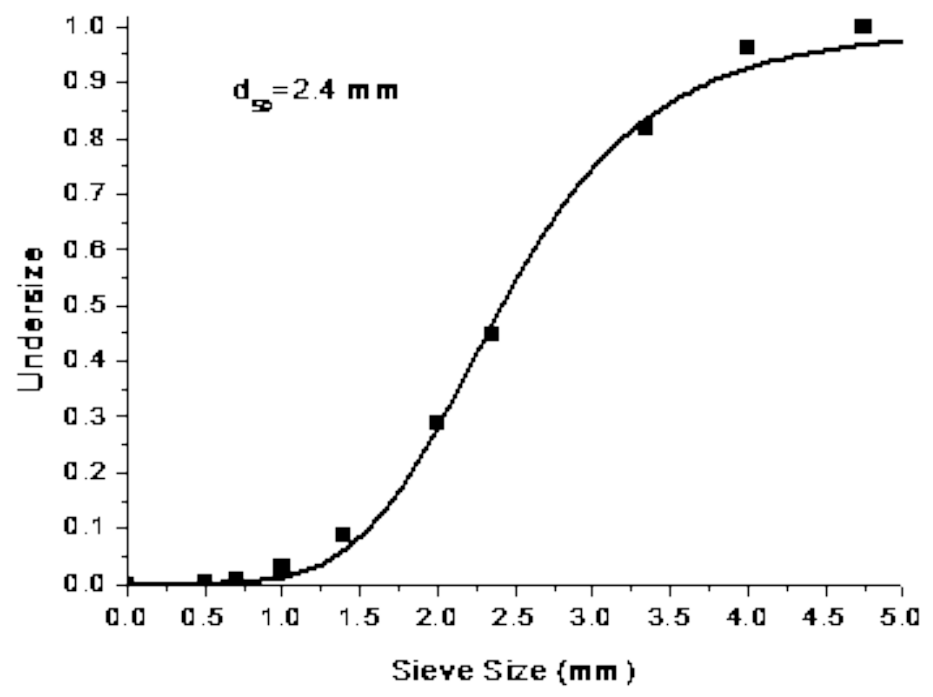

Fig. 3: Size distribution of orange peels.

\section{a.1 Compression Tester}

The strength distribution and elastic properties of individual dry and wet particles are measured by using a custom-built compression tester [3]. According to the principle of the test (Fig. 4), the upper punch, which is operated by a hydro - pneumatic piston, loads the particle at a constant compression force rate until the first breakage appears. The applied force is measured by a Load- 
Cell with an accuracy of $\pm 0.01 \%$ from full scale; and is connected to the lower contact surface. The punch and the lower contact surface are made from alumina 995. The displacement is measured simultaneously by a LVDT sensor with an accuracy of $\pm 5 \mu \mathrm{m}$. The tester is able to conduct experiments with individual particles in the size range of $100 \mu \mathrm{m} \div 6 \mathrm{~mm}$, as well as with particulate beds. All the experiments were conducted with a constant compression force rate of $1 \div 2 \mathrm{~N} / \mathrm{s}$. At least 50 individual particles were compressed for a specific material and size to get statistically representative results according to the criteria reported by Portnikov et al. [3].

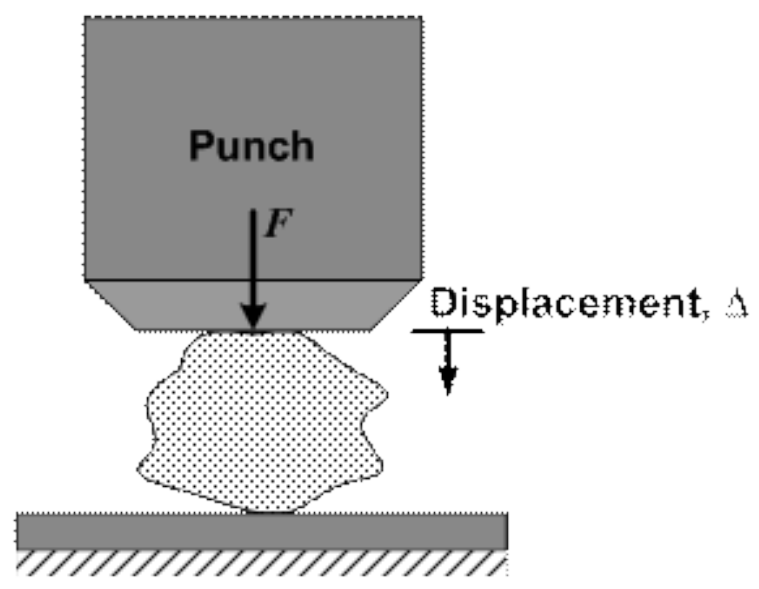

Fig. 4: The principle of a single particle compression test.

In order to compress wet particles, the lower contact plate was modified to insure the particles will remain wet within insoluble liquid throughout the compression process. The lower contact plate was placed inside a cylindrical transparent tank filled with insoluble liquid (see Fig. 5). 


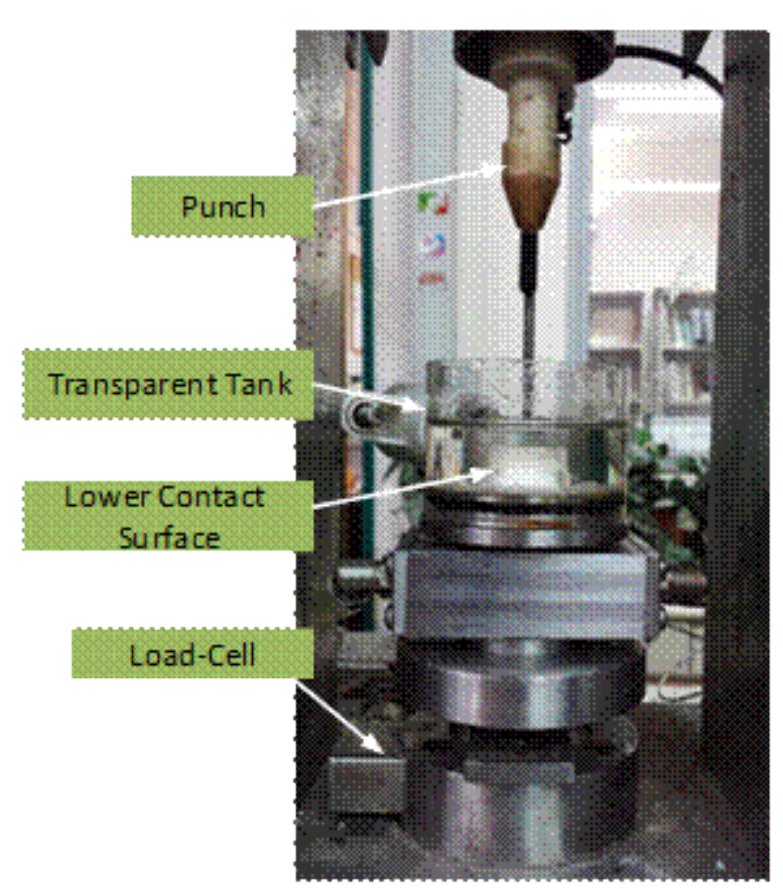

Fig. 5: Modified lower contact surface for measuring wet particles.

Typical force-displacement experimental curves of individual particle compression test for each measured material in the current study are presented later. The graphs show the elastic-plastic behaviour of the particle during compression until the breakage point, which is obtained by a sudden decrease of the measured force. Based on such figures the effective Young modulus can be found by fitting Hertz model to the compression curve

$$
F=C_{H} \Delta^{3 / 2}
$$

where, $C_{H}$ is an empirical parameter that depends on the effective modulus of elasticity $\left(E^{*}\right)$ and the particle size $(d)$ as follows:

$$
C_{H}=\frac{1}{3} E^{*} \sqrt{d}
$$

The effective modulus of elasticity is defined as:

$$
E^{*}=\frac{E}{\left(1-v^{2}\right)}
$$

where, $E$ and $v$ are the Young's modulus and Poisson's ratio of the material.

It is impossible to define any mechanical characteristic such as breakage force or effective modulus of elasticity based on a result of a single particle. Even for the same particle size, the mechanical characteristics of individual particles differ in the microstructure because of the distribution and 
orientation of cracks and pores. Thus, any measured mechanical characteristic should be defined for a certain material based on statistical distributions.

Cumulative distributions of the compression tests are actually represent at least 50 measured particles. The graphs plotted later show least square fit of the logistic function [2]. For each material characteristic shown in the figure, this function has the following forms:

$$
\begin{gathered}
S_{F}=1-\frac{1}{1+\left(F_{B} / F_{50}\right)^{D_{F}}} \\
S_{F_{Y}}=1-\frac{1}{1+\left(F_{Y} / F_{Y 50}\right)^{D_{F y}}} \\
S_{E}=1-\frac{1}{1+\left(E^{*} / E_{50}^{*}\right)^{D_{E}}}
\end{gathered}
$$

where, $S_{F}, S_{F_{Y}}$ and $S_{E}$ are the probabilities to obtain a certain material characteristic, i.e. the breakage force $\left(F_{B}\right)$, yield force $\left(F_{Y}\right)$ and effective modulus of elasticity $\left(E^{*}\right)$, respectively. Each function has two empirical parameters. The parameters $F_{50}, F_{Y 50}$ and $E_{50}^{*}$ are the scale parameters and define the median values of the distributions. The parameters $D_{F}, D_{F y}$ and $D_{E}$ are the shape parameters of the distributions. As the shape parameter increases, the dispersion of the distribution decreases. The variance or the standard deviation $(S D)$ of the distribution can be calculated using the following equation [7]:

$$
S D= \pm x_{50} \sqrt{\frac{2 \pi / D}{\sin (2 \pi / D)}-\left(\frac{\pi / D}{\sin (\pi / D)}\right)^{2}}
$$

where, $x_{50}$ is the scale parameter and $D$ is the shape parameter. By fitting Eqs. (4)-(6) to the experimental data for each case, the empirical parameters were determined and summarized in Tables.

\section{a.2 Testing Wheat Straw}

Since the straw has a shape of a pipe and could be cut to any length, it was measured at a number of orientations and sizes. The straw was tested in a radial direction, axial direction and by bending. It was also cut to various length presenting a number of aspect ratios.

\section{a.2.1 Radial Compressions}

Figure 6 presents a visualization of radial compression of a straw. It is clear that straws have not only different diameters but also different thicknesses. This will result in a wider distribution of the measured properties. Figure 7 presents a typical compression curve for a single particle. While 
Fig. 8 show the compression properties distribution measured for tens of particles at two length ranges. It can be seen that most of the distributions are closely related and the straw length is only slightly affecting the measurement. The length show a more significant difference for Elastic Stiffness.
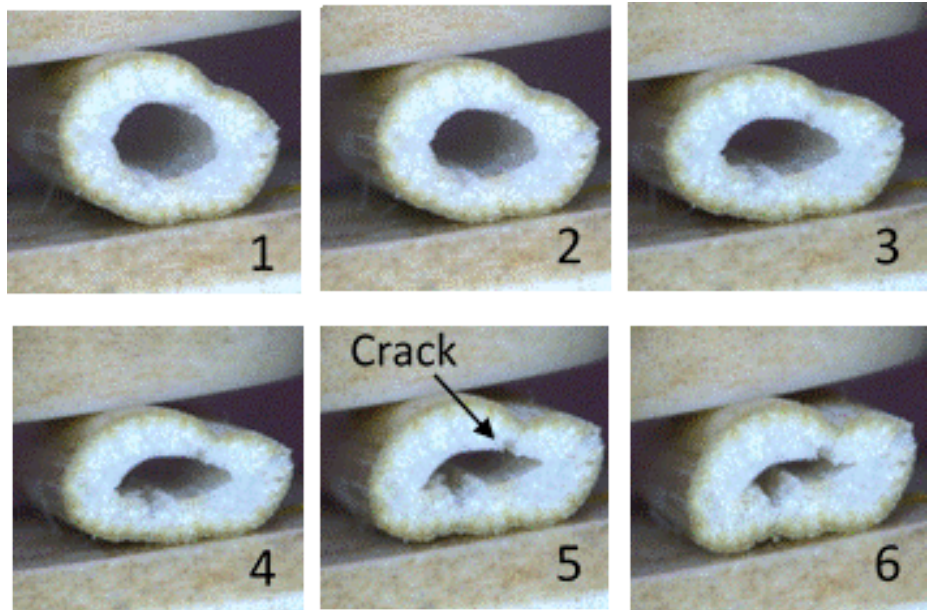

a

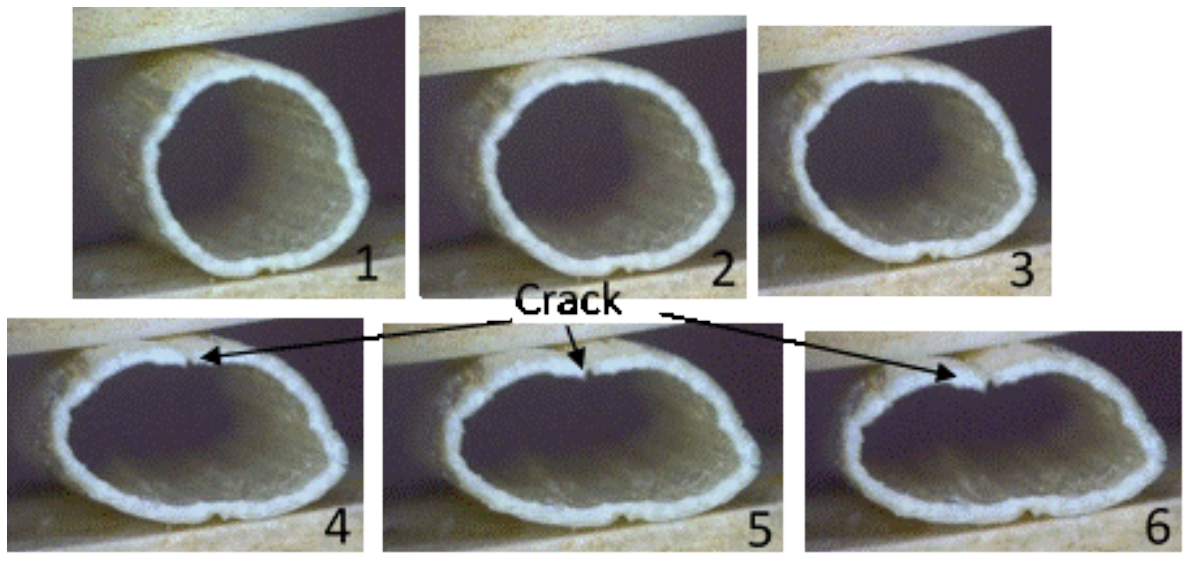

b

Fig. 6: Visualization of radial compression of straw having: a. thick wall; b. thin wall. 


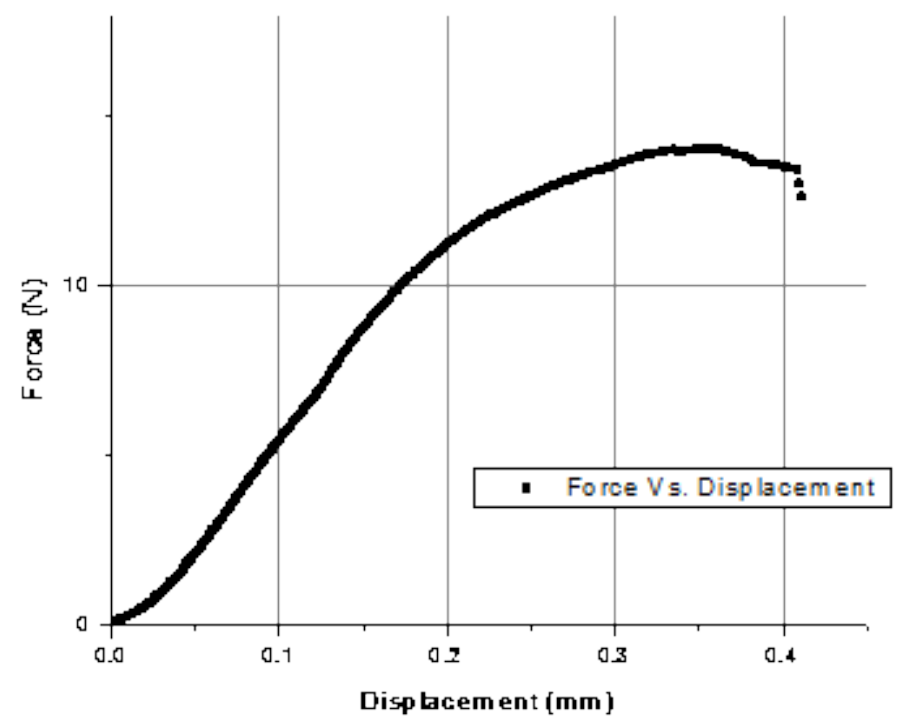

Fig. 7: Typical compression diagram for radial compression of straw. $\mathrm{D}=2.883374 \mathrm{~mm}$, Radial ,5-8mm (112) 


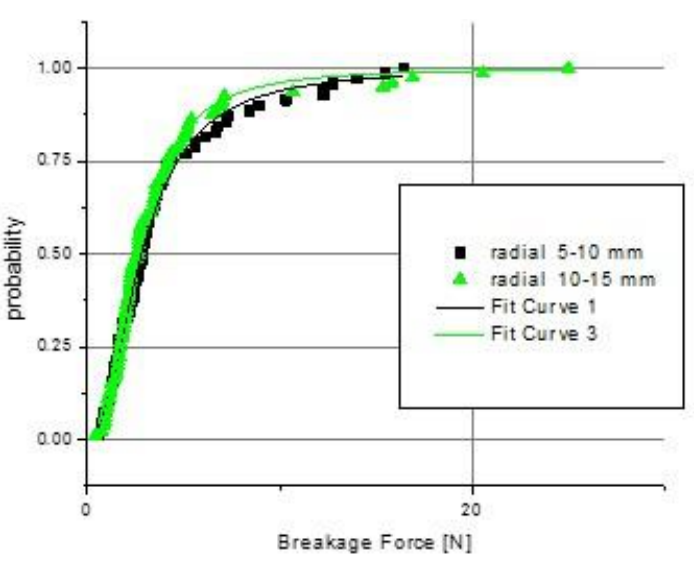

a

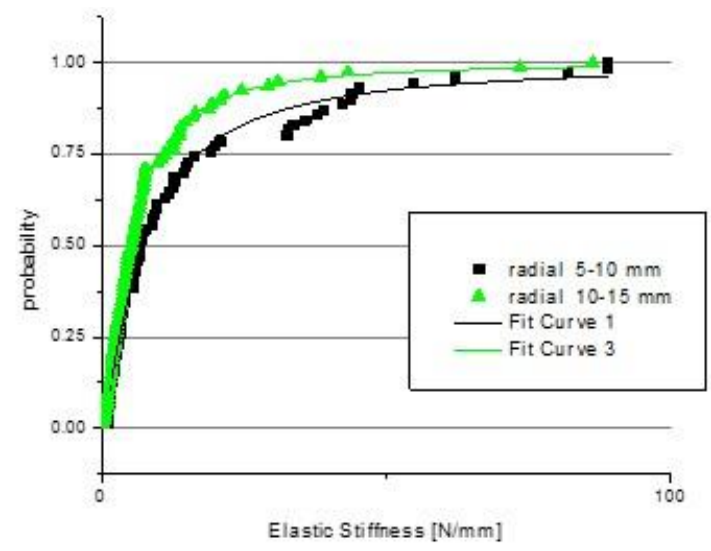

C

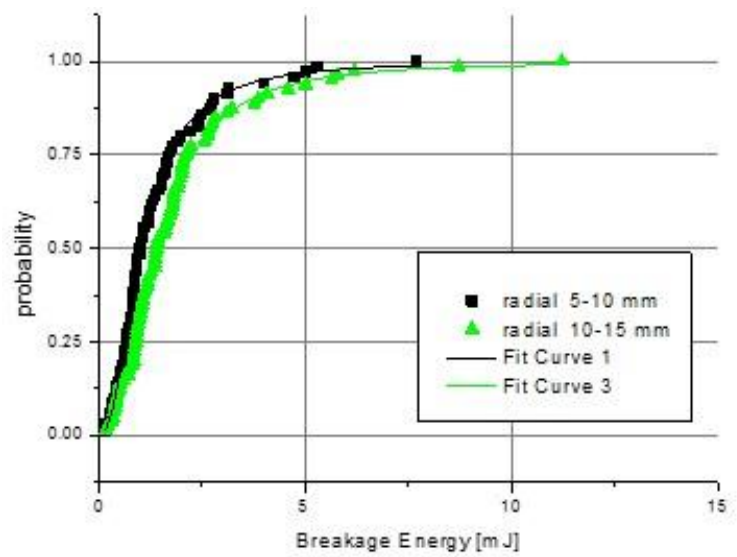

$\mathrm{b}$

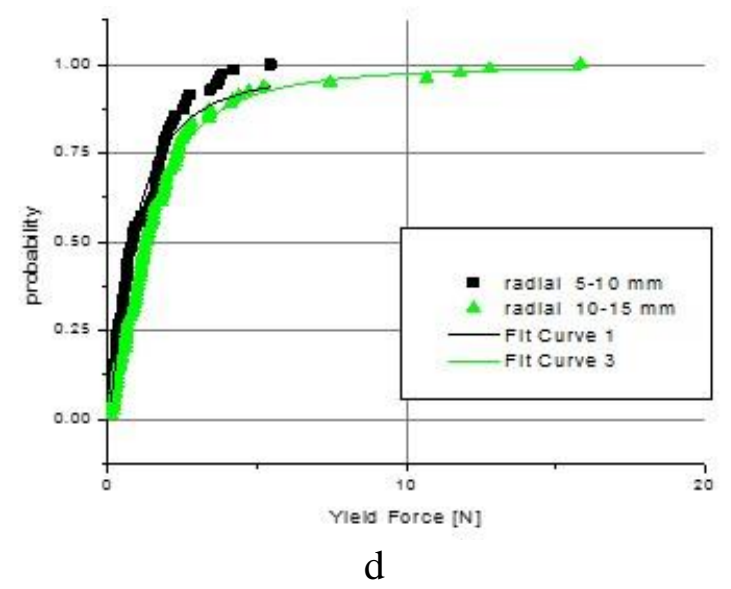

Fig. 8: Strength distribution for radial compression; a. breakage force; b. breakage energy; c. elastic stiffness; $d$. yield force.

Table 2: Empirical parameters for radial straw compression.

\begin{tabular}{|c|c|c|c|c|c|}
\hline $\begin{array}{c}\text { Straw } \\
\text { Length } \\
{[\mathrm{mm}]}\end{array}$ & $\begin{array}{c}\text { Empirical } \\
\text { Parameter }\end{array}$ & $\begin{array}{c}\text { Breakage } \\
\text { Force } \\
{[\mathrm{N}]}\end{array}$ & $\begin{array}{c}\text { Breakage } \\
\text { Energy } \\
{[\mathrm{mJ}]}\end{array}$ & $\begin{array}{c}\text { Yield } \\
\text { Force } \\
{[\mathrm{N}]}\end{array}$ & $\begin{array}{c}\text { Elastic } \\
\text { Stiffness } \\
{[\mathrm{N} / \mathrm{mm}]}\end{array}$ \\
\hline \multirow{2}{*}{$5-10$} & $x_{50}$ & 2.81 & 1.05 & 0.83 & 7.35 \\
\cline { 2 - 6 } & $D$ & 2.15 & 2.22 & 1.44 & 1.30 \\
\hline \multirow{2}{*}{$10-15$} & $x_{50}$ & 2.61 & 1.41 & 1.29 & 5.09 \\
\cline { 2 - 6 } & $D$ & 2.39 & 2.28 & 1.76 & 1.56 \\
\hline
\end{tabular}




\section{a.2.2 Axial Compressions}

The results of the axial measurements are shown in the same way as before. Figures 9 and 10 present visualization and a typical compression curve for a single particle. The results for the strength characterization are presented in Fig. 11 for two size ranges and the final values for the empirical parameters in Table 3. The results show that for axial compression longer straws are
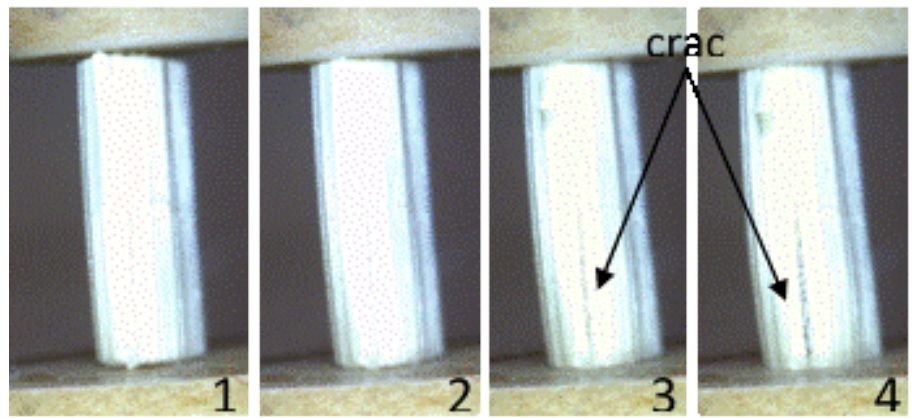

weaker than shorter ones in all aspects.

Fig. 9: Visualization of axial compression of straw.

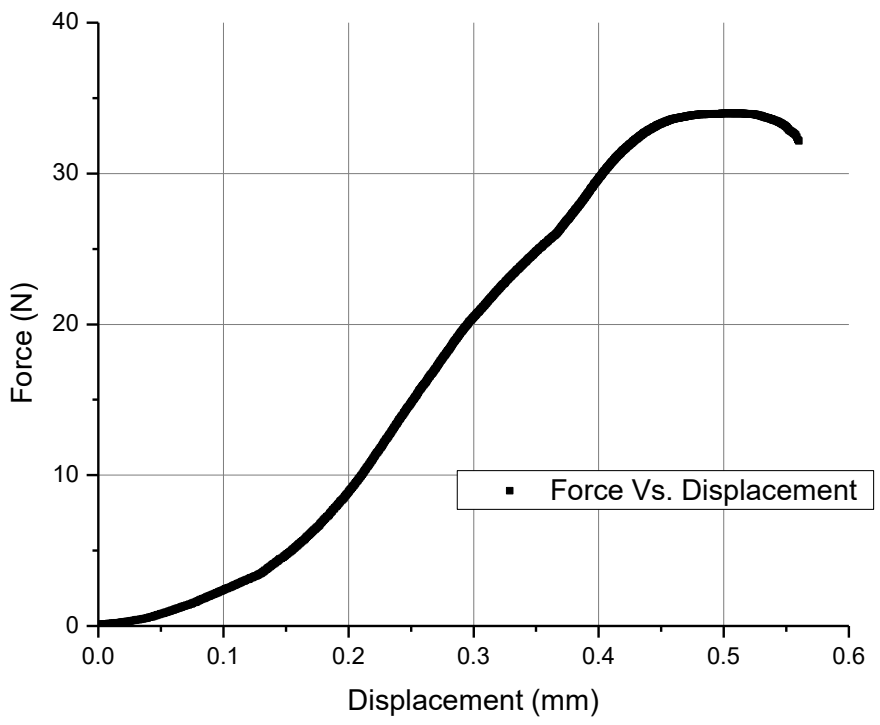

Fig.10: Typical compression diagram for axial compression of straw.

$\mathrm{H}=8.711888 \mathrm{~mm}$, Axial, 5-8mm (131) 

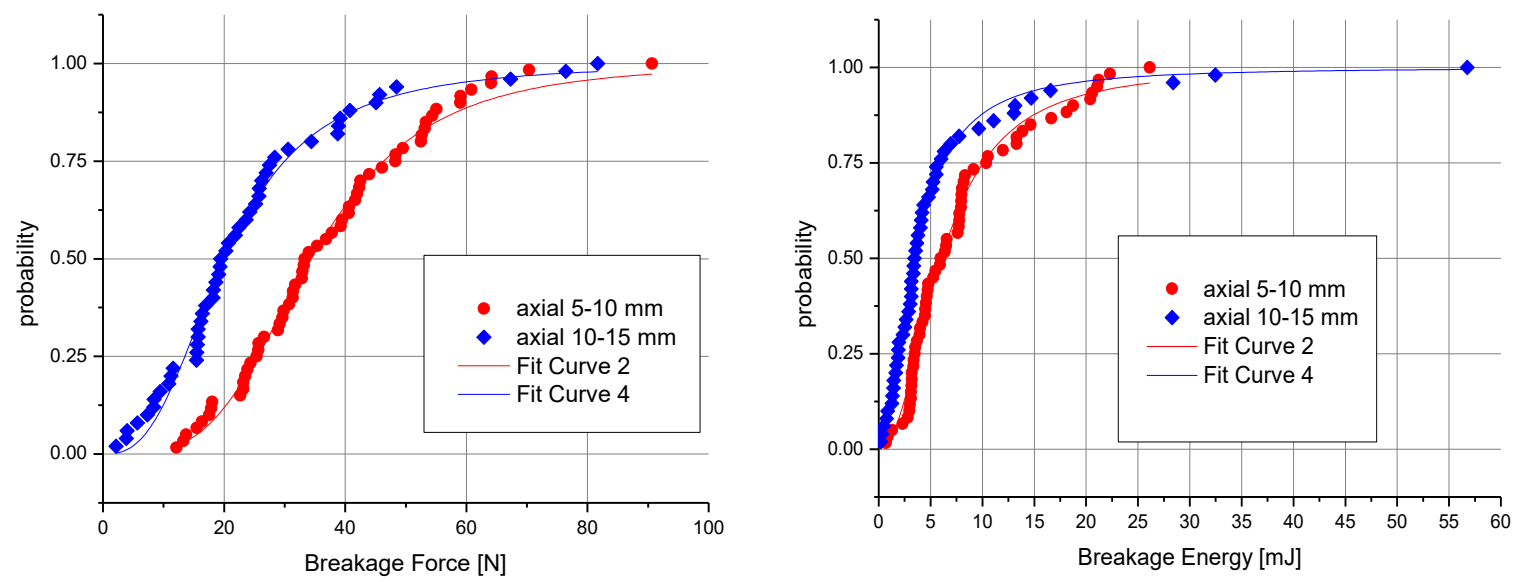

a

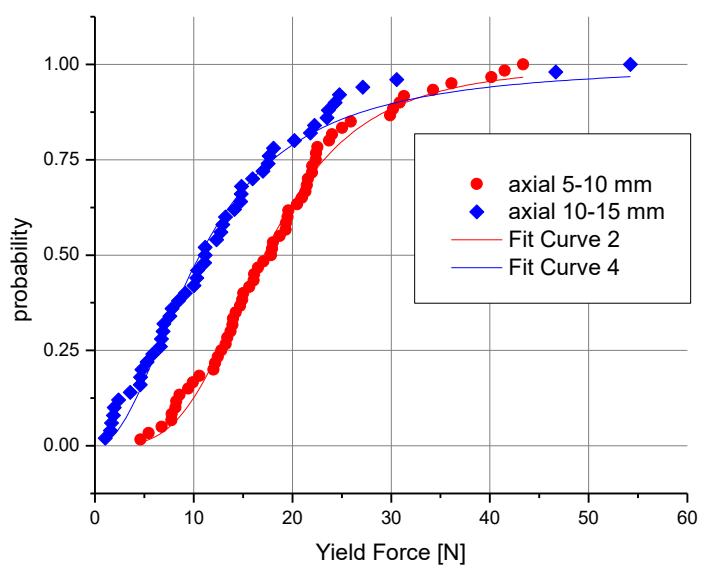

D

Fig. 11: Strength distribution for radial compression; a. breakage force; b. breakage energy; c. elastic stiffness; $d$. yield force.

Table 3: Empirical parameters for axial straw compression.

\begin{tabular}{|c|c|c|c|c|c|}
\hline $\begin{array}{c}\text { Straw } \\
\text { Length } \\
{[\mathrm{mm}]}\end{array}$ & $\begin{array}{c}\text { Empirical } \\
\text { Parameter }\end{array}$ & $\begin{array}{c}\text { Breakage } \\
\text { Force } \\
{[\mathrm{N}]}\end{array}$ & $\begin{array}{c}\text { Breakage } \\
\text { Energy } \\
{[\mathrm{mJ}]}\end{array}$ & $\begin{array}{c}\text { Yield } \\
\text { Force } \\
{[\mathrm{N}]}\end{array}$ & $\begin{array}{c}\text { Elastic } \\
\text { Stiffness } \\
{[\mathrm{N} / \mathrm{mm}]}\end{array}$ \\
\hline \multirow{2}{*}{$5-10$} & $x_{50}$ & 34.4 & 6.04 & 17.10 & 167.94 \\
\cline { 2 - 6 } & $D$ & 3.69 & 2.16 & 3.61 & 3.22 \\
\hline \multirow{2}{*}{$10-15$} & $x_{50}$ & 20.14 & 3.48 & 10.63 & 84.83 \\
\cline { 2 - 6 } & $D$ & 2.76 & 1.88 & 2.08 & 2.41 \\
\hline
\end{tabular}




\section{a.2.3 Bending}

The bending experiments were conducted with two down supports and an upper wedge moving down and bending the straw. Figures 12 and 13 present visualization and a typical bending curve for a single straw. The results for the strength characterization are presented in Fig. 14 for three straw lengths and the final values for the empirical parameters are presented in Table 4 . The results show that the straw length does not affect significantly the results.
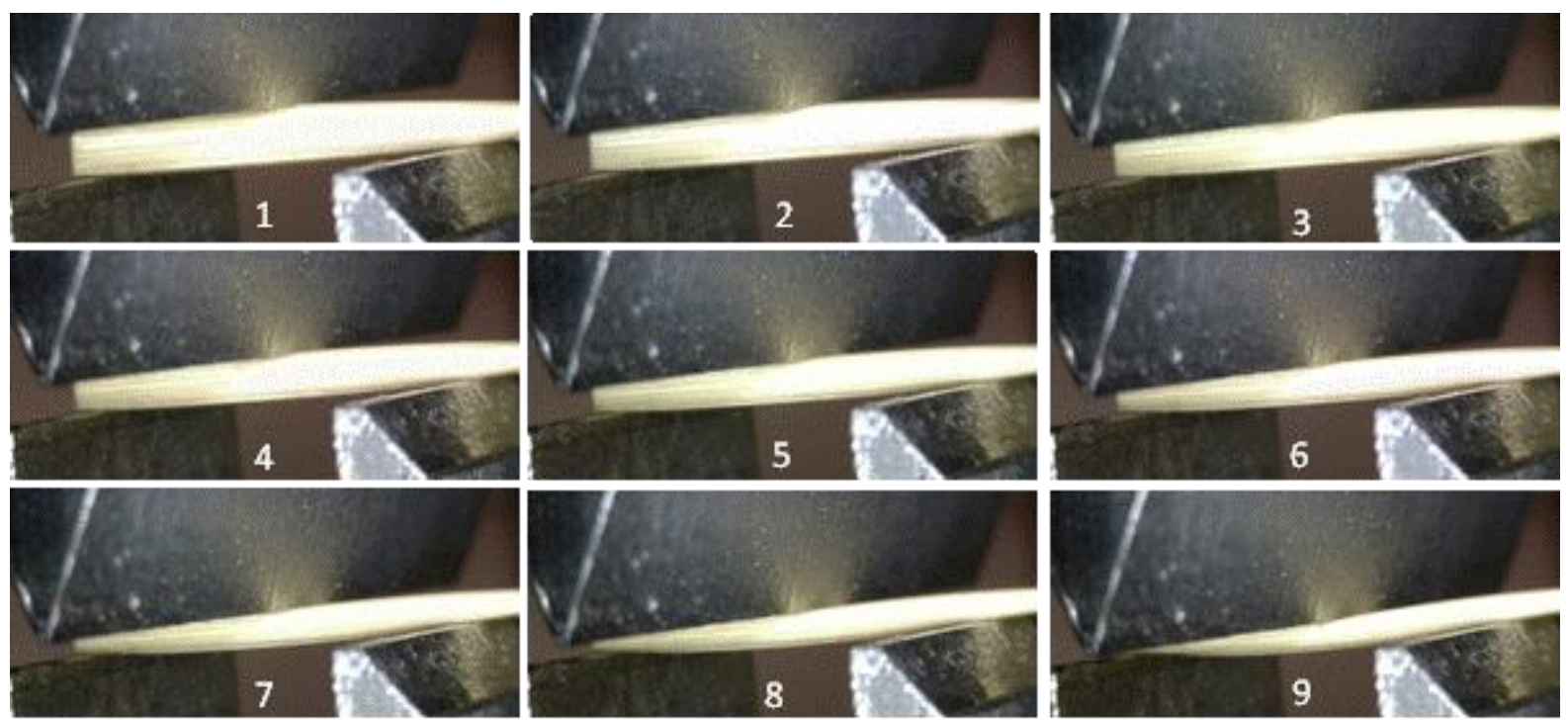

Fig. 12: Visualization of bending of straw. 


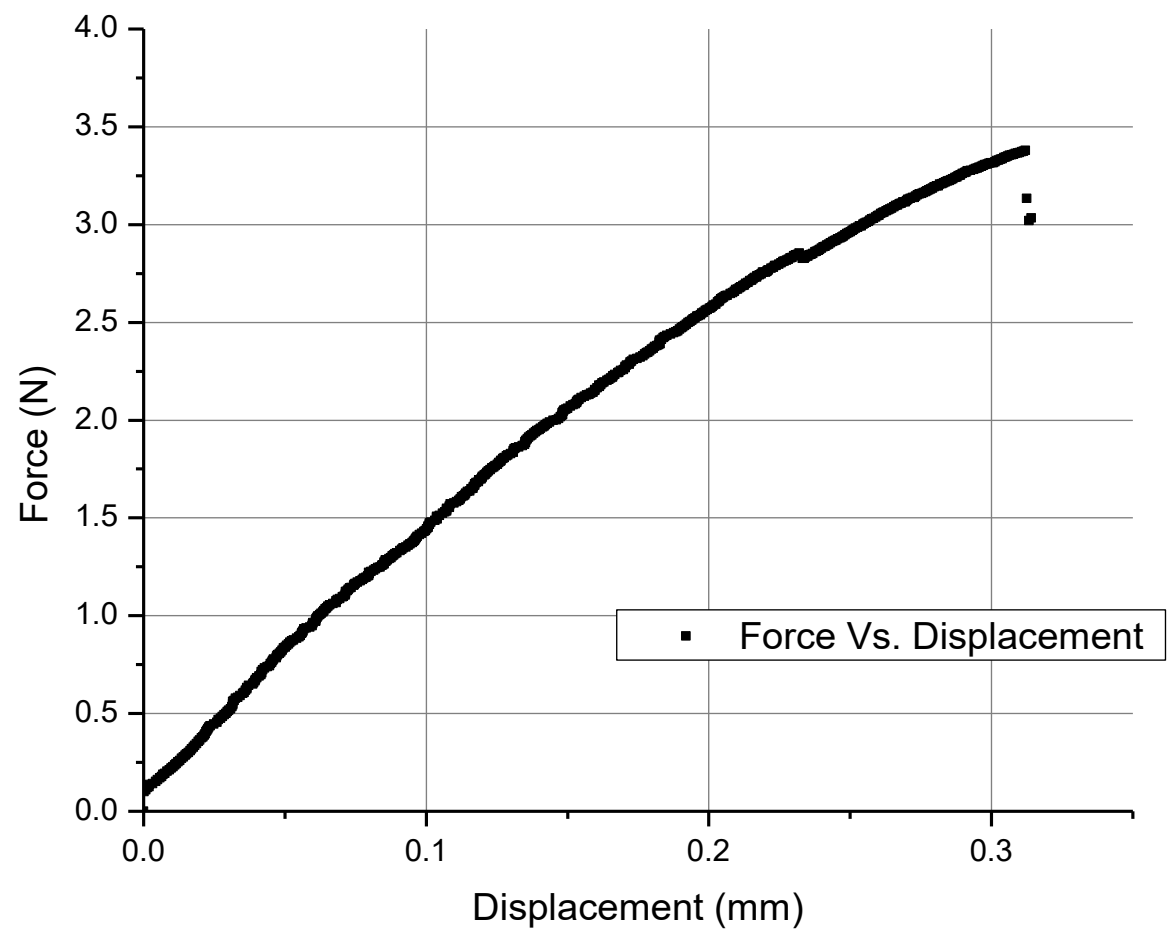

Fig. 13: Typical diagram for bending of straw.

$\mathrm{D}=1.997745 \mathrm{~mm}$, Bending, $10 \mathrm{~mm},(106)$ 

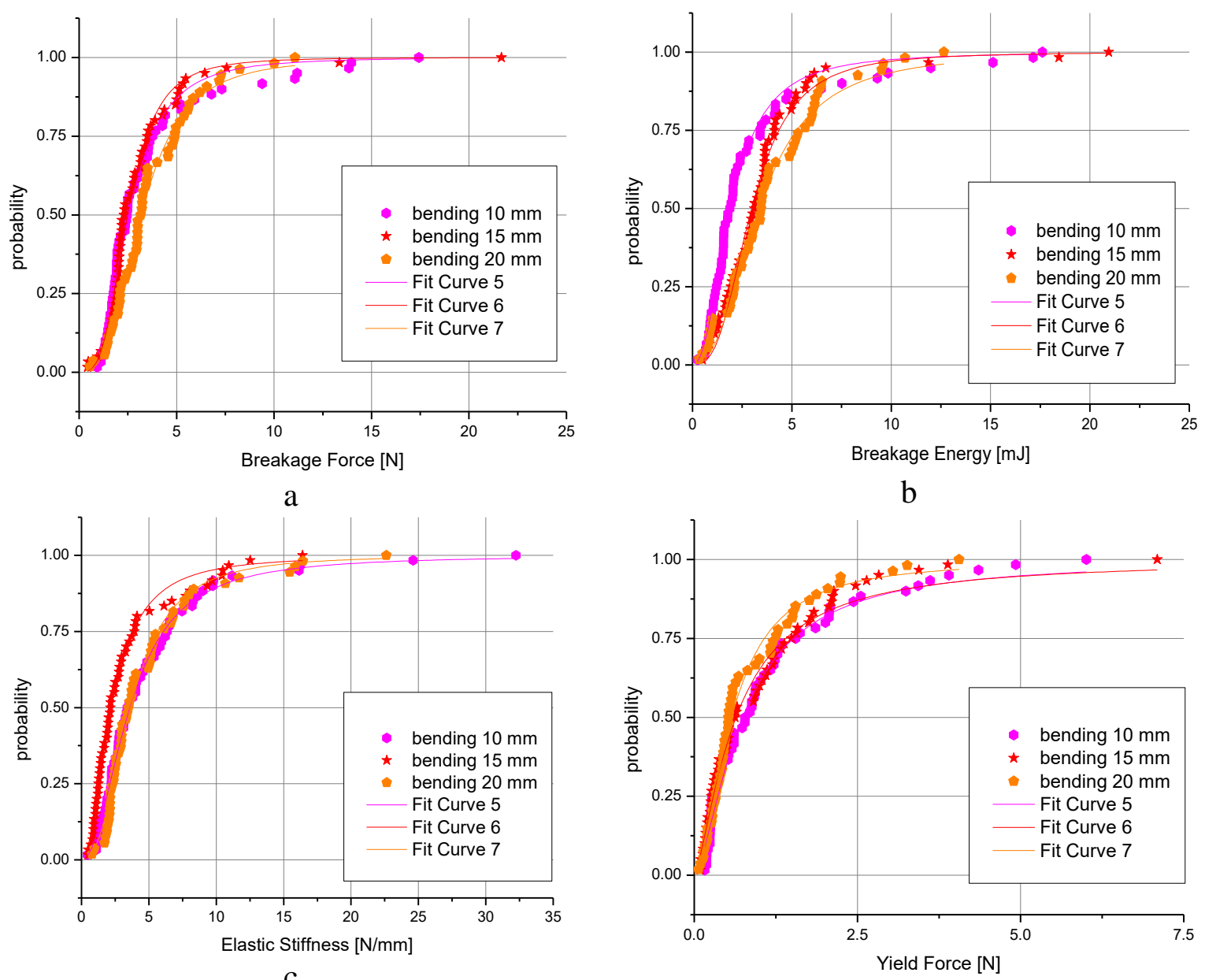

$\mathrm{b}$

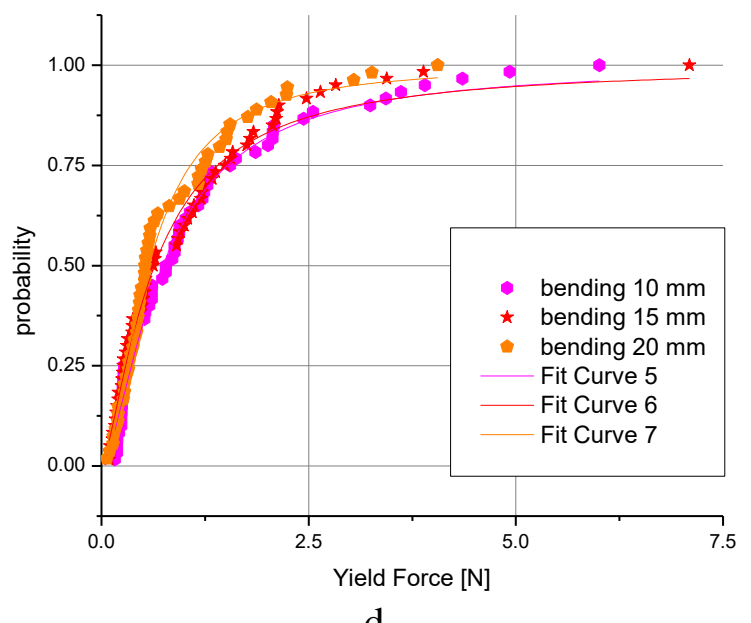

d

Fig. 14: Strength distribution for bending; a. breakage force; b. breakage energy; c. elastic stiffness; $d$. yield force.

Table 4: Empirical parameters for bending of straw.

\begin{tabular}{|c|c|c|c|c|c|}
\hline $\begin{array}{c}\text { Straw } \\
\text { Length } \\
{[\mathrm{mm}]}\end{array}$ & $\begin{array}{c}\text { Empirical } \\
\text { Parameter }\end{array}$ & $\begin{array}{c}\text { Breakage } \\
\text { Force } \\
{[\mathrm{N}]}\end{array}$ & $\begin{array}{c}\text { Breakage } \\
\text { Energy } \\
{[\mathrm{mJ}]}\end{array}$ & $\begin{array}{c}\text { Yield } \\
\text { Force } \\
{[\mathrm{N}]}\end{array}$ & $\begin{array}{c}\text { Elastic } \\
\text { Stiffness } \\
{[\mathrm{N} / \mathrm{mm}]}\end{array}$ \\
\hline \multirow{2}{*}{10} & $x_{50}$ & 2.54 & 1.92 & 0.74 & 3.58 \\
\cline { 2 - 6 } & $D$ & 2.82 & 2.25 & 1.52 & 2.08 \\
\hline \multirow{2}{*}{15} & $x_{50}$ & 2.48 & 2.97 & 0.64 & 2.21 \\
\cline { 2 - 6 } & $D$ & 3.32 & 2.89 & 1.4 & 2.02 \\
\hline \multirow{2}{*}{20} & $x_{50}$ & 3.18 & 3.33 & 0.57 & 3.63 \\
\cline { 2 - 6 } & $D$ & 2.92 & 2.42 & 1.76 & 2.48 \\
\hline
\end{tabular}




\section{a.2.4 Comparing the Loadings}

Figure 15 present comparison of the three tested loadings on the straw. It could not be expected, but the radial compression and the bending are very much closely related for the breakage force and yield force. However, the breakage energy and the elastic stiffness are slightly different. In any case, the axial compression present much higher values for all strength parameters.

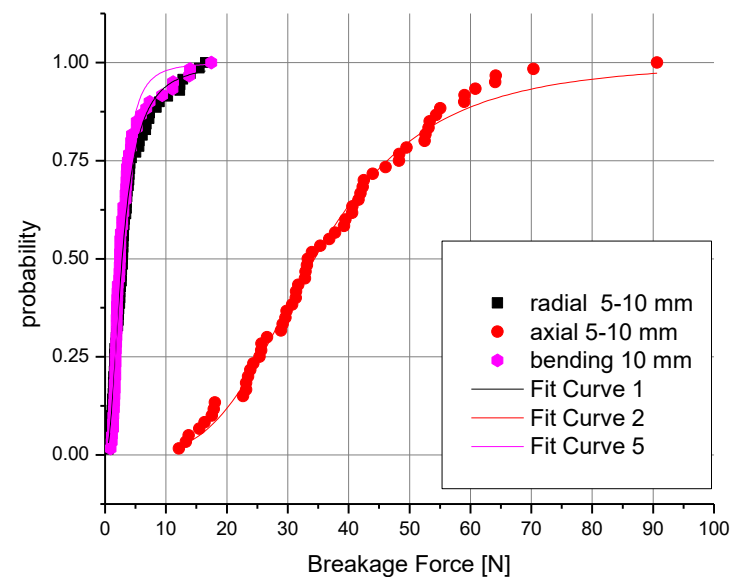

a

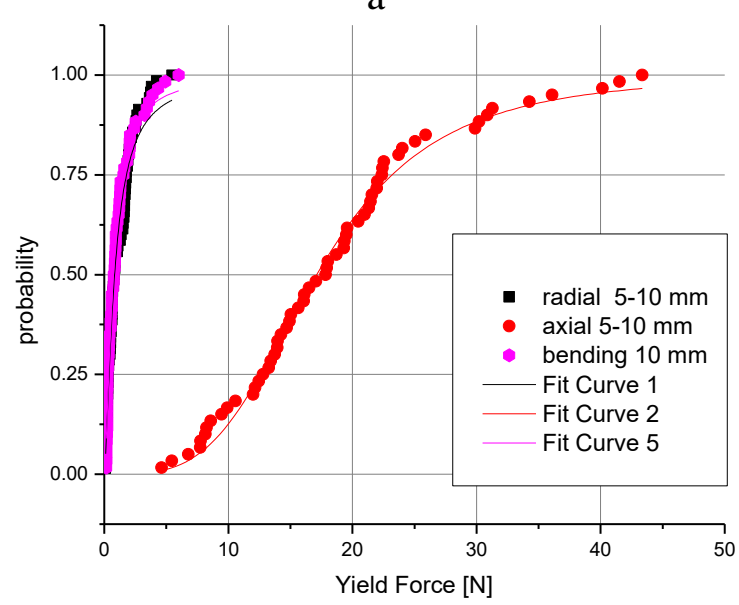

c

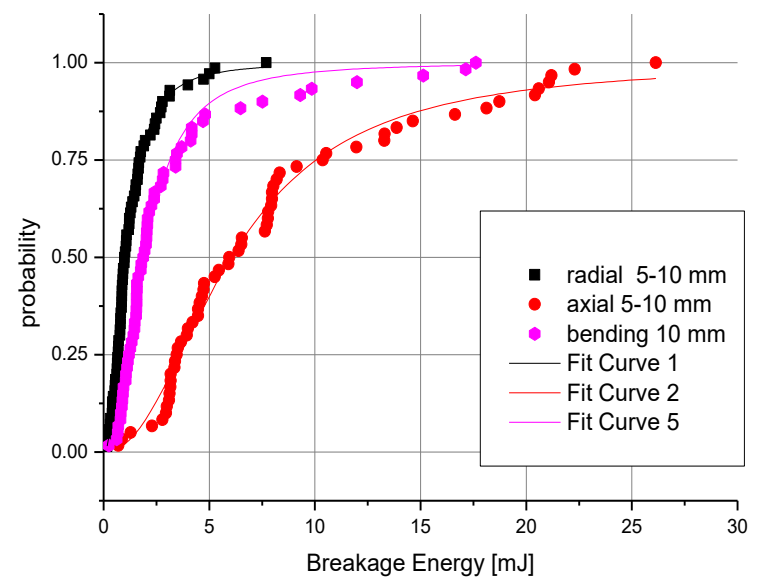

$\mathrm{B}$

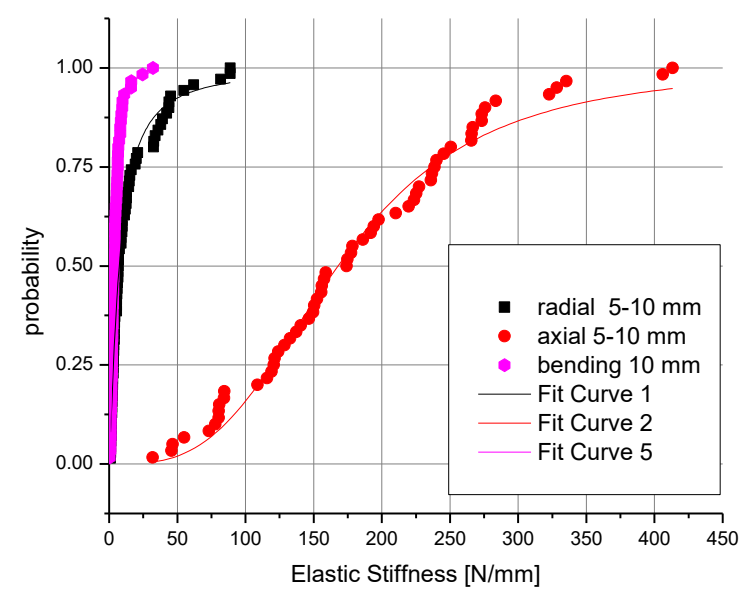

$\mathrm{D}$

Fig. 15: Comparing three methods of loading; a. breakage force; b. breakage energy; c. elastic stiffness; d. yield force. 


\section{a.3 Testing Orange Peels}

The orange peels were compressed fresh, thus id liquid surrounding or very wet. Figures 16 and 17 present visualization and a typical compression curve for a single piece of orange peel. The results for the strength characterization are presented in Fig. 18 and the final values for the empirical parameters are presented in Table 5. The results show that the straw length does not affect significantly the results.

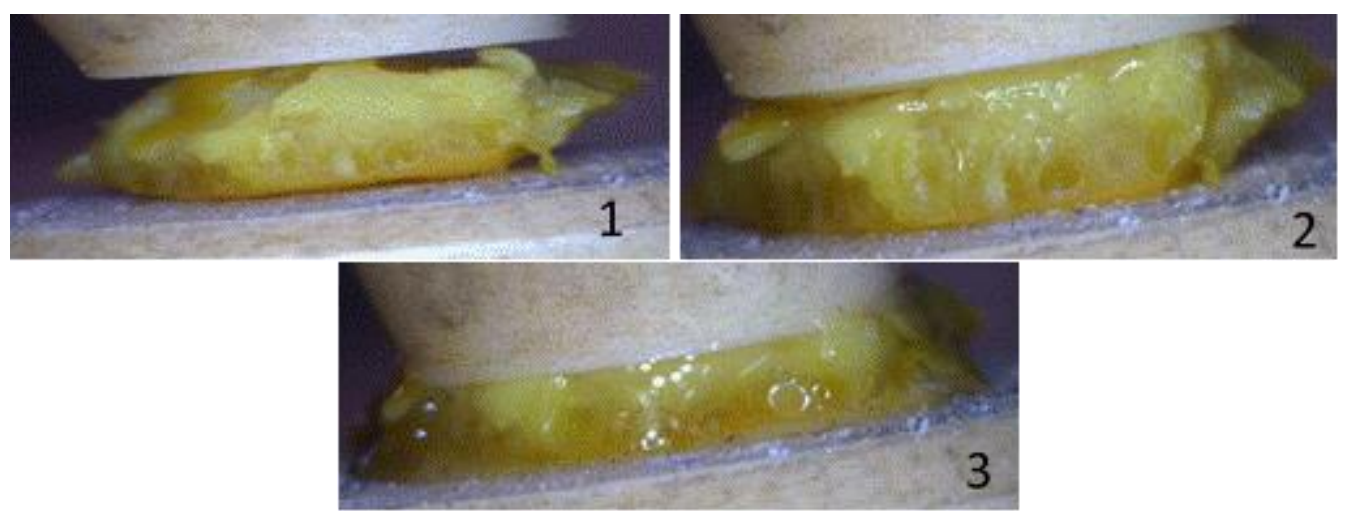

Fig. 16: Visualization of compression of orange peels.

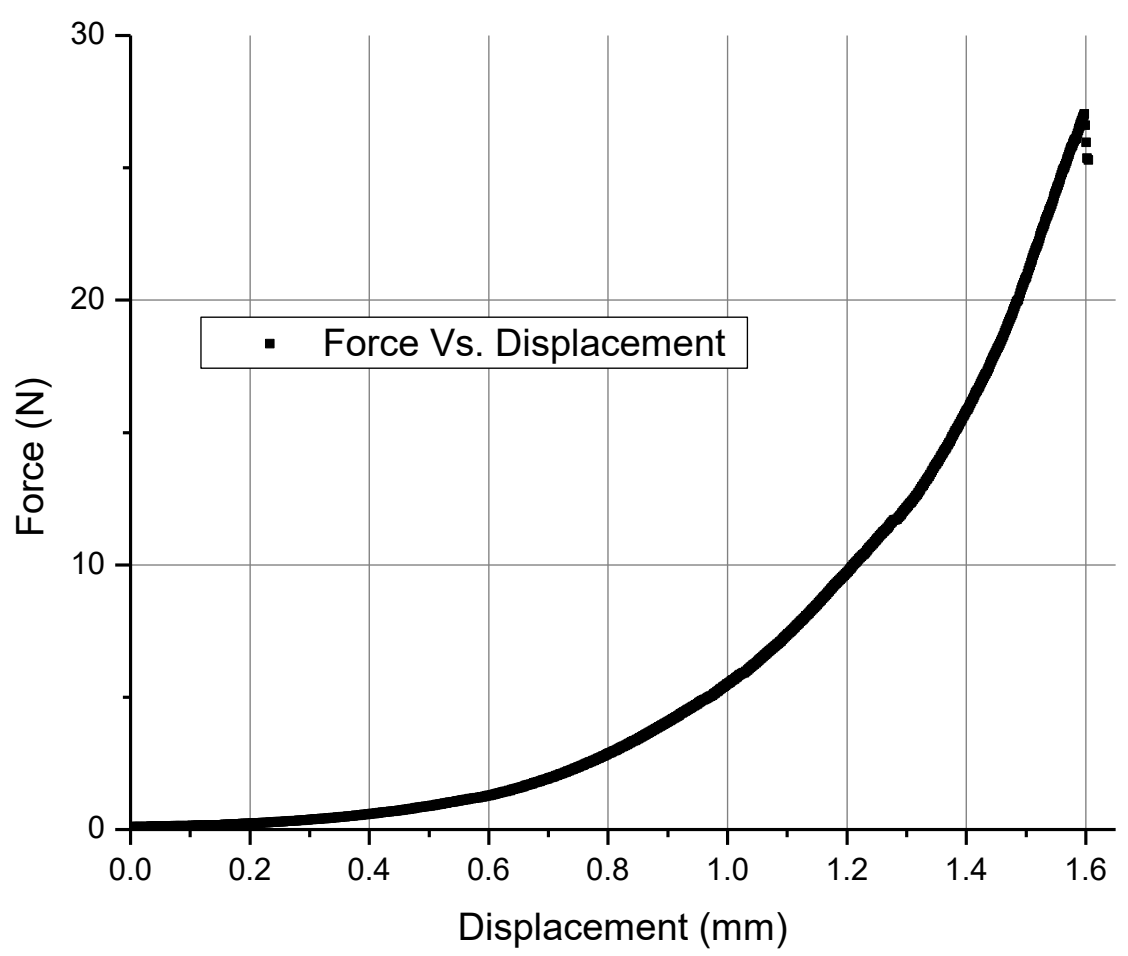

Fig. 17: Typical diagram for bending of straw.

$\mathrm{D}=2.424775 \mathrm{~mm}$, Orange peel, (105) 


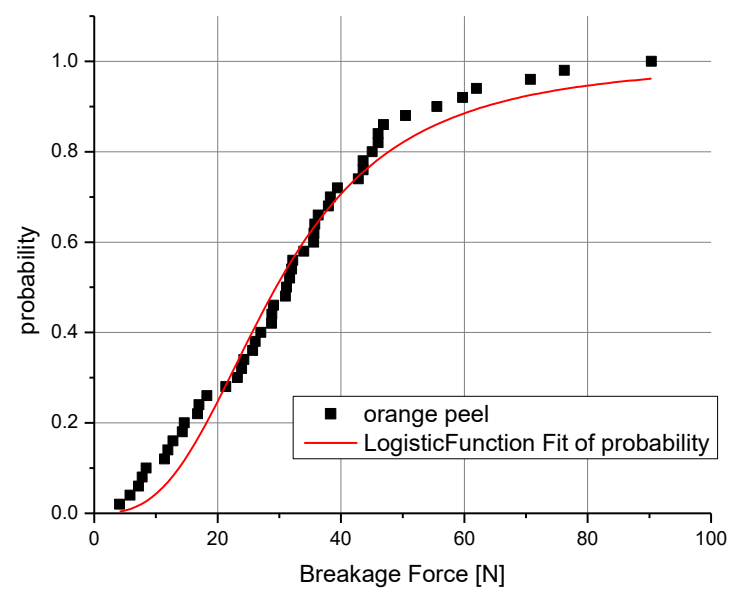

A

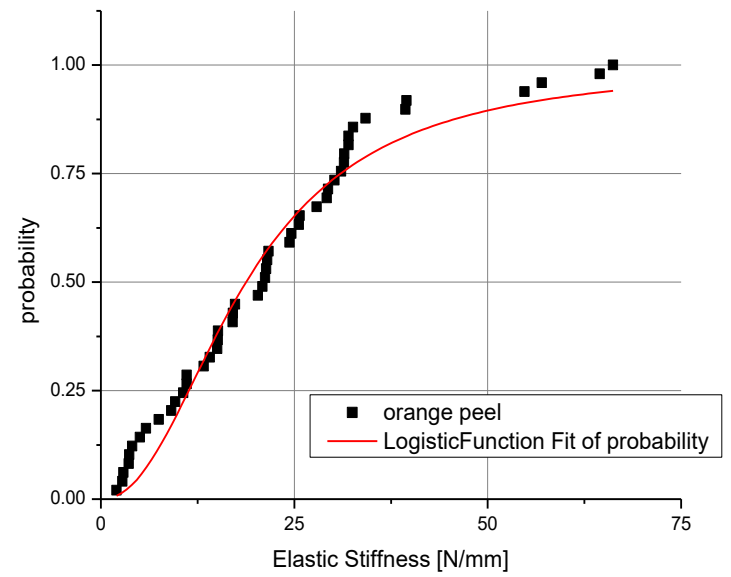

C

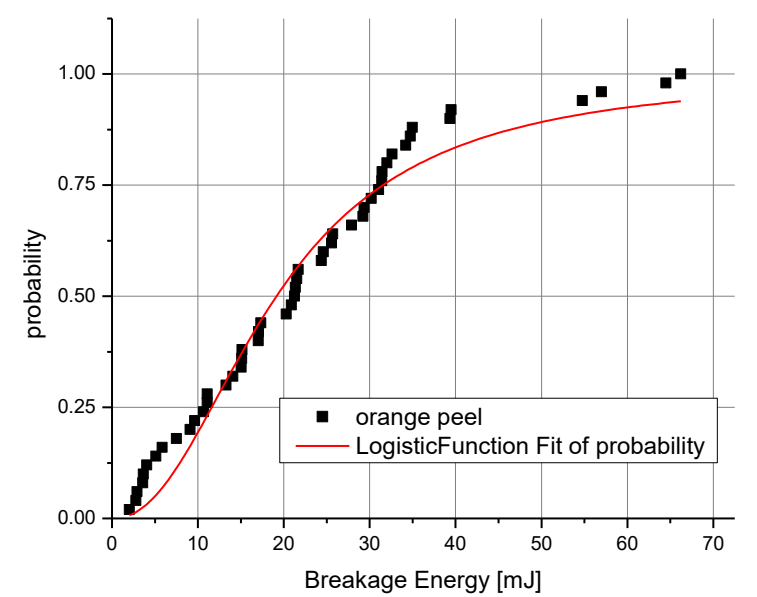

b

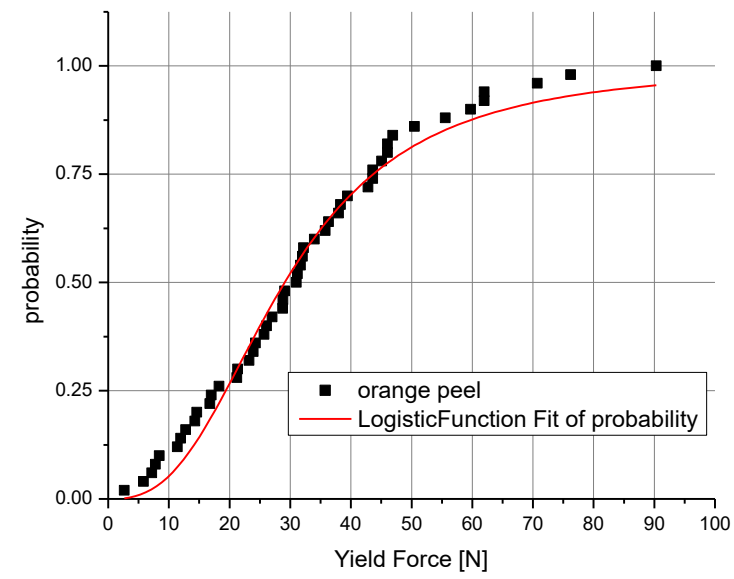

d

Fig. 18: Compression tests for orange peels; a. breakage force; b. breakage energy; c. elastic stiffness; d. yield force.

Table 5: Empirical parameters for compression of orange peels.

\begin{tabular}{|c|c|c|c|c|}
\hline $\begin{array}{c}\text { Empirical } \\
\text { Parameter }\end{array}$ & $\begin{array}{c}\text { Breakage } \\
\text { Force } \\
{[\mathrm{N}]}\end{array}$ & $\begin{array}{c}\text { Breakage } \\
\text { Energy } \\
{[\mathrm{mJ}]}\end{array}$ & $\begin{array}{c}\text { Yield } \\
\text { Force } \\
{[\mathrm{N}]}\end{array}$ & $\begin{array}{c}\text { Elastic } \\
\text { Stiffness } \\
{[\mathrm{N} / \mathrm{mm}]}\end{array}$ \\
\hline$x_{50}$ & 29.5 & 19.14 & 29.09 & 18.76 \\
\hline$D$ & 2.87 & 2.2 & 2.71 & 2.19 \\
\hline
\end{tabular}




\section{a.4 Testing Olive Pulp}

The olive pulp was divided by size and by type: hard (pieces of the hard core) and soft (pieces of the meat). The hard particles were compressed in both air and water and the soft particles only in air. Figure 19 present visualization of a hard particle compression where the crack formation is clearly shown. Figures 20 and 21 present typical compression curves for hard and soft particles, respectively. The results for the strength characterization of hard particles at two sizes both in air and in water are presented in Fig. 22. The hard particles behave as expected as smaller particles are stronger (in terms of stress and not force). The elastic properties are not affected by the particle size. However, the elastic values are higher for dry particles. The results for the strength characterization of soft particles at two sizes only in air are presented in Fig. 23. The size has negligible effect on the measured parameters. The final values for the empirical parameters are presented in Table 6.

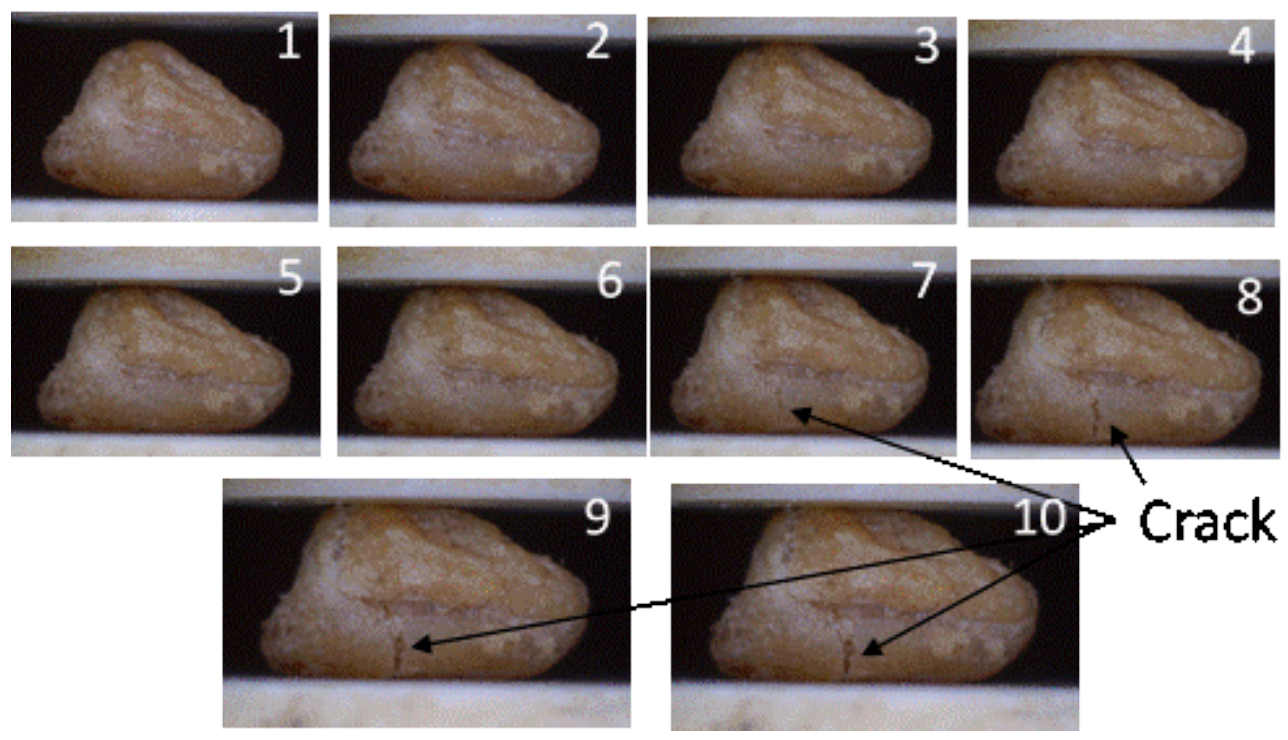

Fig. 19: Visualization of compression of olive pulp. 


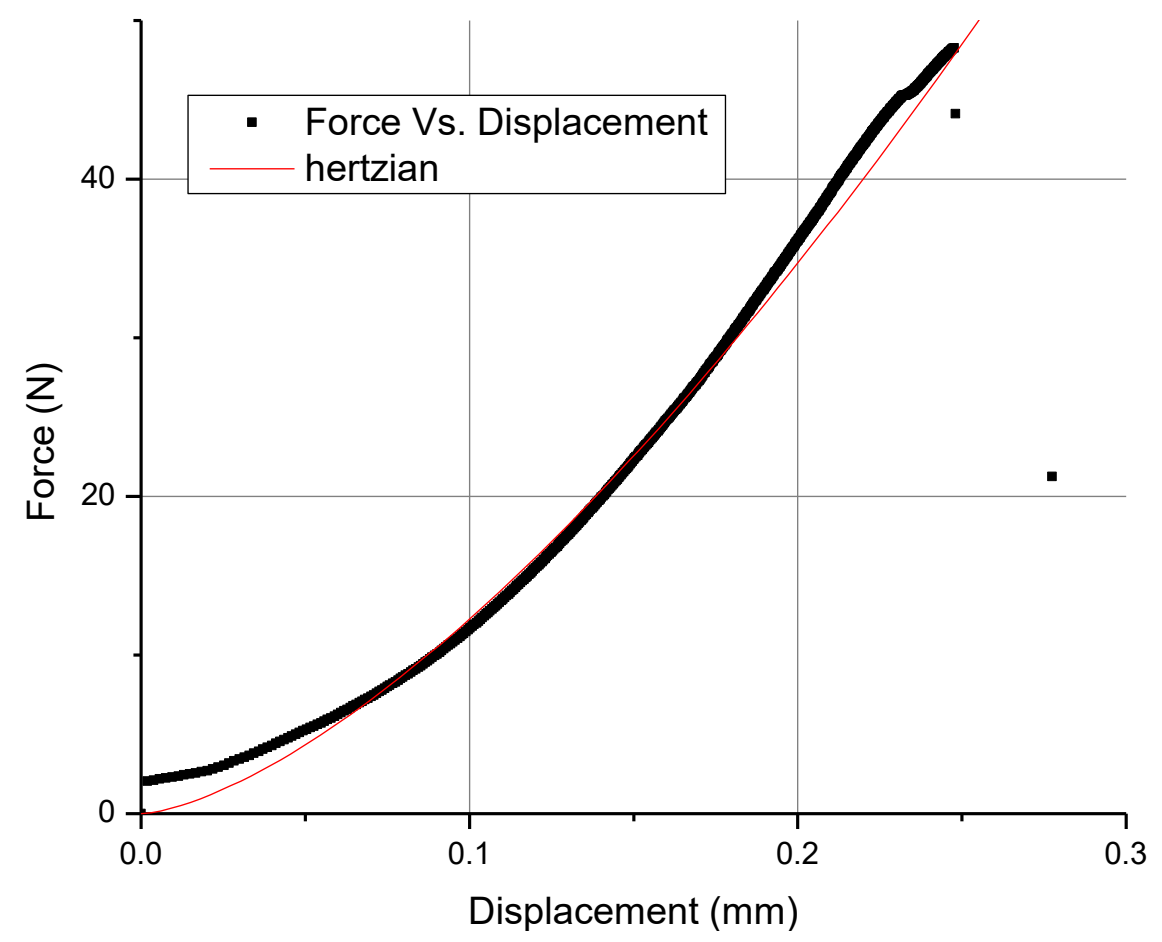

Fig. 20: Typical diagram for hard olive pulp. $\mathrm{E}=806.574434 \mathrm{MPa}, \mathrm{D}=2.083171 \mathrm{~mm}$, Hard olive pulp dry, (145)

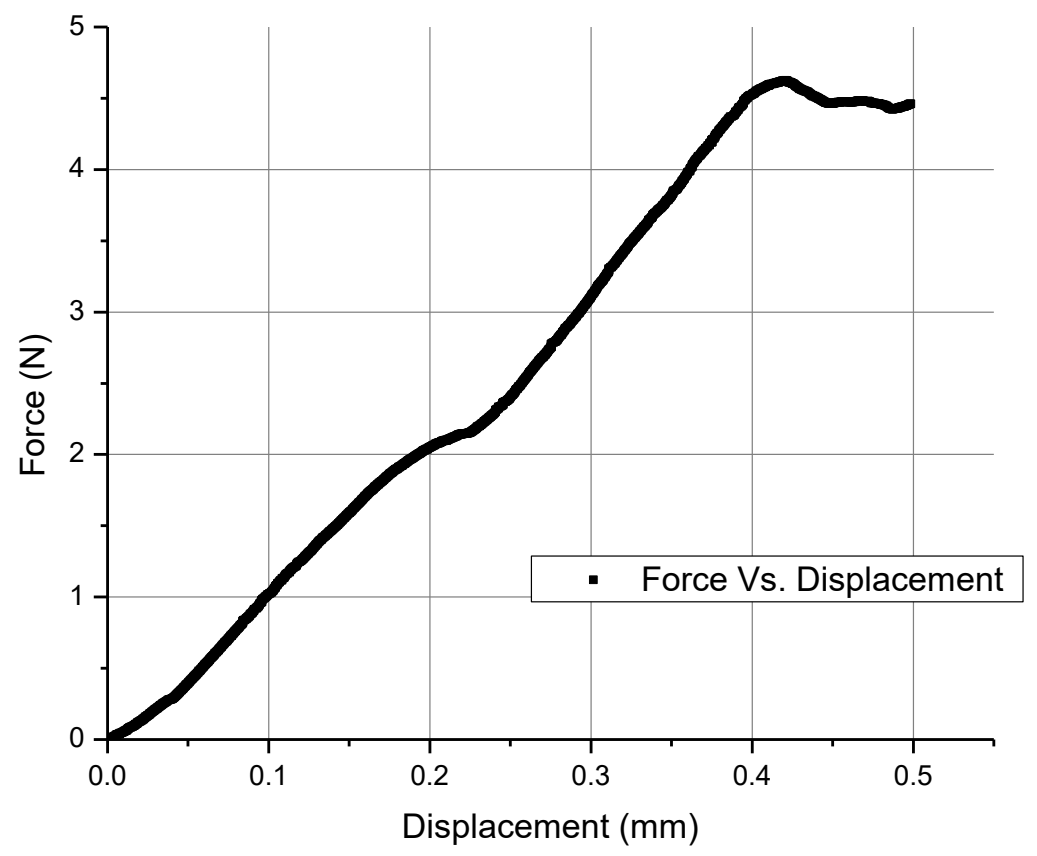

Fig. 21: Typical diagram for soft olive pulp. $\mathrm{D}=2.220753 \mathrm{~mm}$, Soft olive pulp dry, (179) 


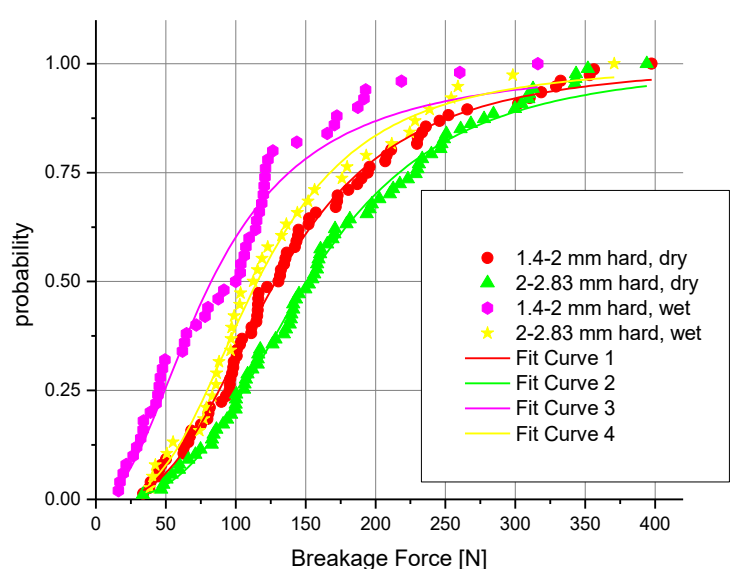

a

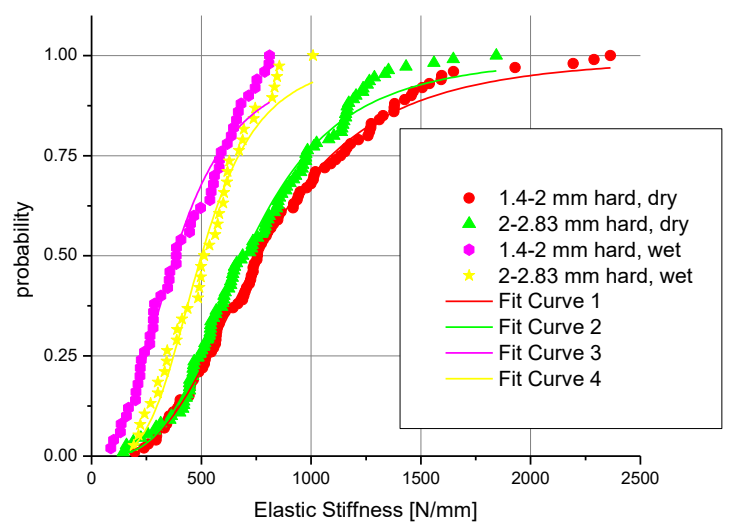

C

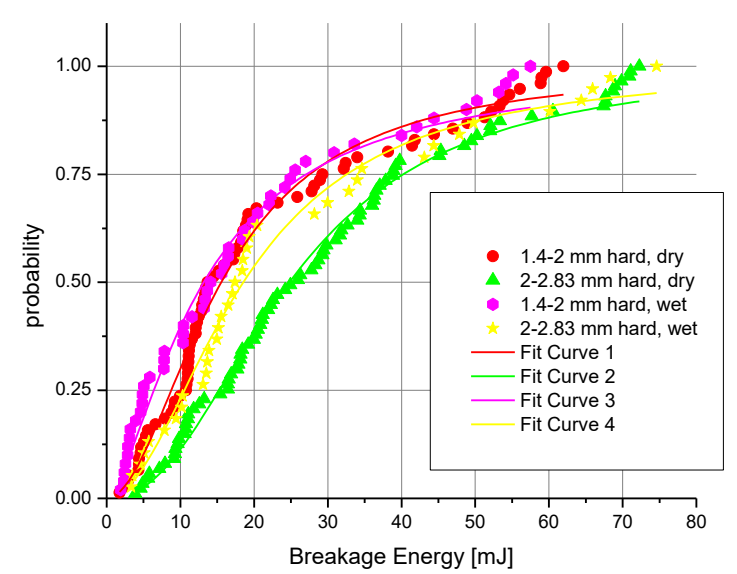

b

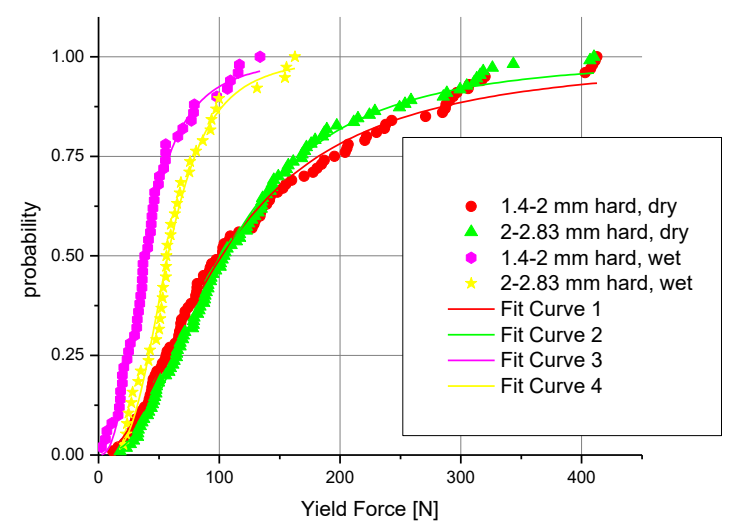

d

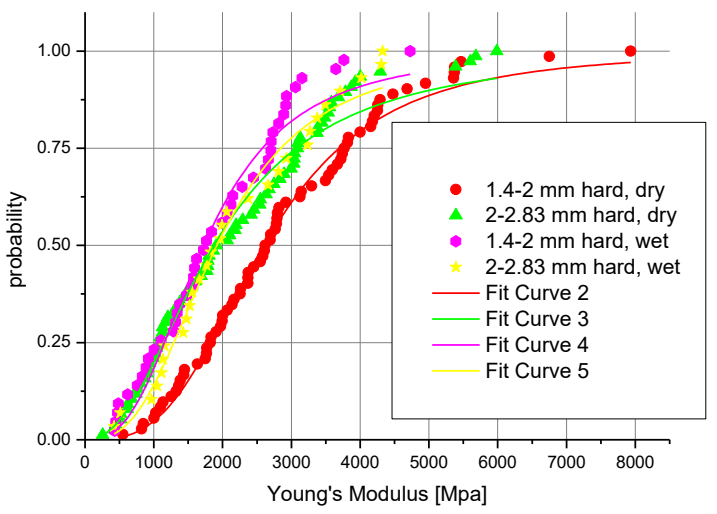

e

Fig. 22: Compression tests for hard olive pulp in air and in water; a. breakage force; b. breakage energy; c. elastic stiffness; d. yield force; e. Young's modulus. 

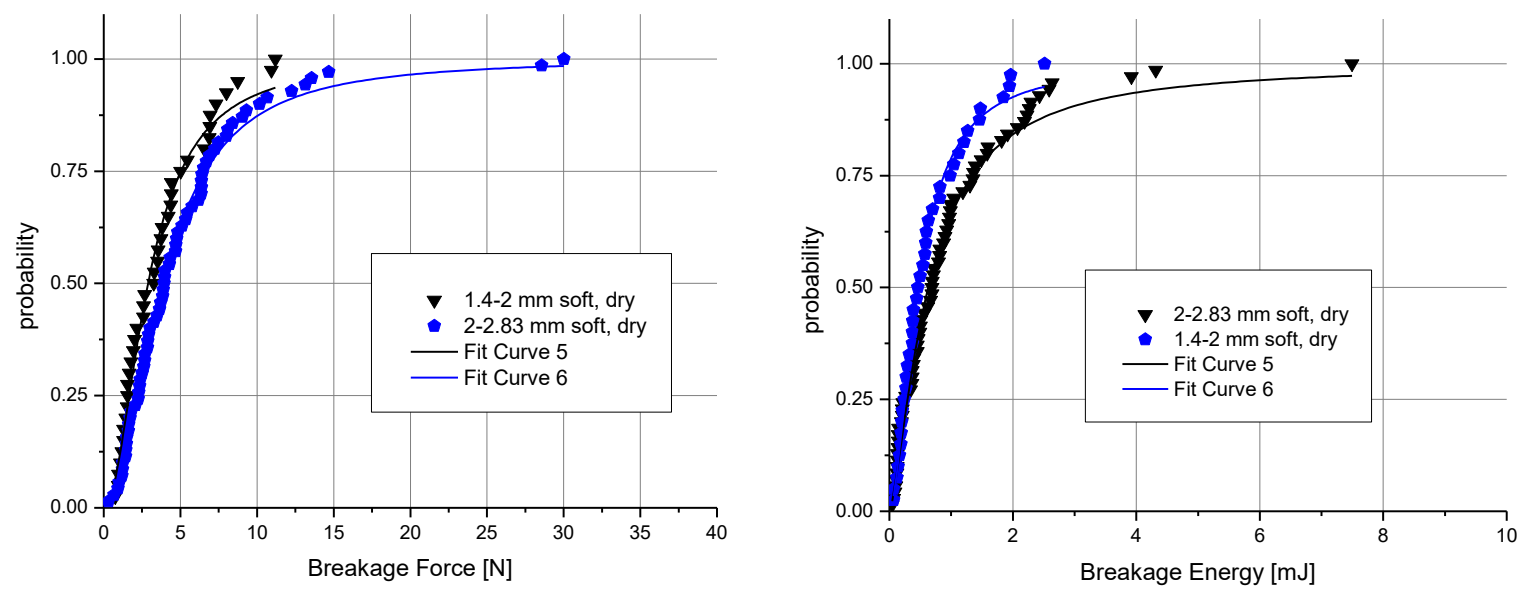

a

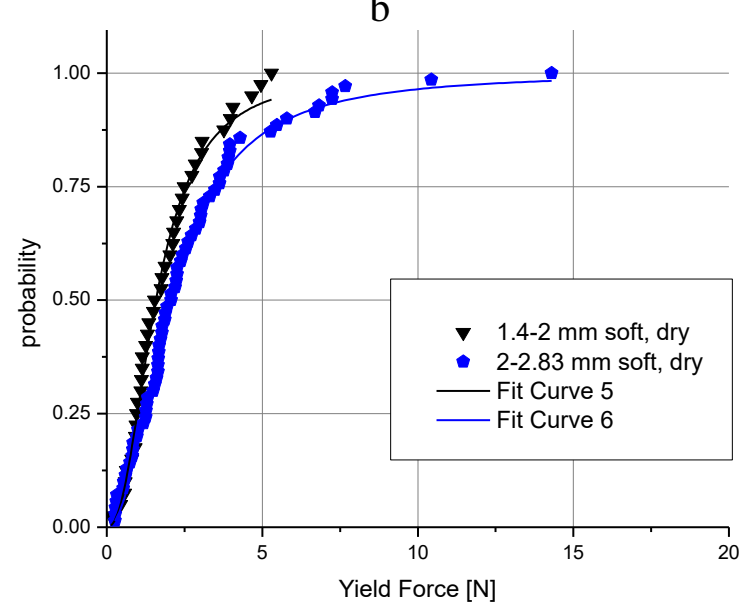

d

$\mathrm{c}$

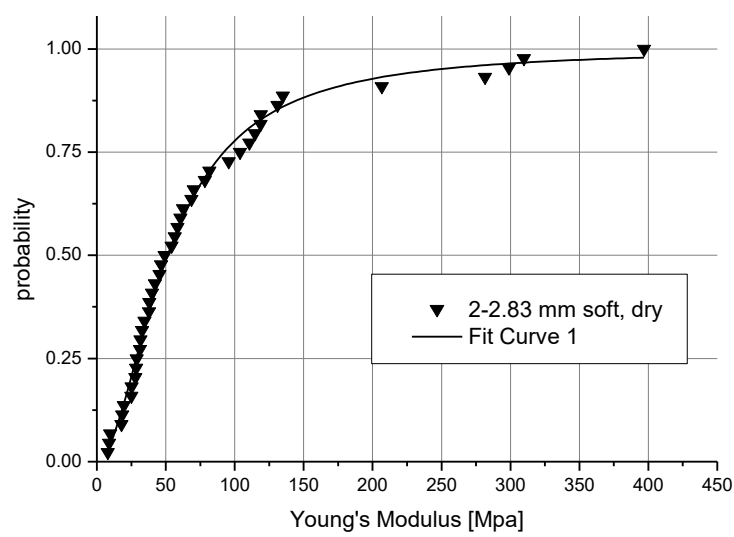

e

Fig. 23: Compression tests for soft olive pulp; a. breakage force; b. breakage energy; c. elastic stiffness; d. yield force; e. Young's modulus. 
Table 6: Empirical parameters for compression of olive pulp.

\begin{tabular}{|c|c|c|c|c|c|c|c|}
\hline $\begin{array}{c}\text { Size } \\
{[\mathrm{mm}]}\end{array}$ & Test & $\begin{array}{l}\text { Empirical } \\
\text { Parameter }\end{array}$ & $\begin{array}{c}\text { Breakage } \\
\text { Force } \\
{[\mathrm{N}]}\end{array}$ & $\begin{array}{c}\text { Breakage } \\
\text { Energy } \\
{[\mathrm{mJ}]}\end{array}$ & $\begin{array}{c}\text { Yield } \\
\text { Force } \\
{[\mathrm{N}]}\end{array}$ & $\begin{array}{c}\text { Elastic } \\
\text { Stiffness } \\
{[\mathrm{N} / \mathrm{mm}]}\end{array}$ & $\begin{array}{l}\text { Young's } \\
\text { Modulus }\end{array}$ \\
\hline \multirow{6}{*}{$1.4-2.0$} & \multirow{2}{*}{$\begin{array}{l}\text { Hard } \\
\text { Dry }\end{array}$} & $x_{50}$ & 128.71 & 15.53 & 101.98 & 760.74 & 2598.94 \\
\hline & & $D$ & 2.9 & 1.92 & 1.89 & 3.05 & 3.129 \\
\hline & \multirow{2}{*}{$\begin{array}{l}\text { Hard } \\
\text { Wet }\end{array}$} & $x_{50}$ & 82.44 & 13.16 & 38.48 & 377.81 & 1725.9 \\
\hline & & $D$ & 2.13 & 1.52 & 2.63 & 2.65 & 2.73 \\
\hline & \multirow{2}{*}{$\begin{array}{l}\text { Soft } \\
\text { Dry }\end{array}$} & $x_{50}$ & 2.89 & 0.47 & 1.58 & 15.33 & --- \\
\hline & & $D$ & 1.98 & 1.73 & 2.3 & 2.44 & --- \\
\hline \multirow{6}{*}{$2.0-2.83$} & \multirow{2}{*}{$\begin{array}{l}\text { Hard } \\
\text { Dry }\end{array}$} & $x_{50}$ & 151.28 & 24.77 & 104.38 & 697.26 & 1875.67 \\
\hline & & $D$ & 3.05 & 2.26 & 2.31 & 3.23 & 2.23 \\
\hline & \multirow{2}{*}{$\begin{array}{l}\text { Hard } \\
\text { Wet }\end{array}$} & $x_{50}$ & 115.43 & 18.53 & 57.43 & 499.86 & 1916.96 \\
\hline & & $D$ & 2.95 & 1.95 & 3.36 & 3.76 & 2.78 \\
\hline & \multirow{2}{*}{$\begin{array}{l}\text { Soft } \\
\text { Dry }\end{array}$} & $x_{50}$ & 3.84 & 0.63 & 2.04 & 16.34 & 51.34 \\
\hline & & $D$ & 2.02 & 1.45 & 2.08 & 2.54 & 1.88 \\
\hline
\end{tabular}

\section{b. Measurement of Shear Stress in a Shear Tester}

The Jenike Shear Cell was adjusted to measure biomass particles both dry and immersed in liquid. However, we have faced difficulties with most of the materials to get steady-state condition after pre-consolidation. Therefore, only olive pulps are measured in air, but at two moisture contents. The results are presented for dry and 20\% moisture content in tables 7 and 8 and yield-locuses are compared in Fig. 24 (showing only slight variation). 
Table 7: Test results for a yield locus for dry olive pulp.

\begin{tabular}{|c|c|c|c|}
\hline \multicolumn{4}{|c|}{ Results of calculation } \\
\hline & & $\sigma p, s, N / m^{2}$ & $\tau^{\prime}, N / m^{2}$ \\
\hline Preshear point & $P$ & 8217 & 9047 \\
\hline \multirow{3}{*}{ Shear points } & S1 & 6611 & 7751 \\
\hline & $S 2$ & 4607 & 5817 \\
\hline & $S 3$ & 2358 & 3331 \\
\hline \multicolumn{3}{|c|}{ Unconfined yield stress $\left(\sigma_{c}\right), N / m^{2}$} & 4594 \\
\hline \multicolumn{3}{|c|}{ Major principal stress $\left(\sigma_{1}\right), N / m^{2}$} & 24761 \\
\hline \multicolumn{3}{|c|}{ Effective angle of internal friction $\left(\varphi_{e}\right)$, deg } & 50.1 \\
\hline \multicolumn{3}{|c|}{ Internal friction angle $\left(\boldsymbol{\varphi}_{\text {lin }}\right)$, deg } & 46.1 \\
\hline \multicolumn{3}{|c|}{ ratio $f f_{c}(\sigma 1 / \sigma c)$} & 5.39 \\
\hline
\end{tabular}

Table 8: Test results for a yield locus for $20 \%$ moisture content of olive pulp.

\begin{tabular}{|c|c|c|c|}
\hline \multicolumn{4}{|c|}{ Results of calculation } \\
\hline & & $\sigma \not p, s, N / m^{2}$ & $\tau^{\prime}, N / m^{2}$ \\
\hline Preshear point & $P$ & 8234 & 8381 \\
\hline \multirow{3}{*}{ Shear points } & $S 1$ & 6637 & 7371 \\
\hline & $S 2$ & 4627 & 5727 \\
\hline & $S 3$ & 2783 & 3766 \\
\hline \multicolumn{3}{|c|}{ Unconfined yield stress $\left(\sigma_{c}\right), N / m^{2}$} & 5750 \\
\hline \multicolumn{3}{|c|}{ Major principal stress $\left(\sigma_{1}\right), N / m^{2}$} & 21662 \\
\hline \multicolumn{3}{|c|}{ Effective angle of internal friction $\left(\varphi_{e}\right)$, deg } & 49.2 \\
\hline \multicolumn{3}{|c|}{ Internal friction angle $\left(\boldsymbol{\varphi}_{\text {lin }}\right)$, deg } & 43.0 \\
\hline \multicolumn{3}{|c|}{ ratio $f f_{c}(\sigma 1 / \sigma c)$} & 3.77 \\
\hline
\end{tabular}




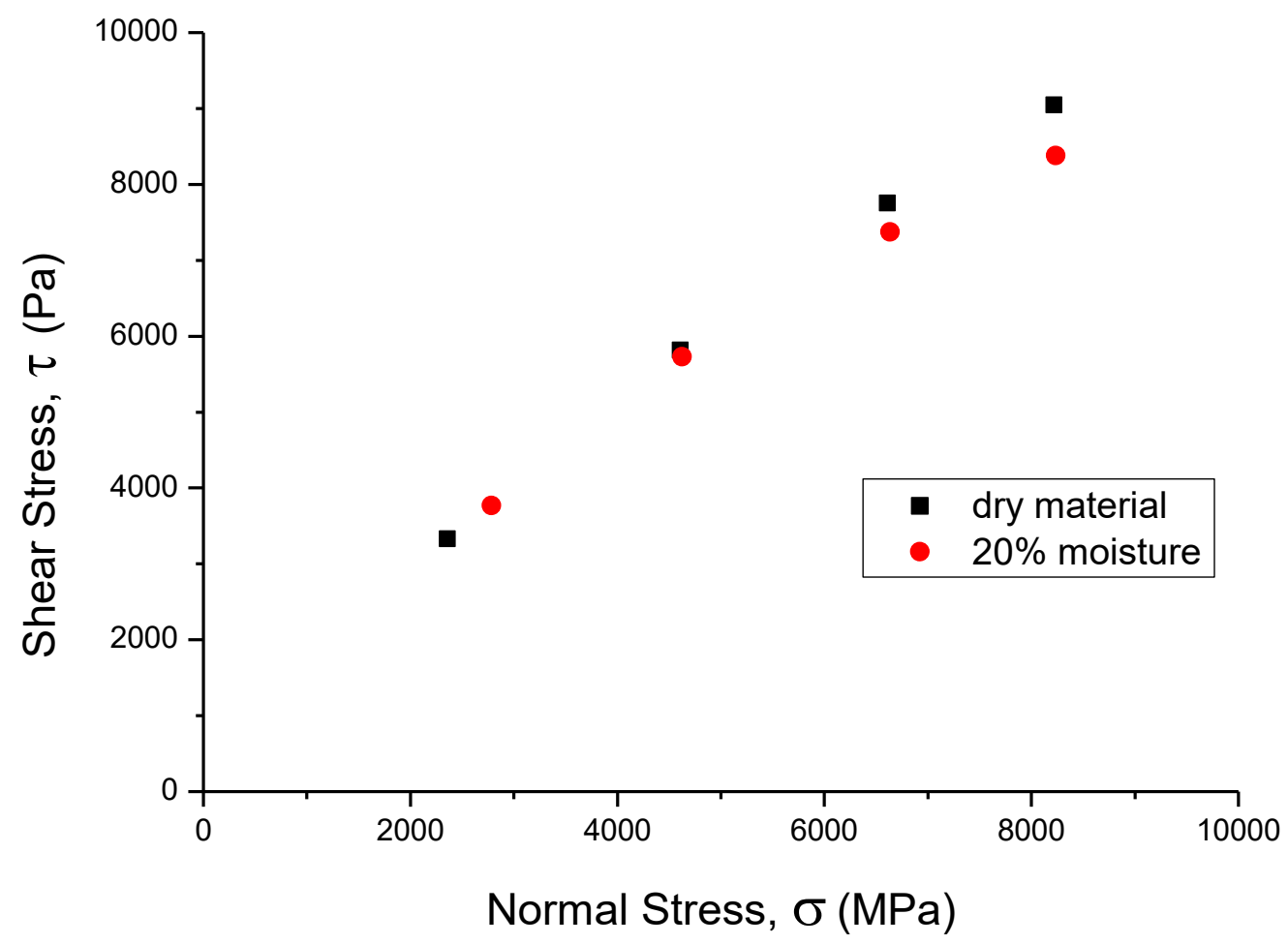

Fig. 24: Yield Locus for dry and 20\% moisture content of olive pulp.

\section{c. Measurement of Shear Forces in a Rheometer}

The shear forces as function of the shear rate are characterized for all materials for a number of volumetric concentrations. We used a Rheometer manufactured by AntonPaar, as presented in Fig. 25. We used for measurements home made rotors (bobs) of $80 \mathrm{~mm}$ height and $35 \mathrm{~mm}$ in diameter for olive pulp and orange peels, and $30 \mathrm{~mm}$ height and $20 \mathrm{~mm}$ in diameter for straw. The rotors outputs were calibrated by measuring oil and glycerol. The results for olive pulp, orange peels and wheat straw for various concentrations are presented in Figs. 26, 27 and 28, respectively. Please note that the measurements are disturbed for the straw due to its elongated shape. 


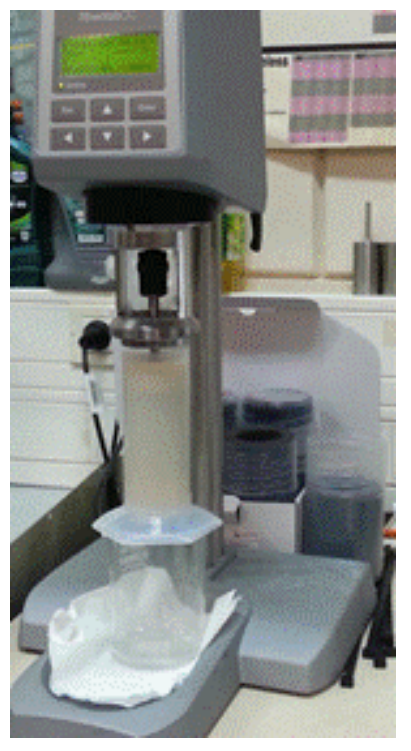

a

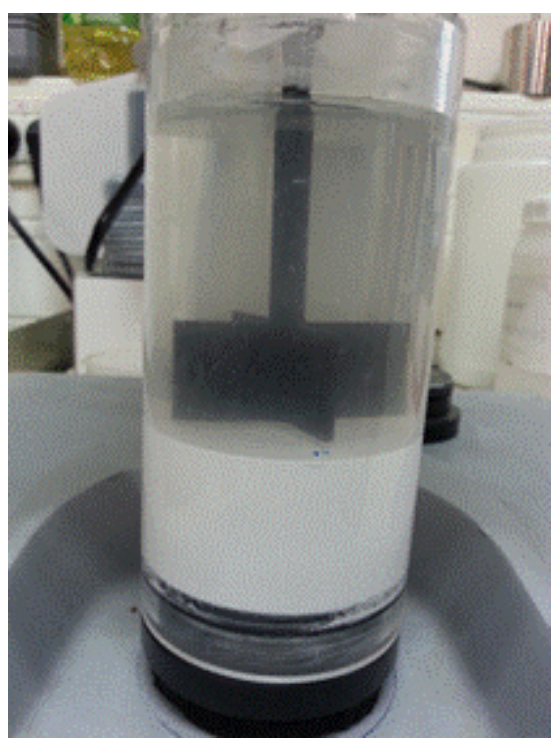

b

Fig. 25: Equipment for Rheometer measurements; a. The rheometer; b. The bob and container.

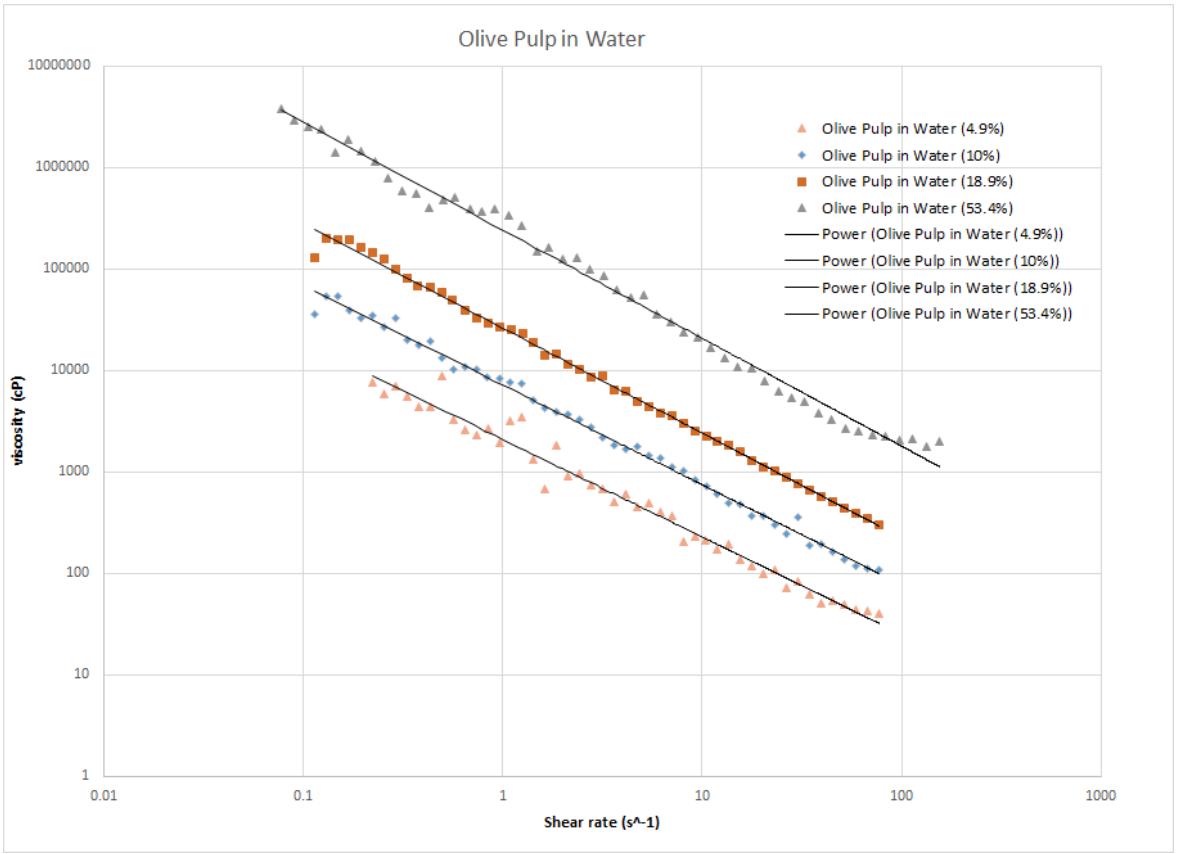

Fig. 26: Viscosity vs. Shear Rate for olive pulps at various concentrations. 


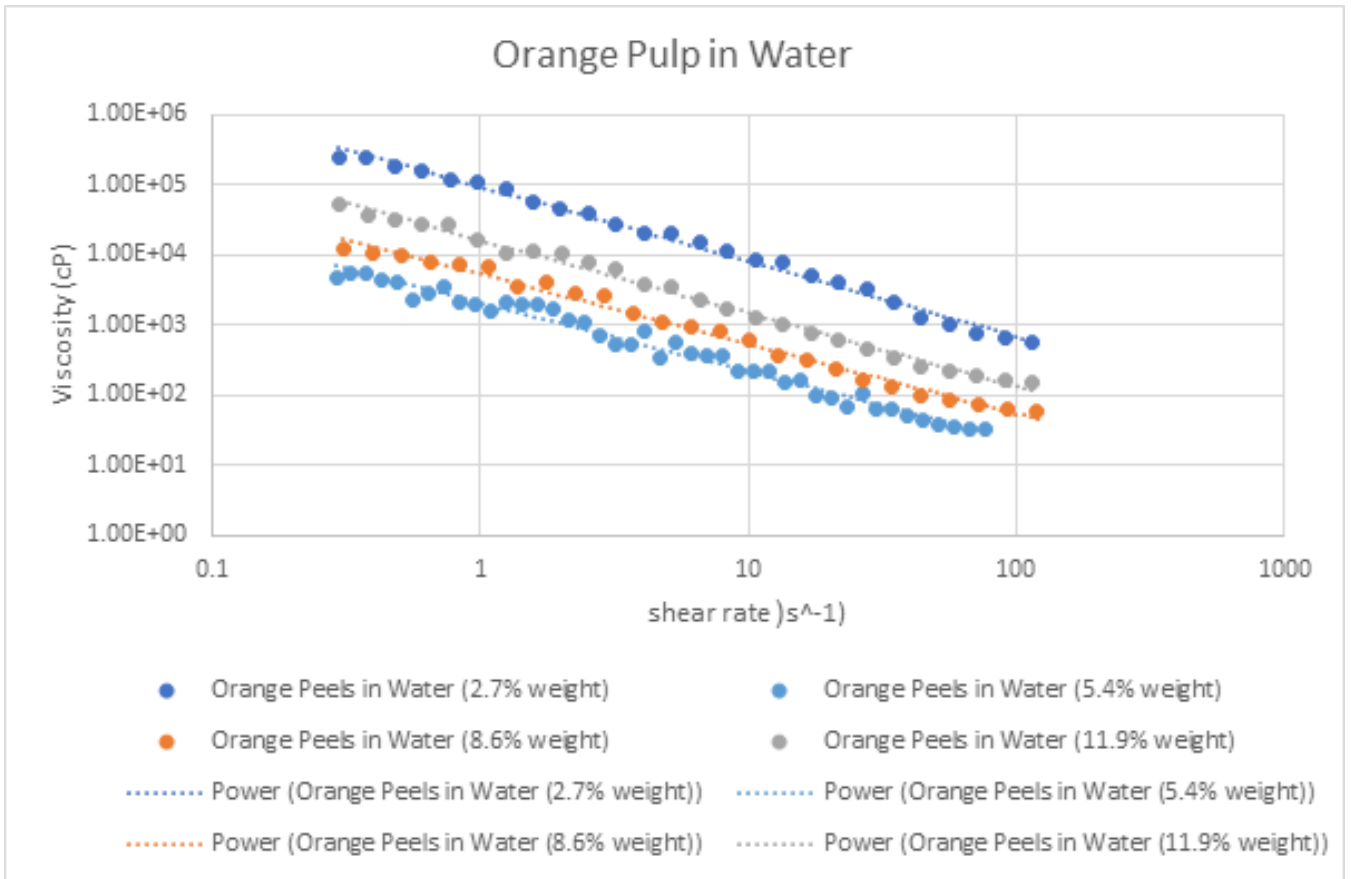

Fig. 27: Viscosity vs. Shear Rate for orange peels at various concentrations.

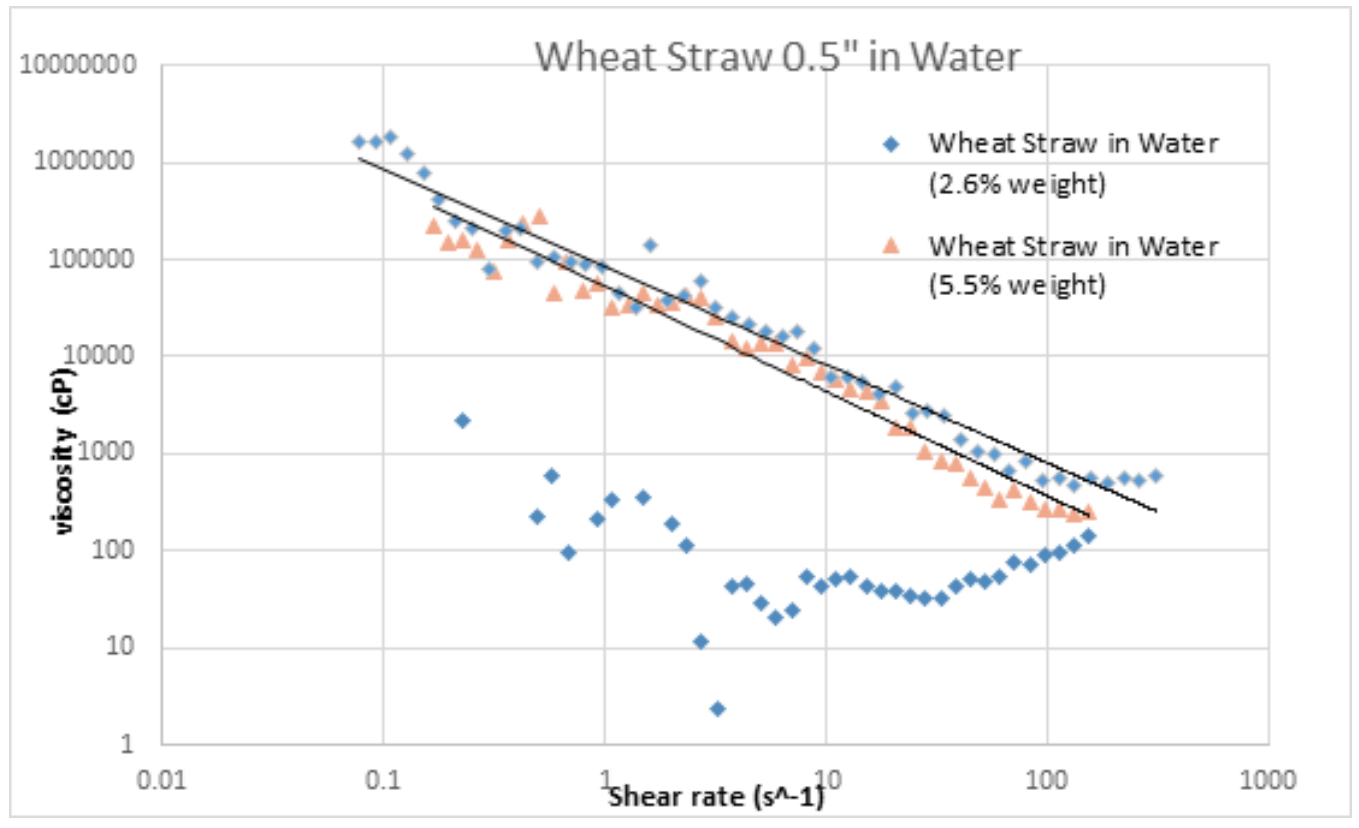

Fig. 28: Viscosity vs. Shear Rate for wheat straw at various concentrations. 


\section{d. Measurement of Flow through a Biomass Packed Bed}

Here we describe the fluidized bed experiments done on bio-materials, using a liquid fluidized bed system. For each material the fluidization curve (pressure drop over the bed vs. the fluids velocity), will be presented alongside a description of the fluidization and an explanation of the curve. The materials tested were: orange peels, olive waste, straw and wheat.

\section{d.1 The Liquid Fluidized Bed System Description}

This system was designed, manufactured and tested in the frame of this research. The water circulating in the liquid fluidized bed setup is preserved in a plastic tank (1) at ambient conditions (see Fig. 29). The water is being pumped out of the tank by a centrifugal pump (2), the pump has only two states on and off, in order to work with the desirable pressure and flow rate, the bypass (3) and the main line valve (4) are being used combined. The water continues to the electromagnetic flow rate meter (5). Before entering the experimental pipe, the water flows through the distributer (6), the distributer is a packed bed of plastic pallets followed by a fibre filter. The experimental pipe (8) is made of glass, its diameter is $81 \mathrm{~mm}$ and its length is $1 \mathrm{~m}$. The water pressure drop over the bed is measured by the pressure transducer (7), through two measuring points one under the experimental pipe and one over it as illustrated. The water departing from the experimental pipe circulates back to the tank. The data measured was acquired by a LabVIEW acquisition system (9).

The liquid fluidized bed experiments are simple to perform. First, the pipe is being filled by the particles, after connecting the pipe back to the system, the pump is switched on filling the pipe with water, wetting the bed entirely. It's important at that point to make sure there aren't any bubbles of air inside the pipe or the system. After the bed is fully wet valve (4) is closed while the pump still works pumping water through the bypass. When the experimental pipe is filled with water, valve (4) can be opened slowly, increasing the water's flow rate. After reaching the desired flow rate, the valves are slowly closed until the flow rate is back to zero. Producing the pressure drop over the bed vs. the water superficial velocity. 


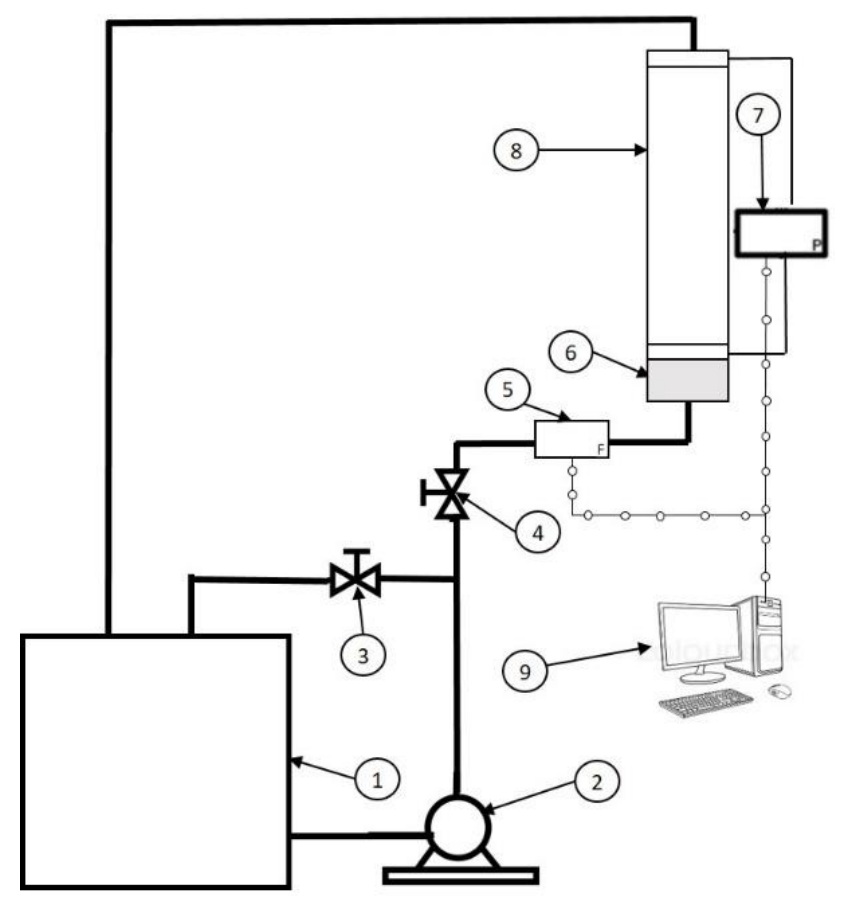

Fig. 29: Schematics of the water fluidized bed system.

\section{d.2 Experiments Results}

\section{d.2.1 Orange Peels}

Before testing the orange peels they were ground by a conventional domestic food processor. Figure 30 presents the orange peels fluidization curve. In the beginning of the fluidization the peels sedimented on the bottom of the fluidization pipe, right after starting to increase the velocity the peels became fluidized that's why the pressure drop almost didn't change. When the velocity was about $0.025 \mathrm{~m} / \mathrm{s}$ the peels started to pile up on the top of the pipe. Increasing the velocity increased the packing of the bed on the top of the pipe and with it the pressure drop over the bed. At a pressure drop of about $16 \mathrm{mbar}$ and a velocity of $0.04 \mathrm{~m} / \mathrm{s}$ the velocity was decreased. At the end of the fluidization test the peels were back at the bottom of the pipe. Shortly, the pressure increase actually describe flow through a packed bed. Figure 31 presents visualization of the process of the orange peels rising to the pipe top. 


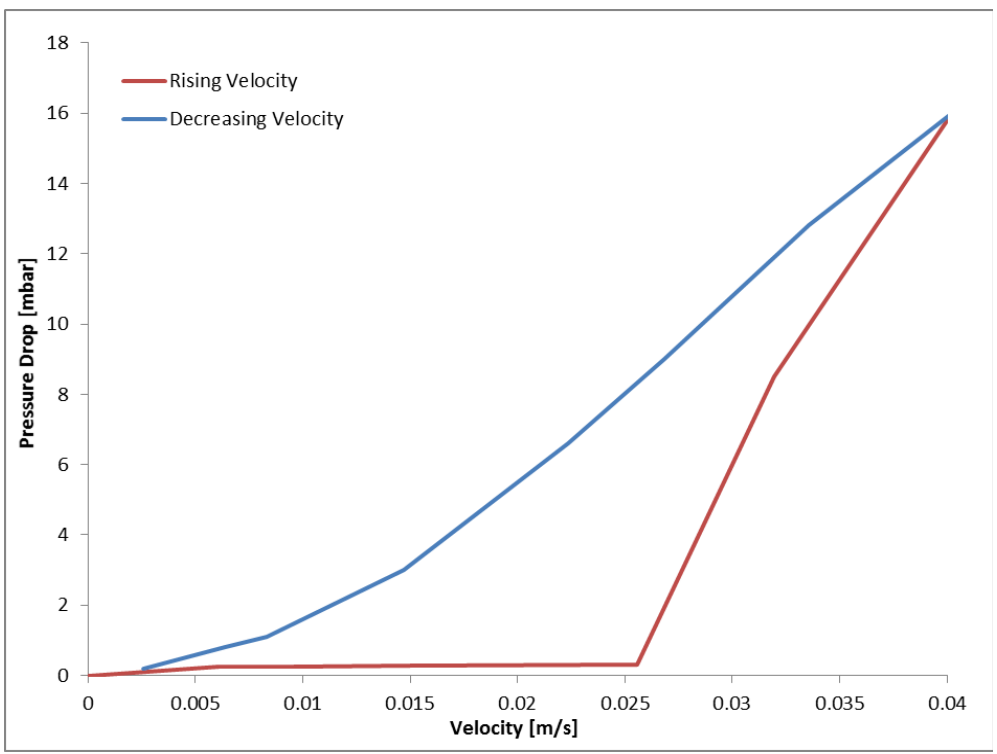

Fig. 30: Orange peels fluidization curve.

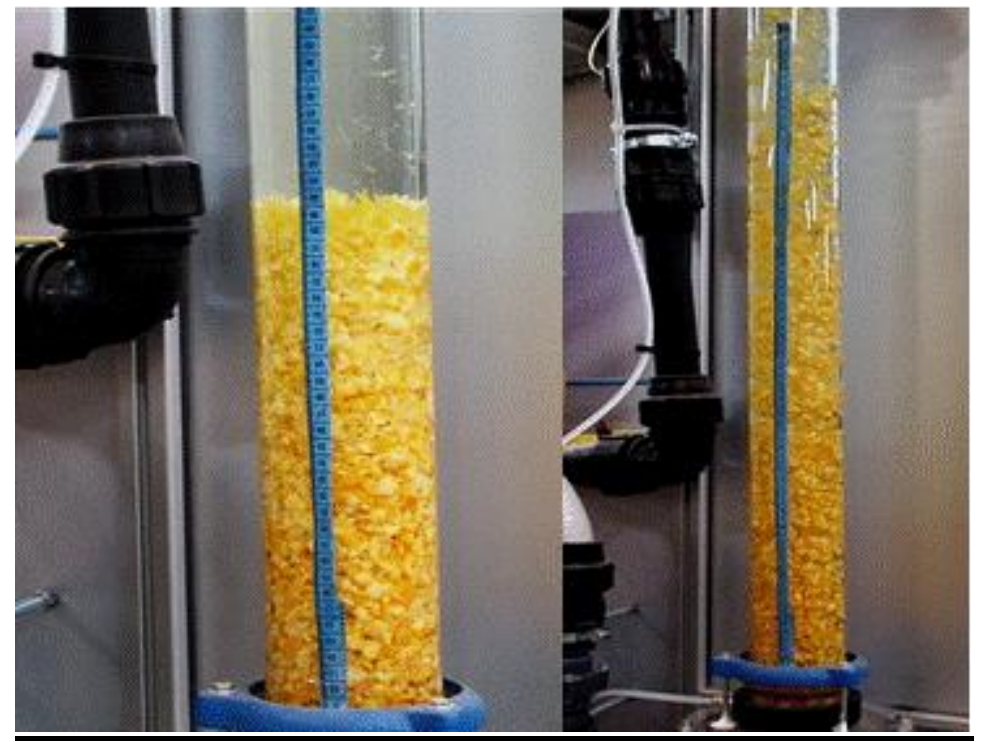

Fig. 31: Orange peels fluidization. Test start on the left and the peels are rising up on the right.

\section{d.2.2 Olive Pulp}

Figure 32 presents the olive pulp fluidization curve. Before letting the water flow through the bed, the particles sedimented at the bottom of the pipe. Because of the material's low density, right at the beginning of the fluidization the particles started fluidizing and the bed expended while increasing the velocity. At a velocity around $0.046 \mathrm{~m} / \mathrm{s}$ the particles started reaching and piling at the top of the pipe. From that point the pressure drop started to rise with the increase in velocity, 
and pecking the bed tighter at the top of the pipe, same as the orange peels experiment. At the end of the fluidization the peels fell back to the bottom of the pipe with the decreasing velocity.

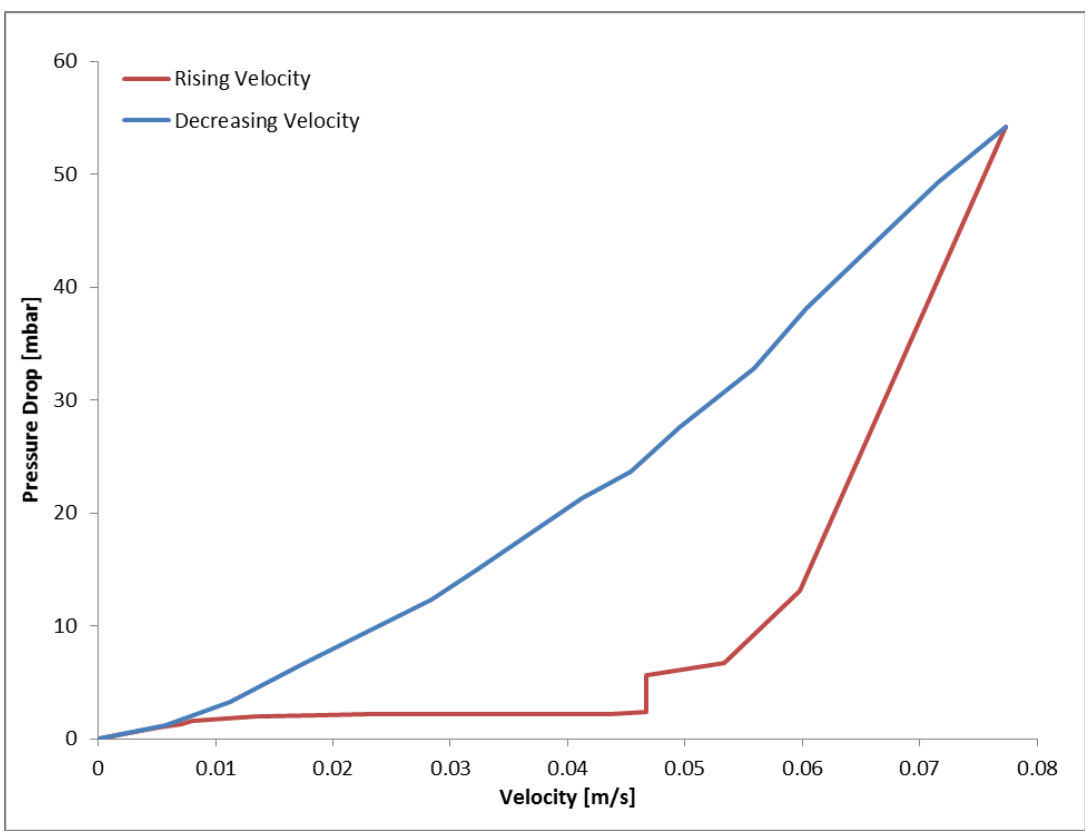

Fig. 32: Olive pulp fluidization curve.

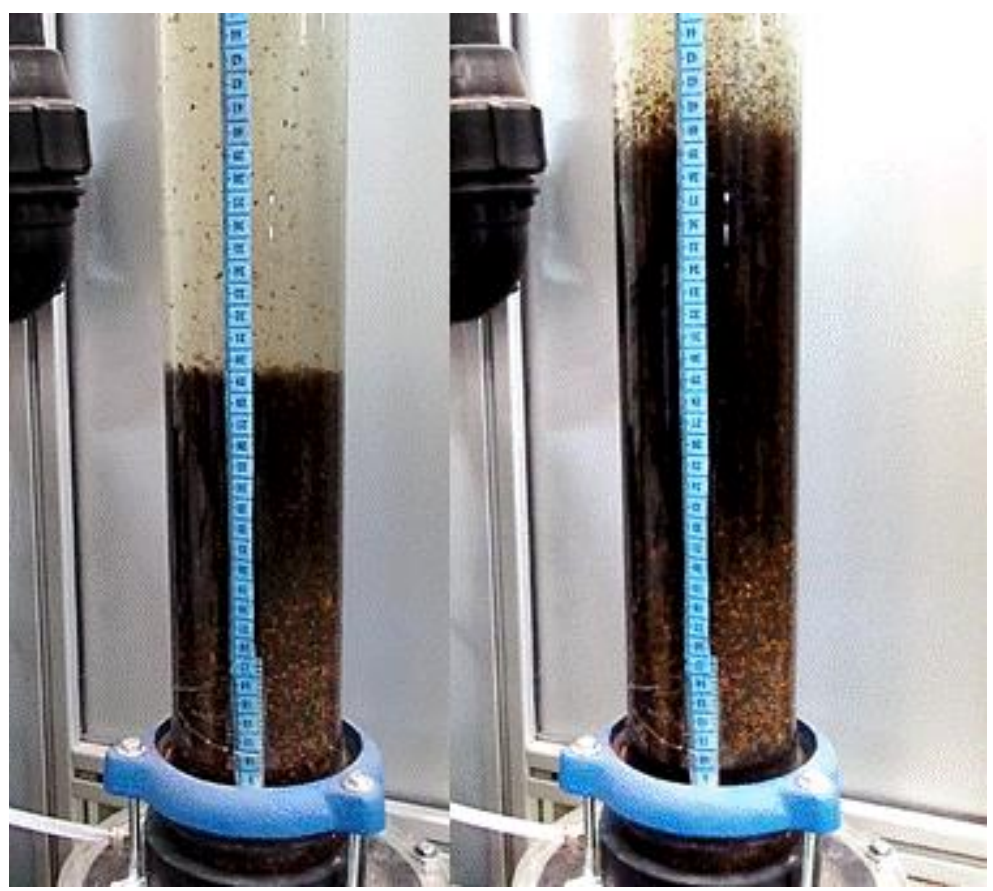

Fig. 33: Olive pulp fluidization. Test start on the left and the pulp is rising up on the right. 


\section{d.2.3 Wheat}

The wheat was tested in its grain form. Figure 34 shows the wheat fluidization curve. The wheat bed stayed fixed at the bottom of the pipe until the velocity reached its critical value of $0.01 \mathrm{~m} / \mathrm{s}$. After the velocity reached its critical value the wheat started fluidizing inside the pipe, and from that point on the bed expended with the increase in velocity and the pressure drop stayed more or less the same until the maximum velocity at about $0.058 \mathrm{~m} / \mathrm{s}$. When decreasing the velocity the particles started sinking to the bottom of the pipe. It is easy to notice that the fluidization line for the decreasing velocity is not the same as the rising velocity. The reason may be the interparticle forces (Van der Waals) which are smaller in a water medium than in air but still exist. Figure 34 presents a fluidization curve of type A according to Geldart classification, in which the first part of the increasing pressure drop describe the packed bed.

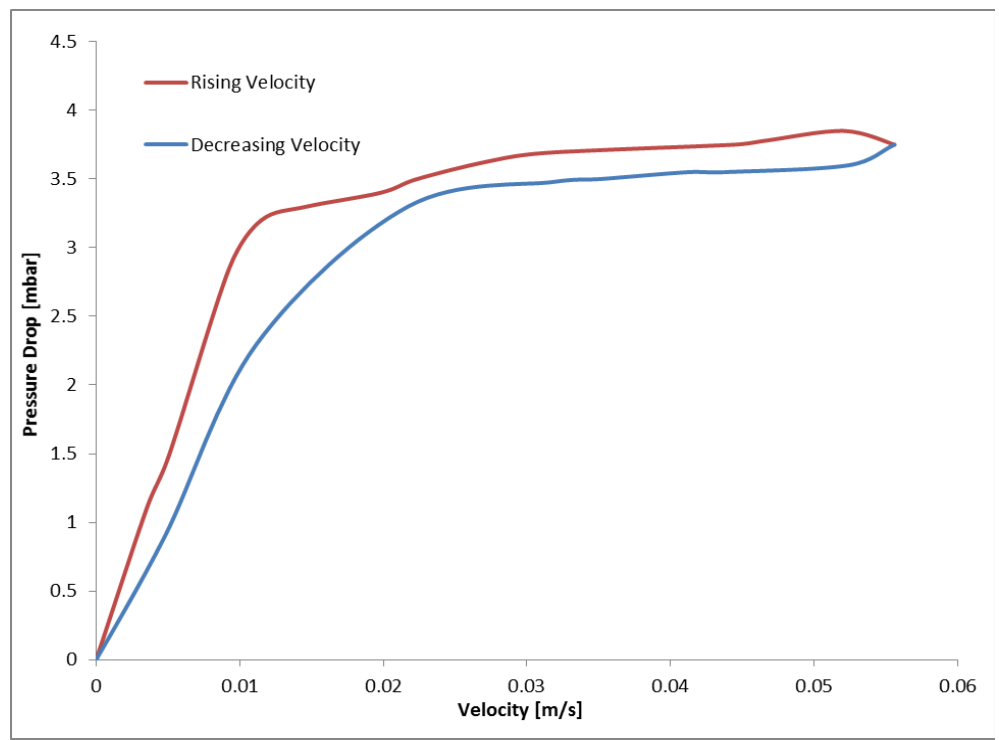

Fig. 34: Wheat grains fluidization curve. 


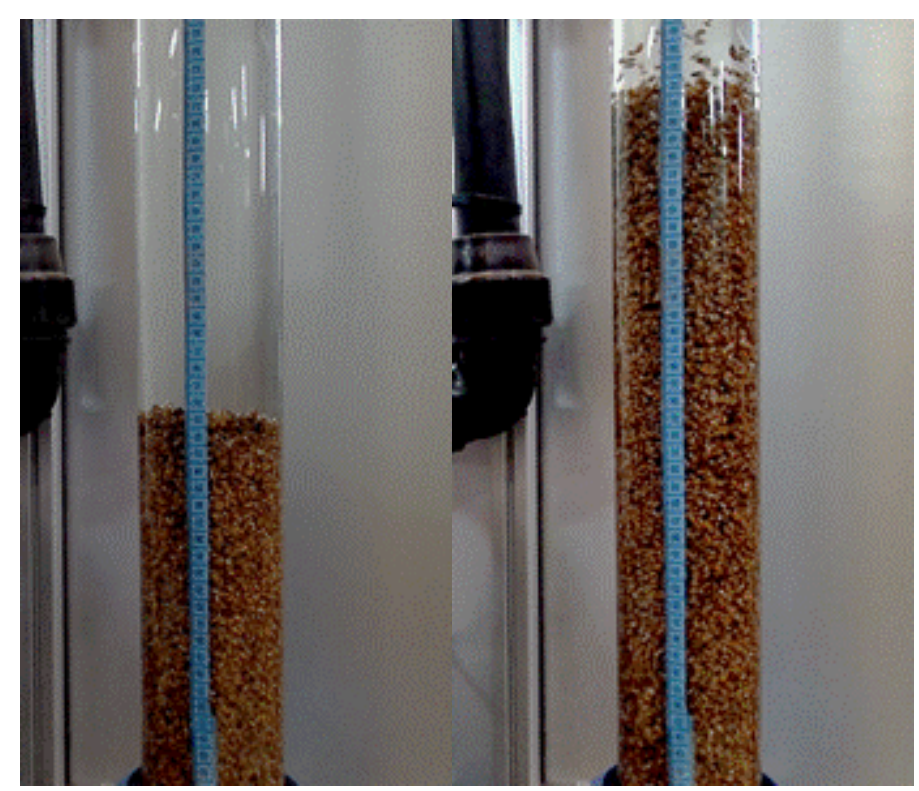

Fig. 35: Wheat grain fluidization. Test start on the left and the grains are fluidized on the right.

\section{d.2.4 Straw}

Two experiments were conducted with the straw. In the first one the straw was cut to around 3.5 cm length (Fig. 36) and in the second it was cut to $0.75 \mathrm{~cm}$ length (Fig. 37). In both of the experiments the straw was floating before the water started flowing. In both of them, increasing the velocity resulted in increasing the packing of the bed of straw at the top of the pipe. In the first experiment the maximum pressure drop was 14.8 mbar for a water velocity of about $0.1 \mathrm{~m} / \mathrm{s}$. In the second fluidization the pressure drop was much higher for a lower velocity, around 121 mbar for a water velocity of $0.065 \mathrm{~m} / \mathrm{s}$. 


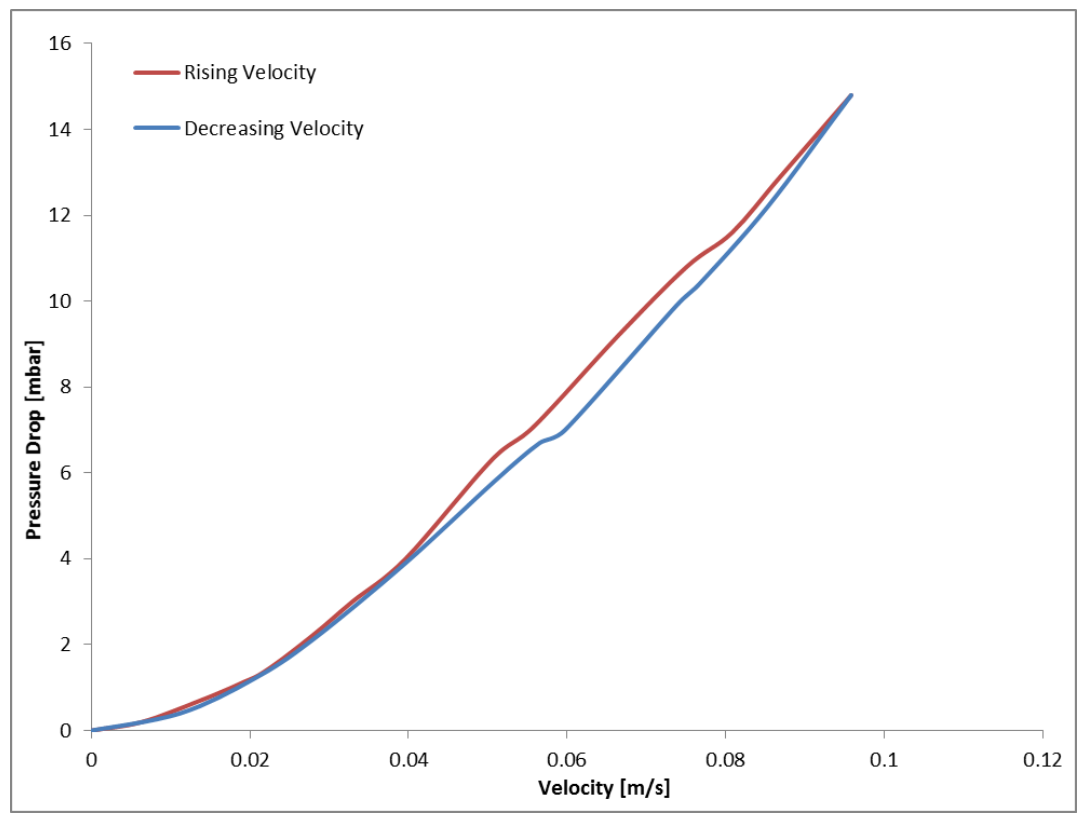

Fig. 36: Wheat straw $3.5 \mathrm{~cm}$ length fluidization curve.

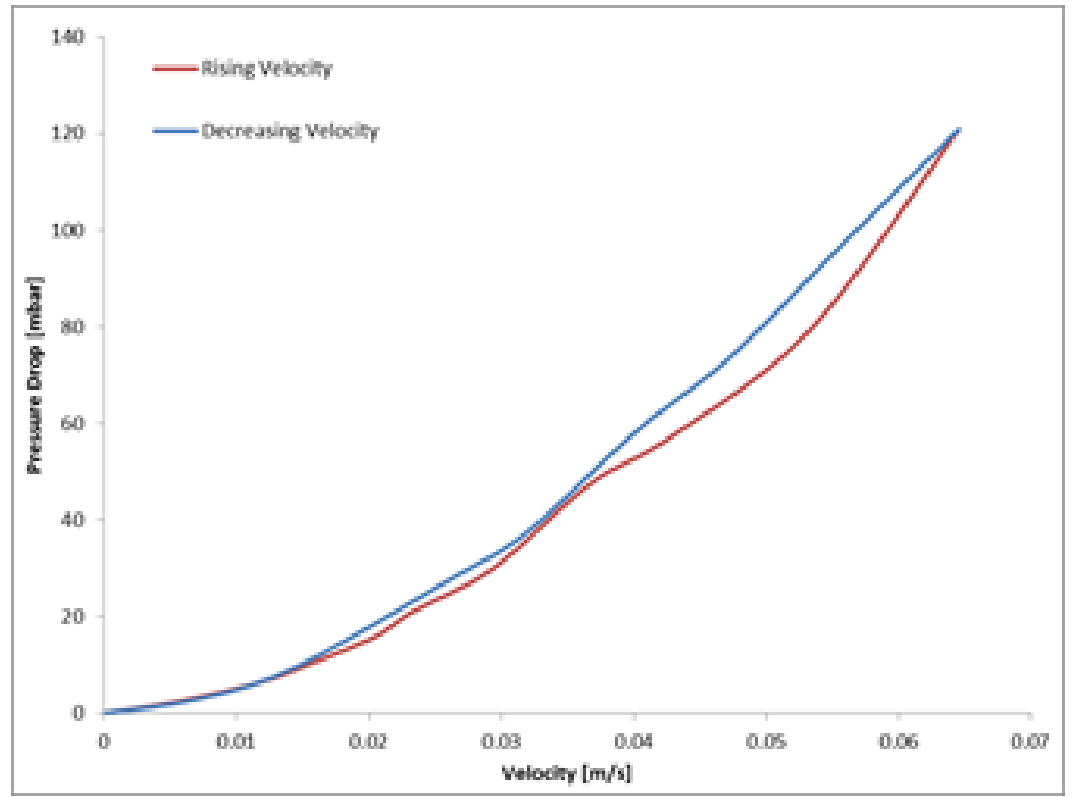

Fig. 37: Wheat straw $0.75 \mathrm{~cm}$ length fluidization curve. 


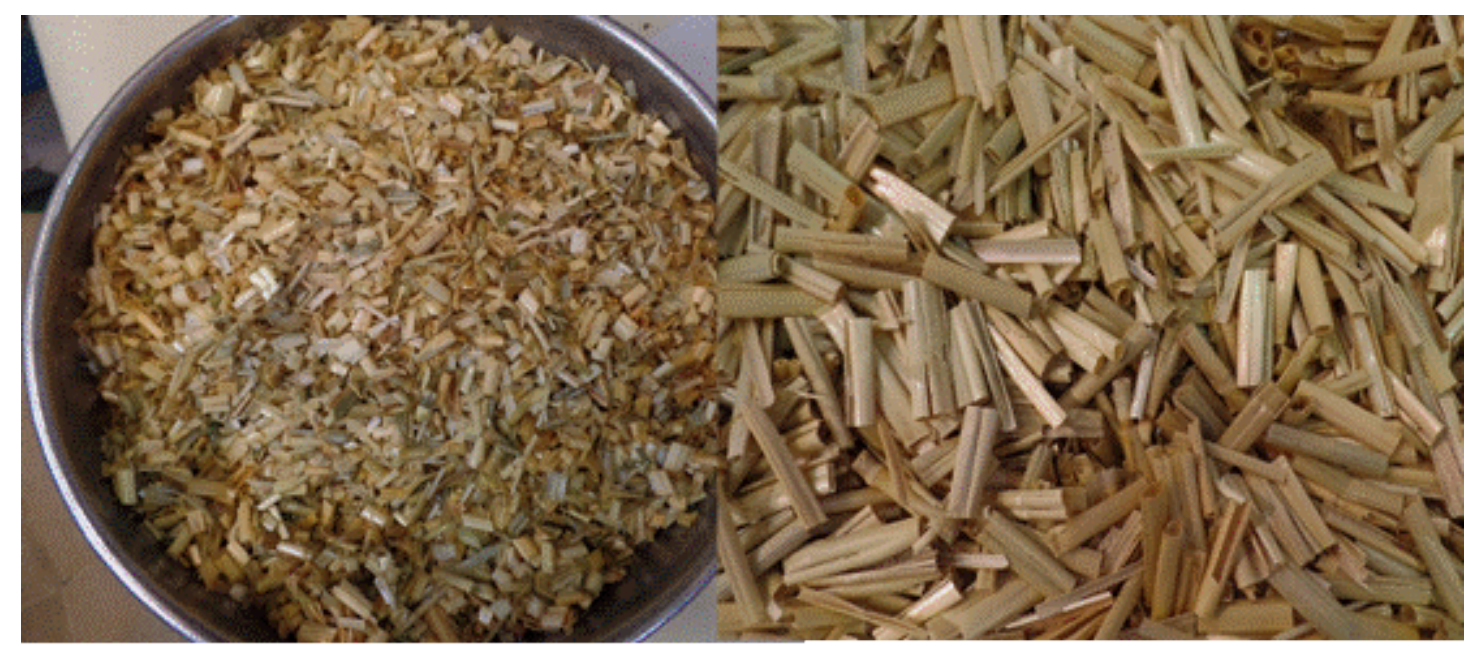

Fig. 38: The two sizes of the straw, on the left $0.5-1 \mathrm{~mm}$ and on the right $3.5 \mathrm{~cm}$.

\section{e. Transport Measurements of Biomass}

This part is aimed to test some of the materials in pneumatic and hydraulic conveying. Following are results presented as the pressure gradient before and after a bend as well as phase diagrams.

\section{e.1 Pneumatic Conveying}

\section{e.1.1 Experimental test rig}

Tests have been conducted to evaluate acceleration pressure drop in an experimental setup, which was on 54.8-meter long and $52.5 \mathrm{~mm}$ ID galvanized steel conveying pipeline. Figure 39 shows the test rig feeding and separation system. Feeding system incorporates with a screw feeder mounted on the bottom of a hopper along with motor and variable mechanical transmission to avoid electrical interference typical of variable-frequency drives. Complete feeding system along with pipeline has grounded to eliminate the possible effect of electrostatic forces of particles during its conveying. In the mixing chamber, a venturi tube was mounted followed by an air pressure regulator. Upon returning from the conveying pipeline, a bag house separator was installed at the end of the pipeline to achieve the separation of the particles from the air. To improve the efficiency of the separator a back fan was installed. Distributor, connected at the bottom of the separator allowed the open or closed loop experiments. Weighing bin connected with pneumatic valve was mounted on a load cell used for on-line measurement of the particle mass flow rate. 
Pipeline layout is presented in Fig. 40. It contains four elbows $(R / D=2)$, two long radius bends $(\mathrm{R} / \mathrm{D}=14)$, one Blind-T $(1 / \mathrm{D}=1)$, five horizontals and two vertical sections. Horizontality and coaxiality of conveying pipeline was verified by using self -levelling pendulum rotating laser. There are four pressure transducers before the Blind-T, or other bend, (P-A, B, C, D) and nine transducers after the bend (P-1, 2-----9) are installed.

The compressed air supply is passed through dehumidifier that is controlled by regulator and valves. A hot wire flow sensor is mounted before the feeder being used to measure air volumetric flow rate. Inlet air temperature and humidity are also monitored. Gas is found to be nearly isothermal along the pipeline; hence, inlet temperature was used all over the pipe length. Throughout the experiments with all materials, temperature has found to be vary from $12-15^{\circ} \mathrm{C}$. Relative humidity of air all over the experiment is between $10-20 \%$.

Three different kinds of pressure readings were obtained. Barometric pressure from a nearby governmental meteorological station was obtained online. Pressure drop along the pipe was measured by using high accuracy flush diaphragm and absolute differential pressure transducers. Those are mounted on riders as per instructions of user manual to ensure accuracy of readings and of the pressure values and for avoiding additional problems common to pressure tapping in pneumatic conveying (Fig. 41). Connection of pressure transducer on main conveying pipeline has been shown in Fig. 41.

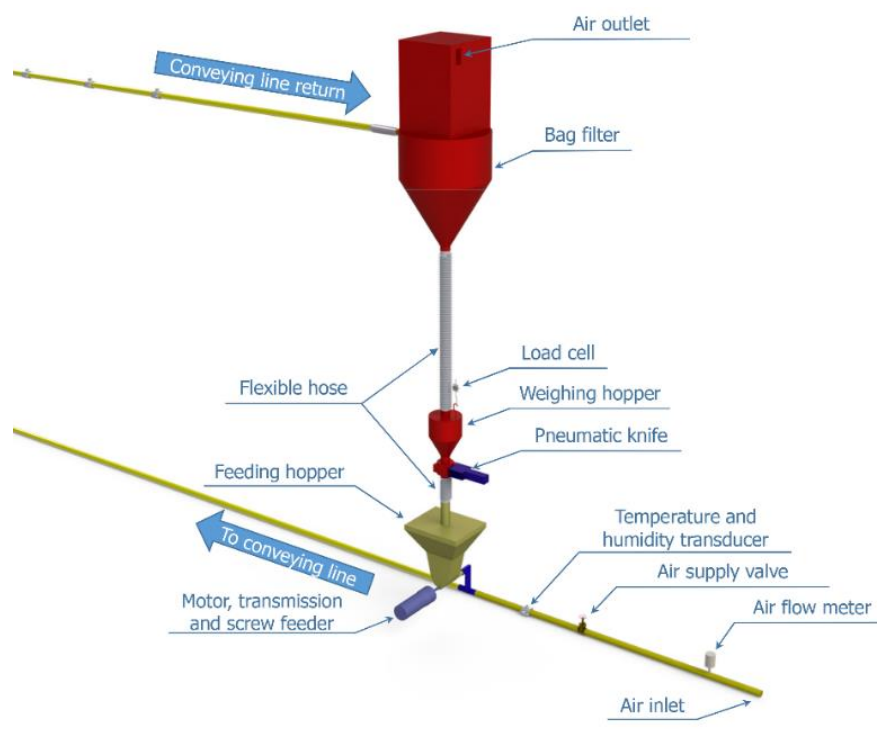

Fig. 39: Feeding and separation apparatus. 


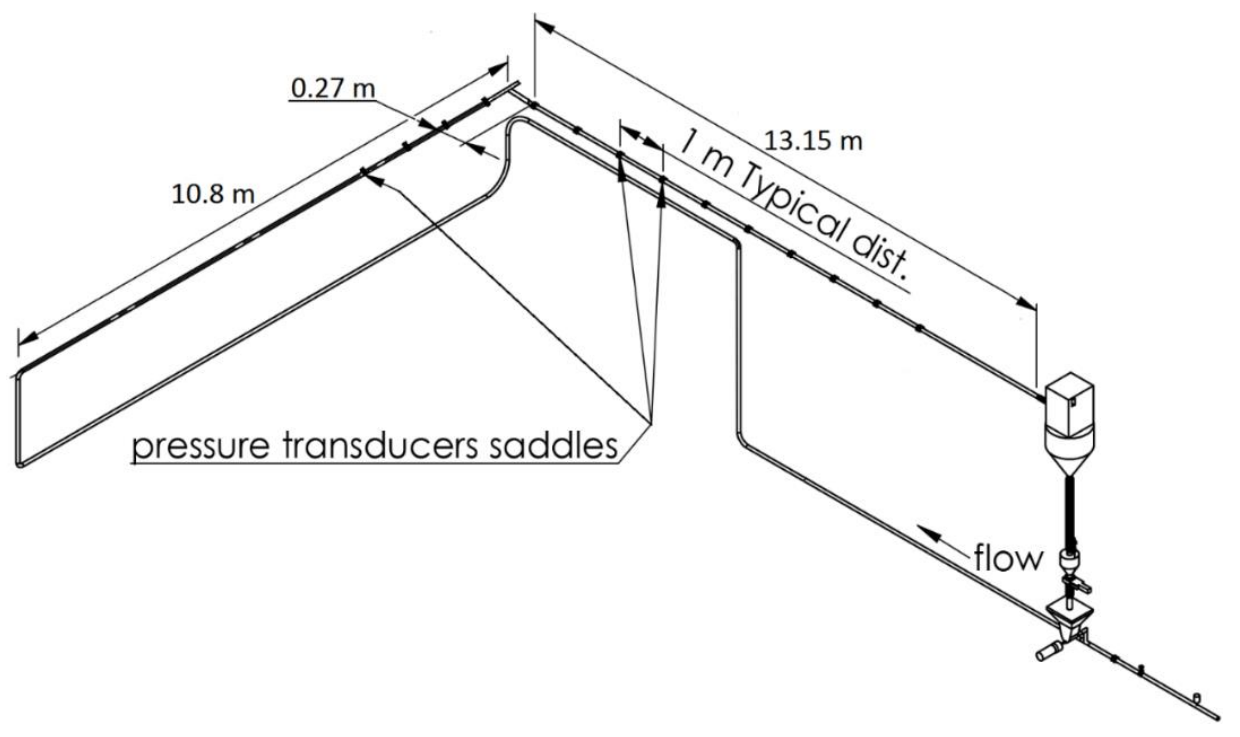

Fig. 40: Layout of the $52.5 \mathrm{~mm}$ ID x $54.8 \mathrm{~m}$ length conveying geometry.

Absolute transducers (Brand: BD-Sensors) have range of (0-100) mbar and accuracy level $\pm 0.1 \%$, whereas differential transducers (Brand: SMAR) have range of (0-50) mbar and accuracy level $\pm 0.075 \%$, Differential transducers were used to find the pressure drop of specific section of pipe in acceleration and steady state zone as well. Local superficial air velocity was calculated using the absolute local pressure. Nevertheless, gas expansion along the pipe might be substantial and deviation of gas density from standard value due to local barometric pressure and ambient temperature cannot be neglected. Hence, density was measured for complete operating range of pressure along the pipeline by using local condition of pressure, temperature and humidity. For an operating range of 500-6000 Pa, variation in air density was $1.13-1.19$. It was found that change of density is not substantial for complete operating range along the pipeline.

For each measured data, steady state condition was achieved by taking measurements at $1 \mathrm{kHz}$. Lowest operating speed of the feeder was for a period of two seconds. In order to avoid any periodical effects caused by the feeder and to minimize attrition due to persisted measurement time reading of all instruments are four seconds for each operating point. A software LabVIEW processed all the data received from the pressure transducers and other sensors.

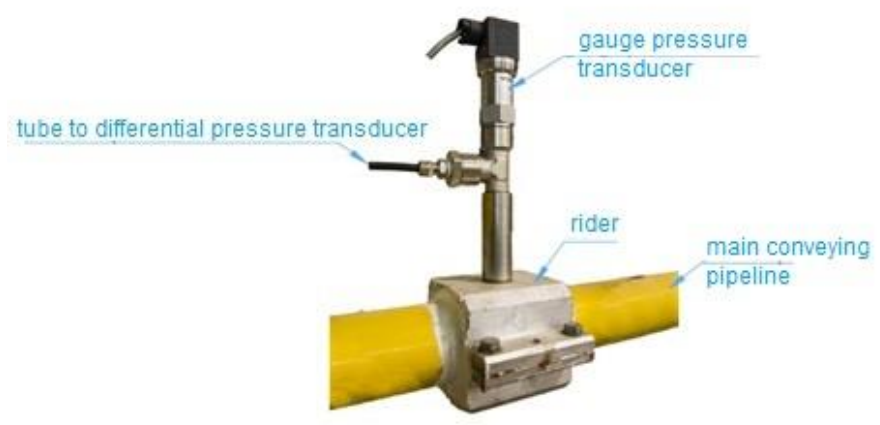

Fig. 41: Arrangement of pressure transducer on main conveying pipeline. 


\section{e.1.2 Semolina}

The Semolina tests were conducted in the full length of the pipeline, namely, $54.8 \mathrm{~m}$. Figures $42-$ 44 present the pressure measurements before and after a blinded-T. These measurements show the steady state condition before the bend and far after the bend. These plots also enable to define the acceleration length as well as the additional pressure drop due to acceleration after the bend and the bend pressure drop. Figure 45 presents a classical phase diagram at the dilute state only.

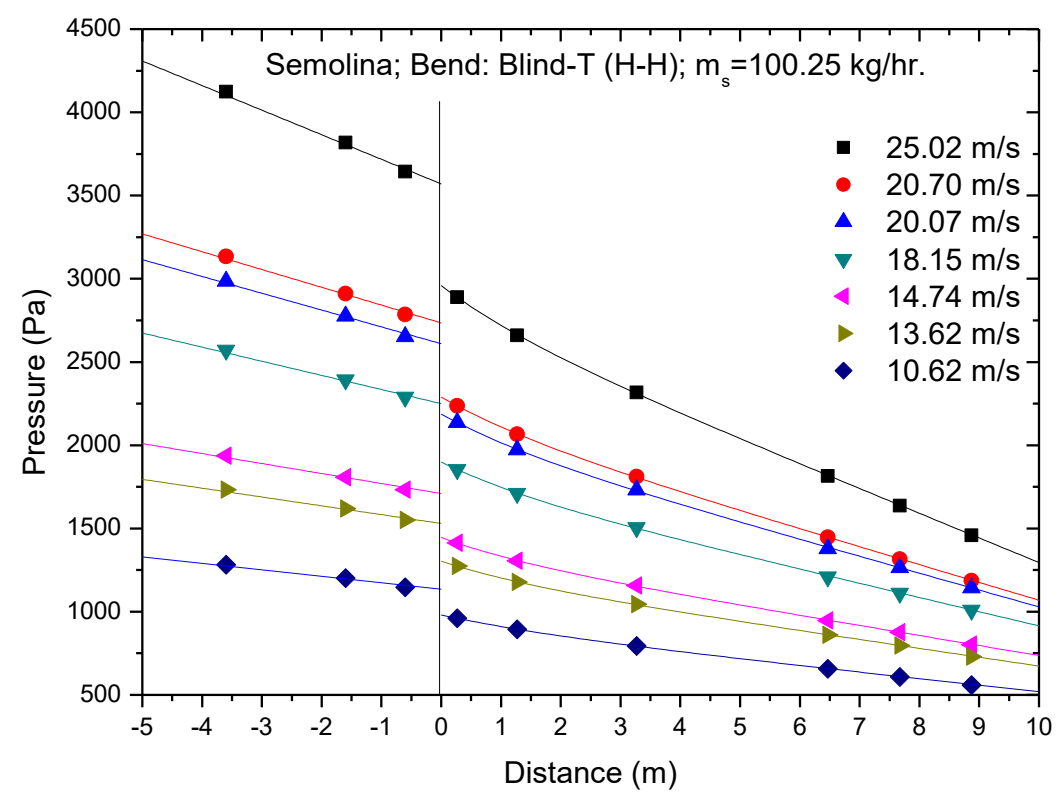

Fig. 42: Pressure measurements at about $100 \mathrm{~kg} / \mathrm{hr}$ of semolina mass flow rate and various superficial air velocities.

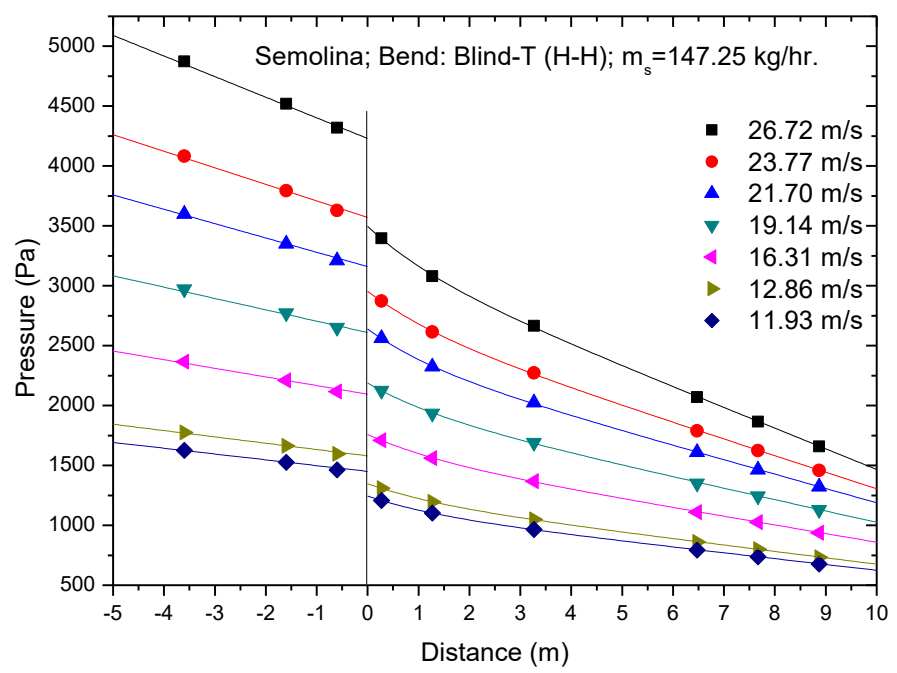

Fig. 43: Pressure measurements at about $150 \mathrm{~kg} / \mathrm{hr}$ of semolina mass flow rate and various superficial air velocities. 


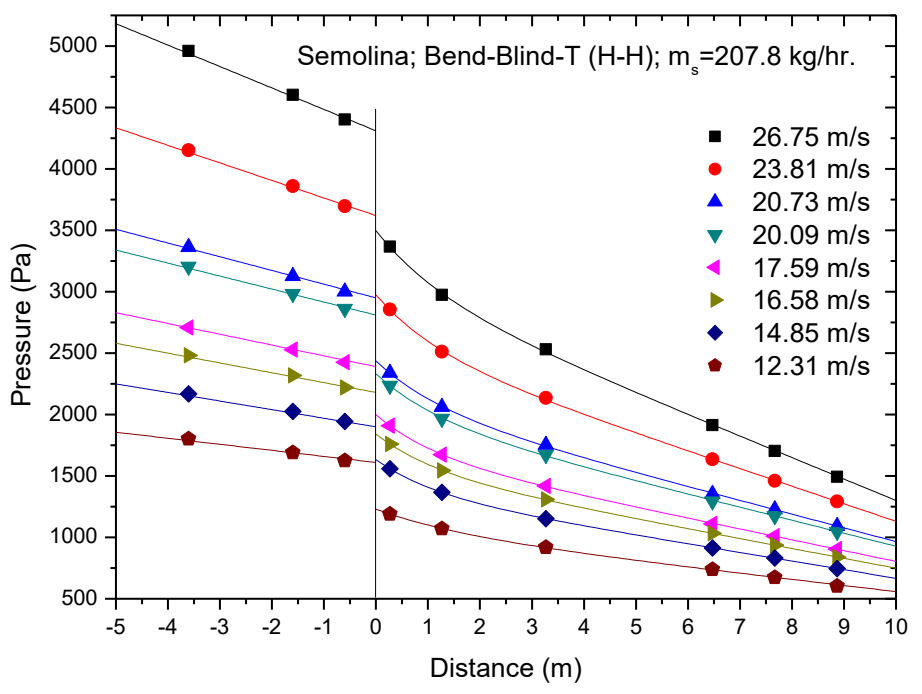

Fig. 44: Pressure measurements at about $200 \mathrm{~kg} / \mathrm{hr}$ of semolina mass flow rate and various superficial air velocities.

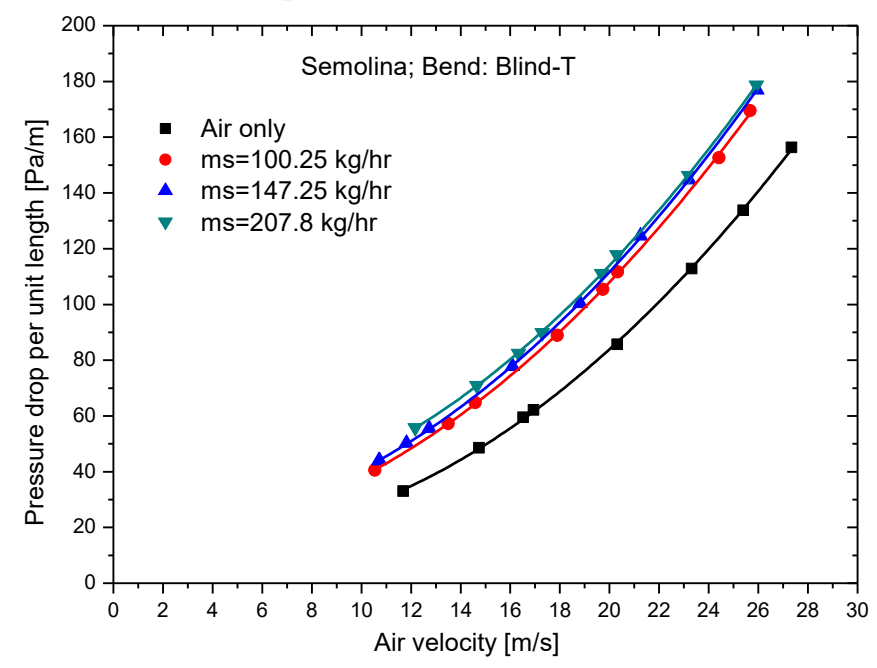

Fig. 45: Phase diagram of semolina in pneumatic conveying.

\section{e.1.3 Wheat Grains}

The wheat grain tests were conducted in the full length of the pipeline, namely, $54.8 \mathrm{~m}$. Figures 46-48 present the pressure measurements before and after a blinded-T. These measurements show the steady state condition before the bend and far after the bend. These plots also enable to define the acceleration length as well as the additional pressure drop due to acceleration after the bend and the bend pressure drop. Figure 49 presents a classical phase diagram at the dilute state only. 


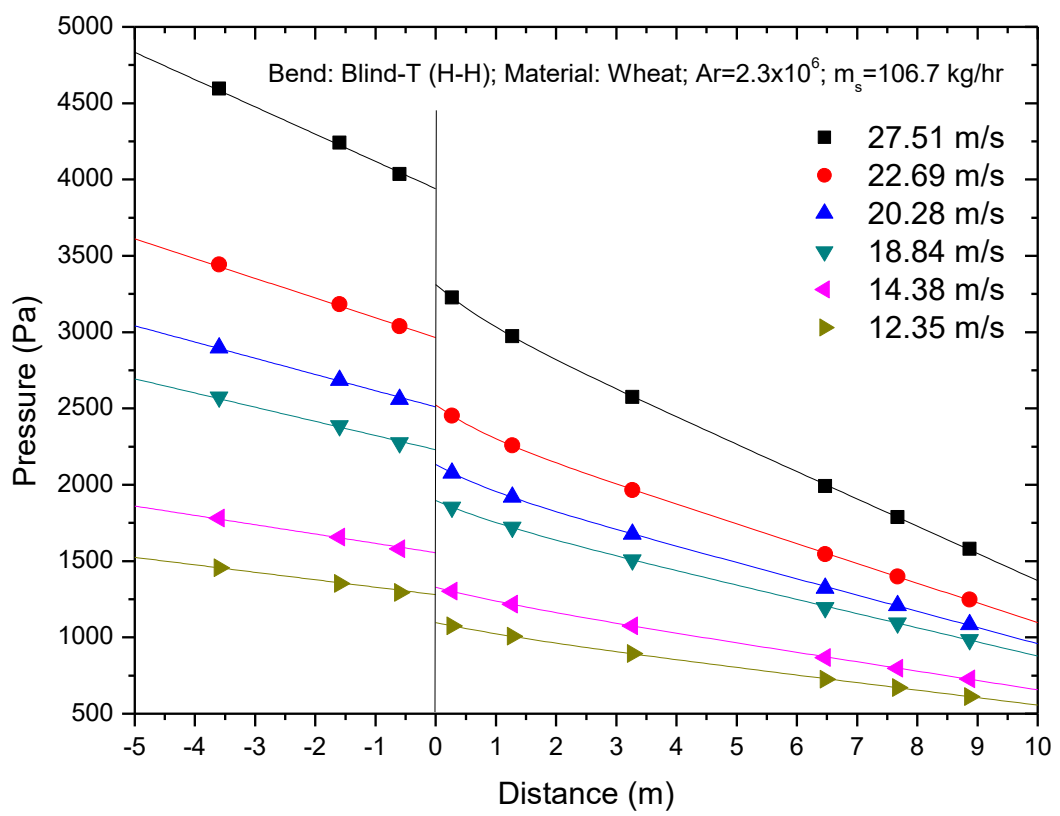

Fig. 46: Pressure measurements at about $100 \mathrm{~kg} / \mathrm{hr}$ of wheat grains mass flow rate and various superficial air velocities.

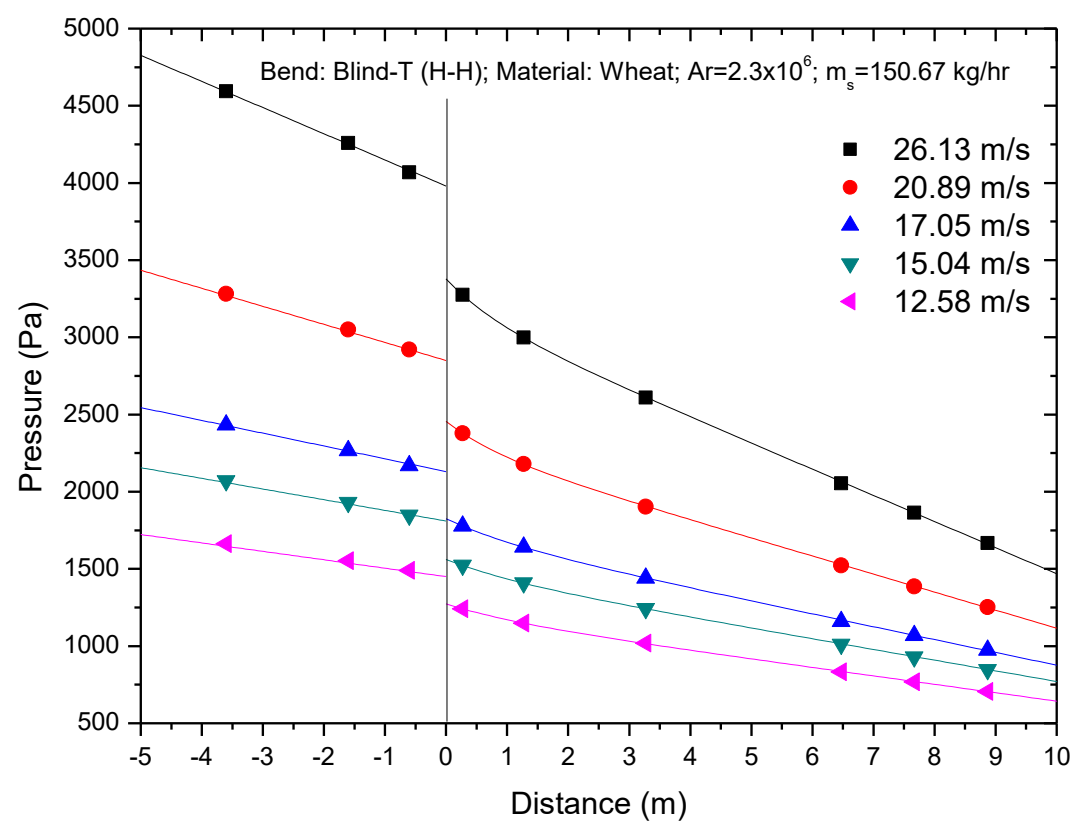

Fig. 47: Pressure measurements at about $150 \mathrm{~kg} / \mathrm{hr}$ of wheat grains mass flow rate and various superficial air velocities. 


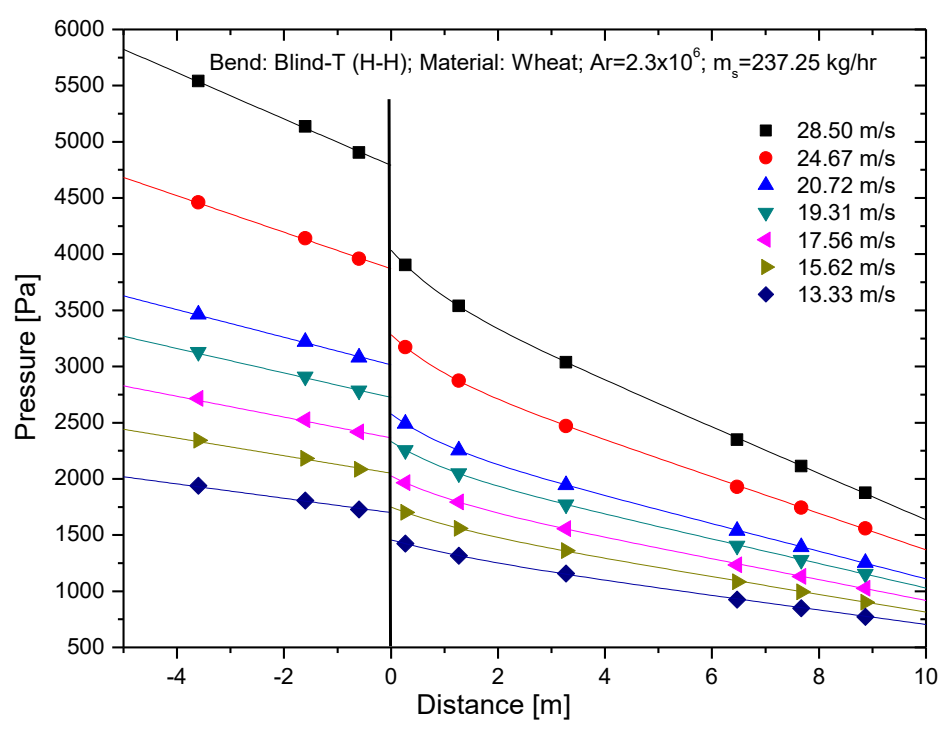

Fig. 48: Pressure measurements at about $250 \mathrm{~kg} / \mathrm{hr}$ of wheat grains mass flow rate and various superficial air velocities.

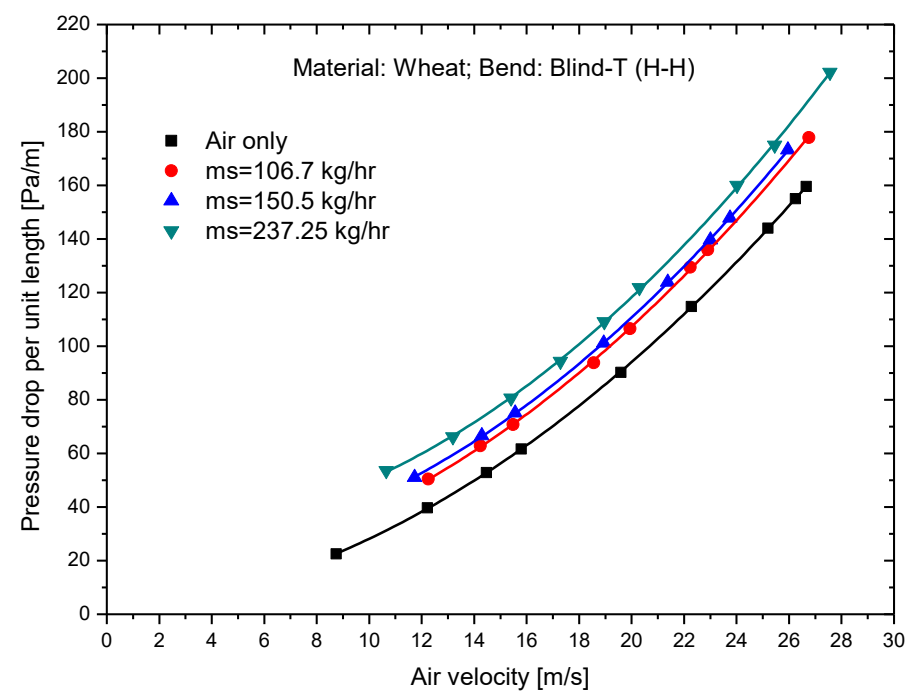

Fig. 49: Phase diagram of wheat grains in pneumatic conveying.

\section{e.1.4 Olive Pulp}

The olive pulp tests were conducted in the short version of the pipeline, namely, $21 \mathrm{~m}$. Figures 5052 present the pressure measurements before and after an elbow $(\mathrm{R} / \mathrm{D}=1.5)$. These measurements show the steady state condition before the bend and far after the bend. These plots also enable to define the acceleration length as well as the additional pressure drop due to acceleration after the bend and the bend pressure drop. Figure 53 presents a classical phase diagram at the dilute state only. 


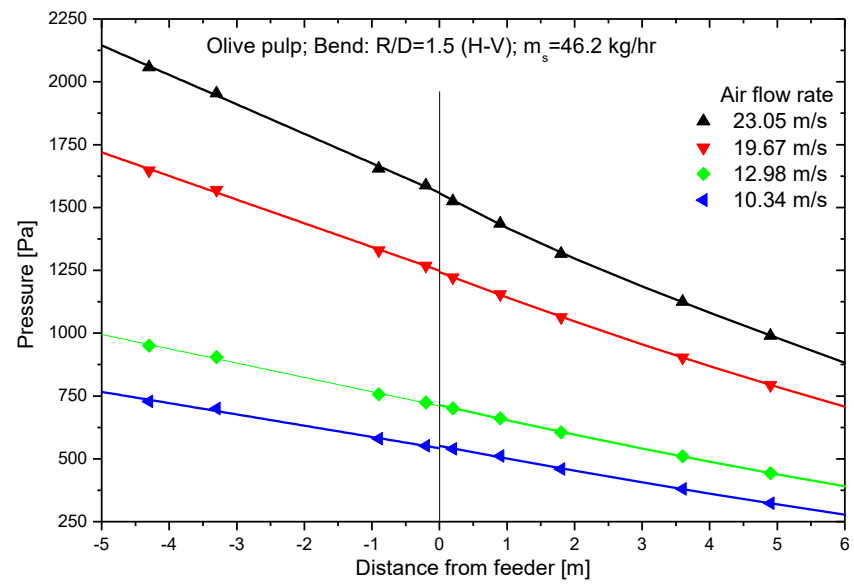

Fig. 50: Pressure measurements at about $50 \mathrm{~kg} / \mathrm{hr}$ of olive pulp mass flow rate and various superficial air velocities.

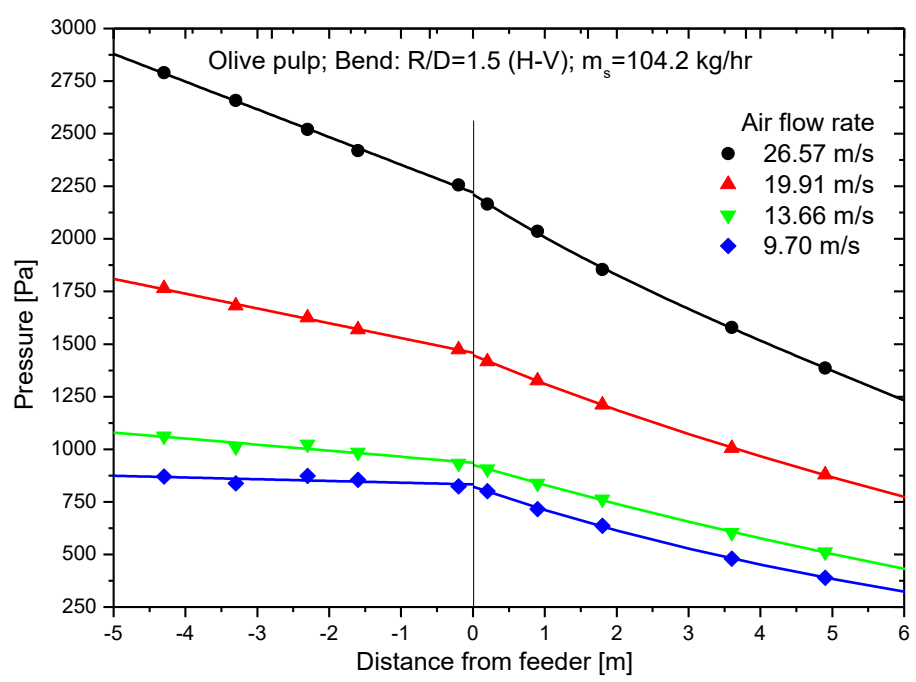

Fig. 51: Pressure measurements at about $100 \mathrm{~kg} / \mathrm{hr}$ of olive pulp mass flow rate and various superficial air velocities. 


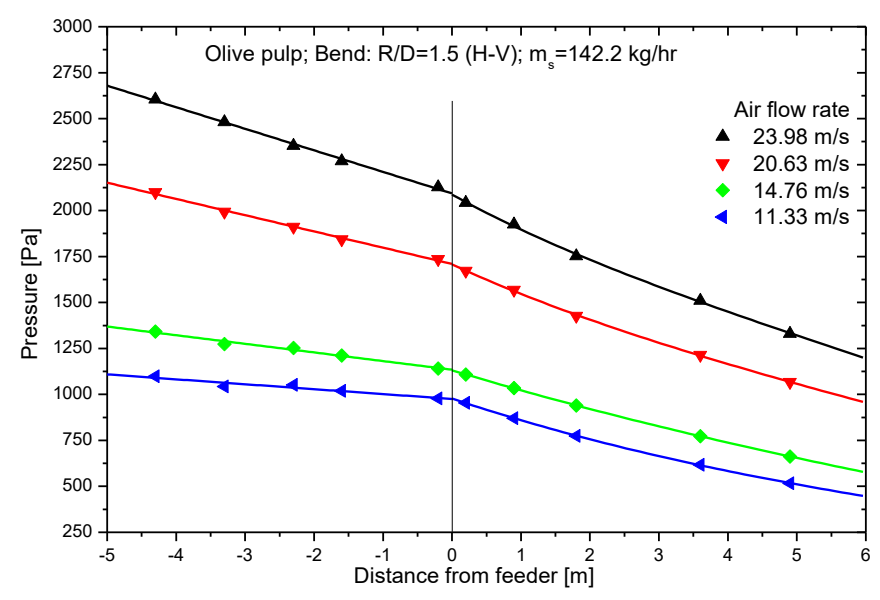

Fig. 52: Pressure measurements at about $150 \mathrm{~kg} / \mathrm{hr}$ of olive pulp mass flow rate and various superficial air velocities.

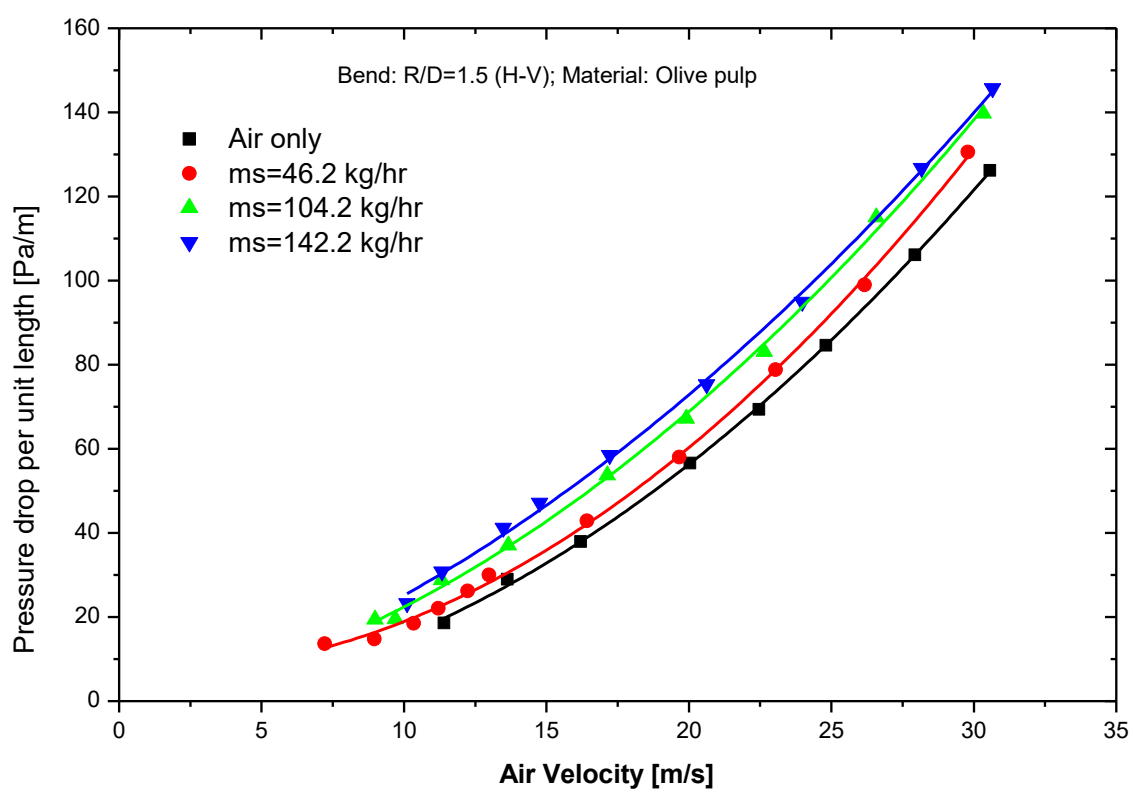

Fig. 53: Phase diagram of olive pulp in pneumatic conveying.

\section{e.1.5 Dry Orange Peels}

The dry orange peels tests were conducted in the full length of the pipeline, namely, $54.8 \mathrm{~m}$. Figures 54-55 present the pressure measurements before and after a bend $(R / D=10)$. These measurements show the steady state condition before the bend and far after the bend. These plots also enable to define the acceleration length as well as the additional pressure drop due to acceleration after the bend and the bend pressure drop. Figure 56 presents a classical phase diagram at the dilute state only. 


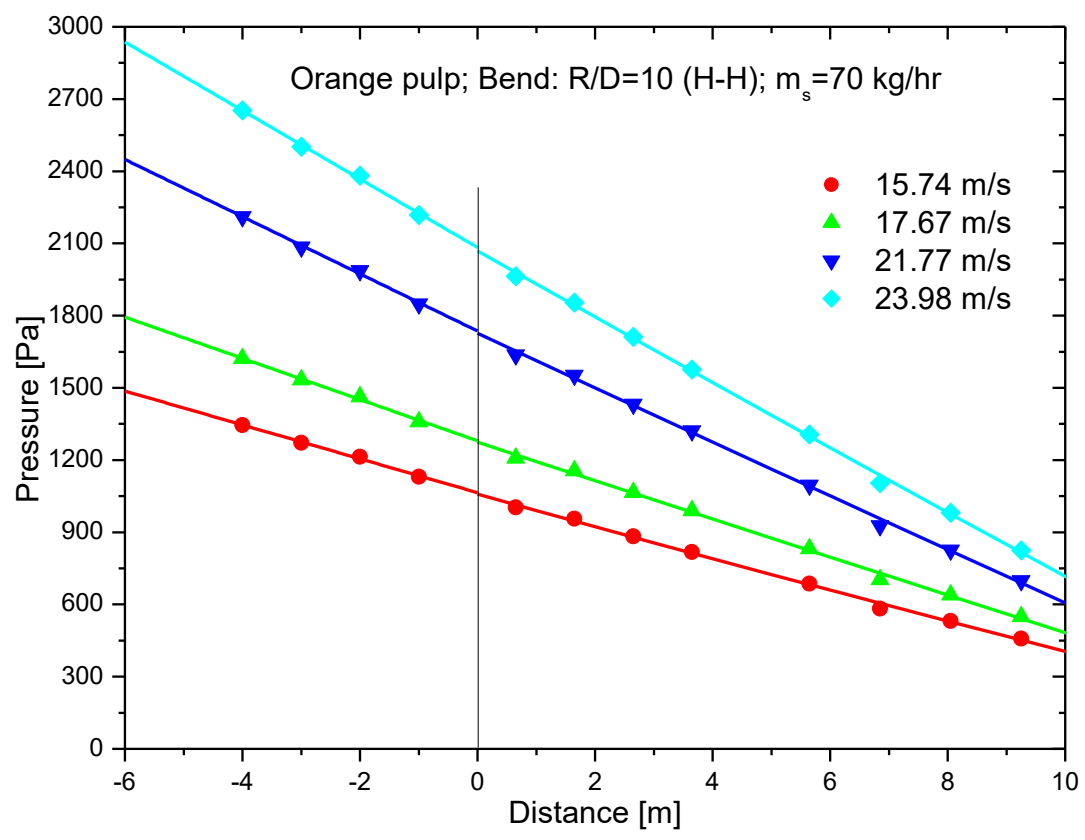

Fig. 54: Pressure measurements at about $70 \mathrm{~kg} / \mathrm{hr}$ of dry orange peels mass flow rate and various superficial air velocities.

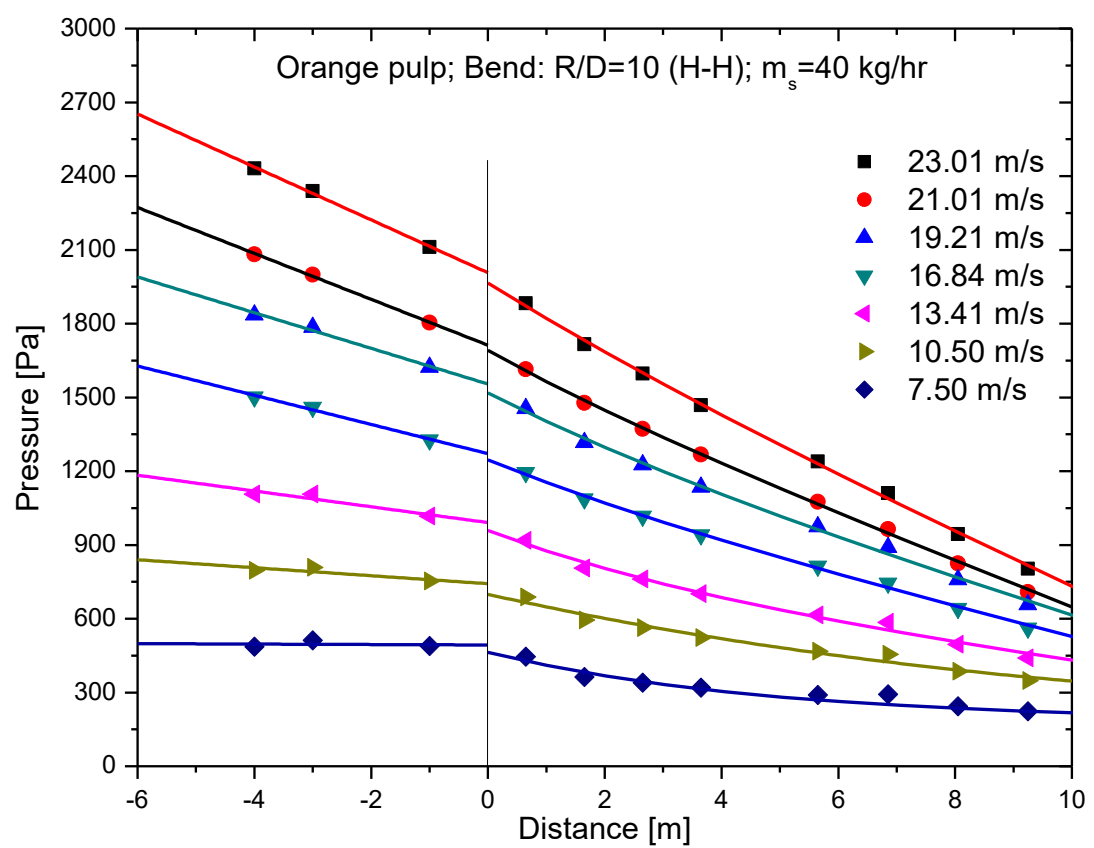

Fig. 55: Pressure measurements at about $40 \mathrm{~kg} / \mathrm{hr}$ of dry orange peels mass flow rate and various superficial air velocities. 


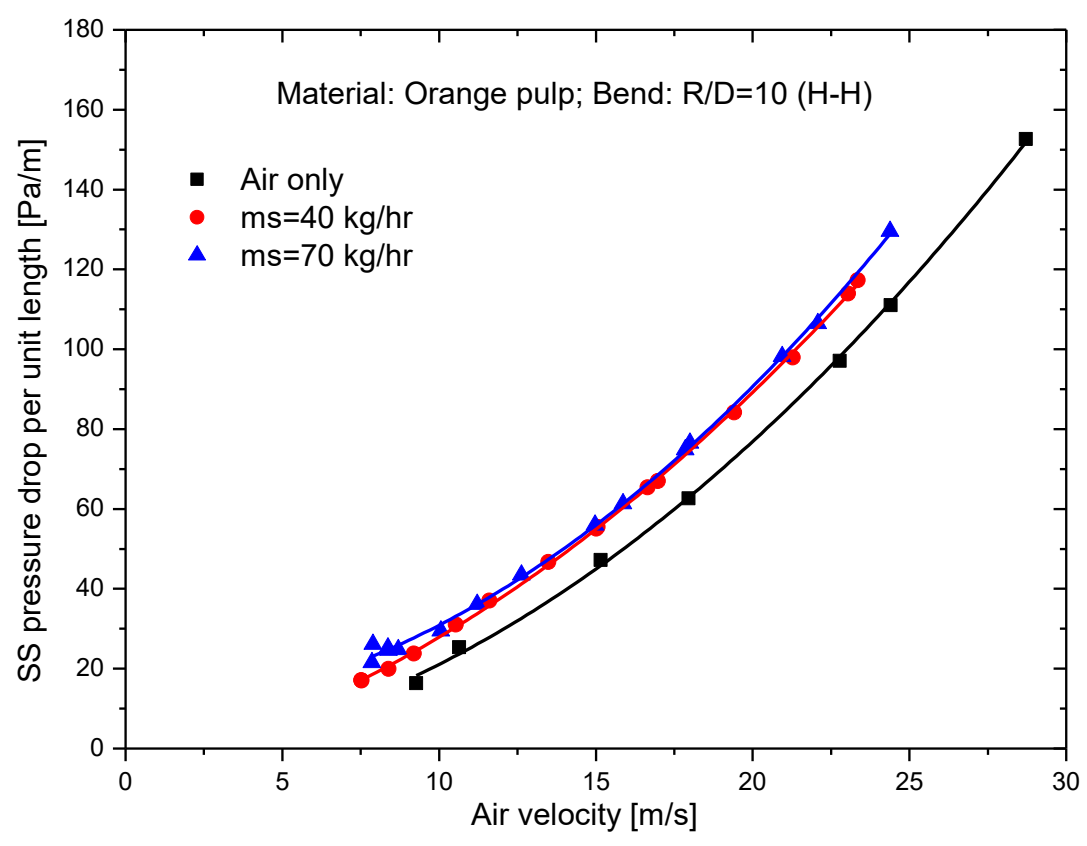

Fig. 56: Phase diagram of dry orange peels in pneumatic conveying.

\section{e.2 Hydraulic Conveying}

The hydraulic conveying apparatus will not described here in details since it was not published yet and it was developed in the frame of another grant. However, it has also a 2" pipe and the particles are fed to the water pipeline through a rotary valve. The only experiments we conducted with bio materials was the wheat grains and the phase diagram is presented in Fig. 57. 


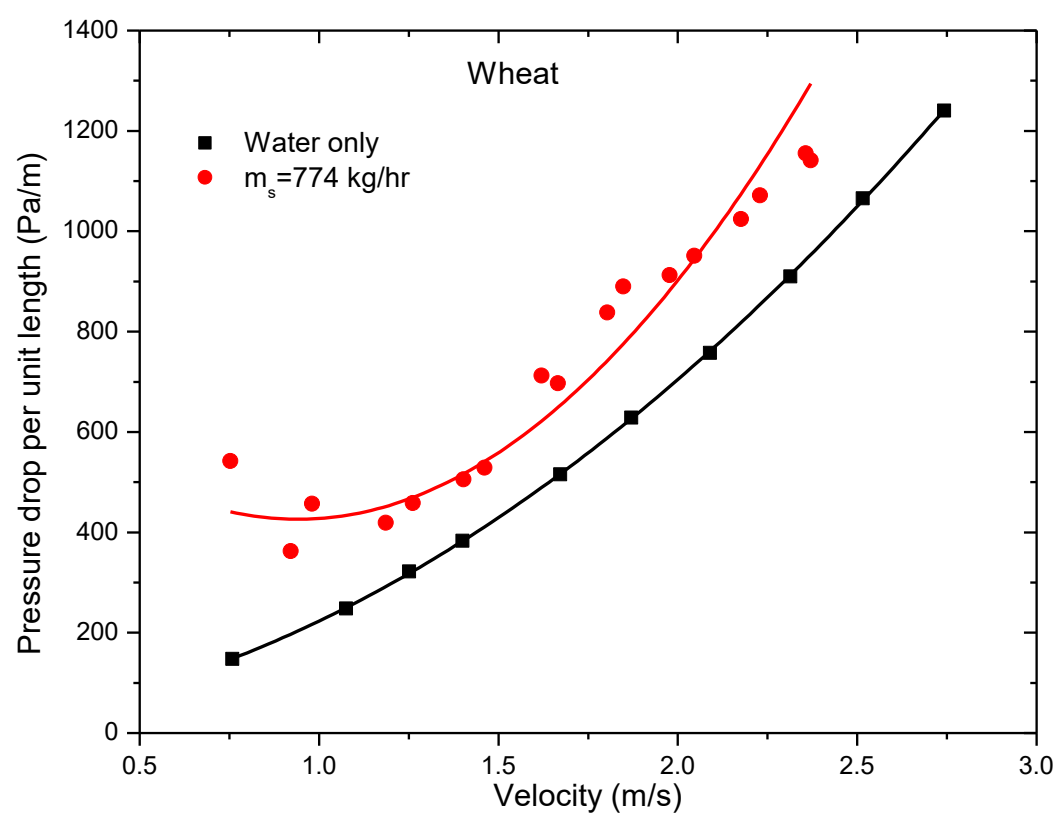

Fig. 57: Phase diagram of wheat grains in hydraulic conveying.

\section{Task 3: Modeling Multiphase Flow in the Digester}

Successful computational fluid dynamics (CFD) simulation of multiphase flow in the digester is dependent on the accuracy of constitutive models which describe (1) the particle phase stress due to particle interactions, (2) the particle phase dissipation due to inelastic interactions between particles and (3) the drag force between the fibres and the digester fluid. Particle phase stress models have already been developed (before the start of this project) for fibrous particles using the discrete element method (DEM).

In order to simulate multiphase flow in the digester, the granular energy balance for the solid phase needs to be modified to correct for the fibrous nature of the particles. The state-of-the art equations for the granular phase in commercial CFD codes (e.g. Fluent, ANSYS) and open-source CFD codes (e.g. DOE-MFIX) assume spherical particles. The granular energy balance is given as:

$$
\frac{3}{2}\left[\frac{d}{d t}\left(\alpha_{s} \rho_{s} \theta\right)+\frac{d}{d x_{j}}\left(\alpha_{s} \rho_{s} u_{s, j} \theta\right)\right]=\frac{d}{d x_{j}}\left(\kappa_{s} \frac{d \theta}{d x_{j}}\right)+\tau_{s_{i j}} \frac{d u_{s, i}}{d x_{j}}-\Gamma_{s}
$$

in which, $t$ is the time, $x$ defines the coordinate system to describe the location within a domain, $u_{s}$ is the solid velocity, $\alpha_{s}$ is the solid volume fraction, $\rho_{s}$ is the solid density, $\theta$ is the granular 
temperature, $\kappa_{S}$ is the granular conductivity, $\tau_{s}$ is the solid stress tensor, and $\Gamma_{S}$ is the collisional dissipation rate. New constitutive models for $\kappa_{S}, \tau_{s}$, and $\Gamma_{S}$ should be implemented in order to close the governing equations of the fibrous particle phase. Granular conductivity, $\kappa_{s}$, is insignificant for moderately dense flows and can be neglected in a digester. However, new constitutive models for the fibre stress tensor, $\tau_{s}$, and the fibre collisional dissipation rate, $\Gamma_{s}$, need to be developed in order to simulate multiphase flow in the digester.

DEM simulations of Homogeneous Cooling Systems (HCS) were used to develop a particle phase dissipation rate model for non-spherical particle systems that can be incorporated in a two-fluid CFD multiphase flow model framework. Two types of frictionless, elongated particle models were compared in the HCS simulations: glued-sphere and true cylinder. Simulation results show that the ratio of translational to rotational granular temperatures is equal to one for the true cylindrical particles with particle aspect ratios (AR) greater than one and glued-sphere particles with AR > 1.5, while the temperature ratio is less than one for glued-sphere particles with $1<\mathrm{AR}<1.5$. The total collisional dissipation rate, which is associated with both translational and rotational granular temperature change rates, increases linearly with the particle aspect ratio. Based on these DEM simulations, a dissipation rate model for elongated fibres has now been developed by a simple modification of the existing spherical particle dissipation model. This new model is valid for a wide range of fibre friction, fibre coefficient of restitution, fibre volume faction, and fibre aspect ratio.

In regards to drag forces, previous published simulations of non-spherical particles by others have applied spherical drag models to non-spherical particles or have used ad-hoc methods to account for particle shape. In order to validate the accuracy of these previous approaches for describing the drag force for non-spherical particles, single-phase computational fluid dynamics (CFD) simulations of fluid flow over random arrays of ellipsoids were used to directly calculate the fluidparticle drag forces. Based on these CFD simulation "measurements", the previously-applied approaches to describe non-spherical drag were found to be lacking. A new model for drag for elongated fibres was developed which depends on Reynolds number, solids fraction, and fibre aspect ratio. These new models for the particle phase stress, particle dissipation, and drag force was incorporated in the DOE's MFIX code so that large scale simulations can be conducted. 
In Task 1, new models for the fibre (solid) shear stress were developed via DEM simulations, and these new models are now implemented into the DOE-MFIX open-source CFD code to describe multiphase flow of a fibrous system of particles in a digester.

The simulation results show that surface roughness plays a significant role in the fibre collisional dissipation rate. The fibre kinetic energy within the rotational degrees of freedom is shown to be on the order of the energy in the translational degrees of freedom which greatly simplified the development of the new collisional dissipation rate model. This and the presence of a linear relationship between the collisional dissipation rate and the fibre aspect ratio allowed a simple modification to the existing collisional dissipation rate model for spheres. This new model involves a decoupling of the effect of the coefficient of restitution and the coefficient of friction. The fibre collisional dissipation rate model has also been incorporated into the open-source CFD code DOE-MFIX in order to describe the multiphase flow of particles in a digester.

\section{Task 4: Anaerobic Digestion Experiments}

For the purposes of evaluating anaerobic digestion of organic materials tested in above Tasks, two anaerobic digesters were assembled. These digesters allow ease of access for adding and arranging biomass manually within the vessel. The digester was made from a 20 liter Pyrex glass bottle. The bottle was thermally cut at its base and a flanged lip was curled, resulting in an inverted carboy bottle with a complete cross-sectional opening at the top. The neck of the bottle was adjusted by thermally fusing a glass flange to increase overall length. A 316 stainless steel lid was mounted on the curled flanged lip and held by twelve wing-nut bolts and a silicon gasket. This provided sufficient sealing for near ambient pressures that would be experienced in the digester. A custom-build glass Duran O-ring flange bottom was machined to fit the carboyneck flange, and was secured by a stainless steel, quick-release clamp. The digester was mounted on a stand. The vessel and its contents were heated by two flexible electric heating tapes (Thermolyne, BriskHeat $\odot$,Waltham Massachussetts) and insulated by fiber glass insulation. The temperature was monitored by a T-type thermocouple (Omega, Stamford, Connecticut) probe. The $\mathrm{pH}$ of leachate was monitored continuously using an on-line $\mathrm{pH}$ probe (Campbell Scientific $@$ CSIM 11, Logan, Utah) mounted in an external flowcell within the leachate re- 
circulation line. The temperature, $\mathrm{pH}$ and gas production were recorded by a data logger/control module (CR10X, Campbell Scientific, Inc, Logan, Utah) and later transferred to a PC. The control module also controlled the temperature of the digester contents at a pre-determined setpoint by turning on/off the heating tapes. Figure 58 shows a schematic diagram of the digester setup. Gas production from the digesters was measured using a positive displacement gas meter. Gas production from the digesters was measured using a positive displacement gas meter. This device consisted of a clear PVC U-tube filled with anti-freeze solution, solid state time delay relay (Dayton OFF Delay Model 6X153E), a float switch (Grainger), a counter (Redington Inc.) and a solenoid valve (Fabco Air). The U-tube gas meter was calibrated in-line to determine volume of biogas per count. A count was considered as that amount of gas read on syringe (in milliliters) for which the gas meter completes one whole number count (e.g. one count $=0.045 \mathrm{~L}$, then two counts $=0.09 \mathrm{~L}$ and continued on). The gas composition was initially measured offline in a gas chromatograph (GC) equipped with a thermal conductivity detector. Later a low-cost device was constructed for off-line and on-line measurements. Details of these devices are provided later. At various stages of digestion the vessel can be opened to remove biomass samples. The bulk densities of the packed biomass could be varied.

Biogasification experiments were carried out using orange peels and olive pulp. Orange peels were supplied by Duda Products Inc, from their Belle Glade Florida, citrus processing plant in 5 gallon buckets. Aliquots of $0.45 \mathrm{~kg}$ (wet weight as received) of peel waste were taken in Ziploc airtight plastic bags and stored in deep freezer at $-30^{\circ} \mathrm{C}$. Olive processing is a fledgling industry in Florida. Arbequina olives grown, harvested and processed in Citra, Florida. Olive pulp was collected in 5 gallon buckets from olive mill. As with peel waste, aliquots were stored in Ziploc plastic bags at $-30{ }^{\circ} \mathrm{C}$.

The dry matter content of the peel waste as received was $19 \%$, and $97 \%$ of the dry matter was volatile. Initially peel waste was directly into digester at a bulk density of around $300 \mathrm{~kg} / \mathrm{m}^{3}$. Upon adding inoculum, the material compacted thereby increasing in bulk density, floated and did not decompose. The loading bulk density was adjusted by bulking the material with landscaping lava rocks. Experiments with different bulk densities were carried out. It was found that only when bulk densities were at or below $100 \mathrm{~kg} / \mathrm{m}^{3}$, balanced decomposition was initiated and the material was successfully digested. The methane yield was $0.627 \mathrm{~L} \mathrm{CH}_{4}$ at STP $\mathrm{g} \mathrm{VS}^{-1}$. 
In other experiments two days after the onset of balanced decomposition at a bulk density of 100 $\mathrm{kg} / \mathrm{m}^{3}$, the digester was opened, the lava rocks were removed and decomposing fibers were placed back in the digester bulking at a higher density of around $250 \mathrm{~kg} / \mathrm{m}^{3}$. Under these conditions, the material continued to decompose and was successfully digested. It appeared that a low bulk density was required to initiate decomposition, however once balance methanogenesis has been established, the biomass undergoes successful digestion at higher bulk densities.

Olive pulp contained $29.5 \%$ dry matter of which $93 \%$ was volatile. The density of wet olive pulp as received was $1092 \mathrm{~kg} / \mathrm{m}^{3}$ which on a dry basis was $322 \mathrm{~kg} / \mathrm{m}^{3}$. As with the peel waste, olive pulp could not be successfully digested by directly loading at bulk density of $322 \mathrm{~kg} / \mathrm{m}^{3}$. Instead the material had to be bulked to around $75 \mathrm{~kg} / \mathrm{m}^{3}$ before it could be successfully digested. The methane yield was $0.457 \mathrm{~L} \mathrm{CH}_{4}$ at STP $\mathrm{g} \mathrm{VS}^{-1}$. The lower methane yield when compared to orange peels was due to the presence of higher amount of lignin (38\% of dry matter) in olive pulp. Like with peel waste, after onset of balanced decomposition, the biomass could be bulked to around $250 \mathrm{~kg} / \mathrm{m}^{3}$ for continued digestion.

Wheat straw could not be successfully digested even at every low bulk density. This was not surprising as the carbohydrates of wheat straw are in form of highly crystalline cellulose which is not readily decomposed by anaerobic digestion microbial consortia. 


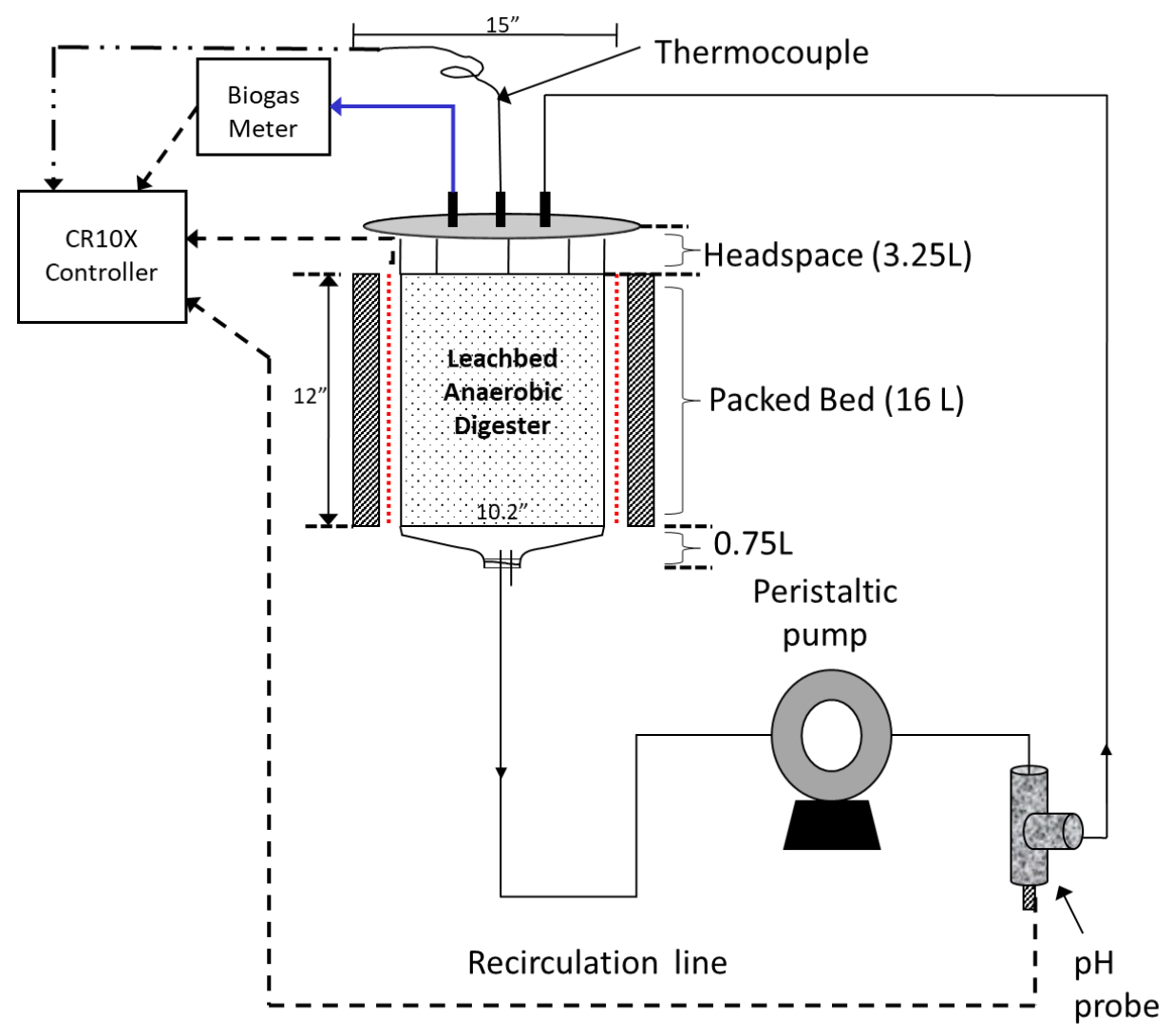

Fig 58: Schematic diagram of anaerobic digesters used for digesting biomass.

As part of this task there were two other notable outcomes related to the measurement of methane content of biogas from an anaerobic digester. An inexpensive, portable device for off-line measurement of methane content of biogas samples was constructed. The central component of the device was an MQ-4 methane sensor. This sensor, along with humidity, temperature and pressure sensors, was enclosed in an airtight glass jar and interfaced with a programmable Arduino Uno clone for data logging and operation. Figure 59 shows a schematic diagram and a photograph of this measurement device. 


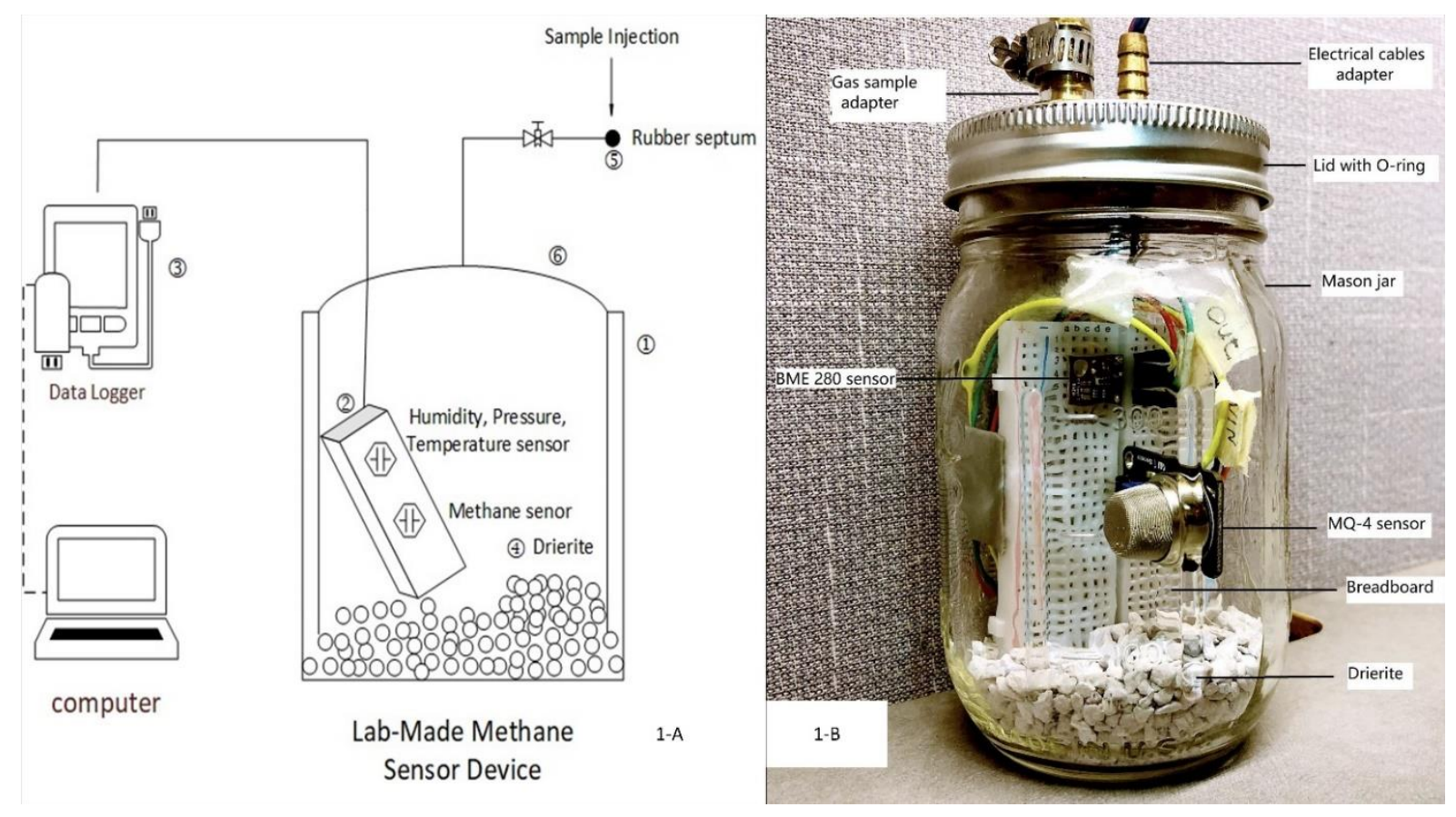

Fig 59: Schematic of diagram and photograph of methane measurement device.

1. Mason jar 2. Sensors and breadboard 3. Arduino data logger 4. Drierite 5. Rubber septum 6. Lid with O-ring

The sensor was able to detect methane within the jar to as low as $400 \mathrm{ppm}$, but responded linearly to concentrations ranging from about 4,000 to $110,000 \mathrm{ppm}$. Measurements made by the sensor were compared to analysis by a gas chromatograph equipped with a thermal conductivity detector. Figure 60 compares the measurement of methane content in a biogas sample from the anaerobic digester made by this device to the measurement made using a gas chromatograph (GC). As can be seen the measurement made by device agrees well with GC measurements. The average absolute error being $0.69 \pm 0.55 \%$ when compared to GC measurements. Using $10 \mathrm{ml}$ biogas sample size, methane content as low as $18 \%$ by volume in the biogas could be reliably measured by the device. By increasing sample size to $90 \mathrm{ml}$, methane content as low as $2.4 \%$ could be analyzed. This device was assembled for a cost of only US\$37. A field version that includes an LED display and power pack could be assembled for under US\$50. Conventional methane composition measurement devices like gas chromatographs, landfill gas analyzers and infrared devices cost thousands of dollars. 


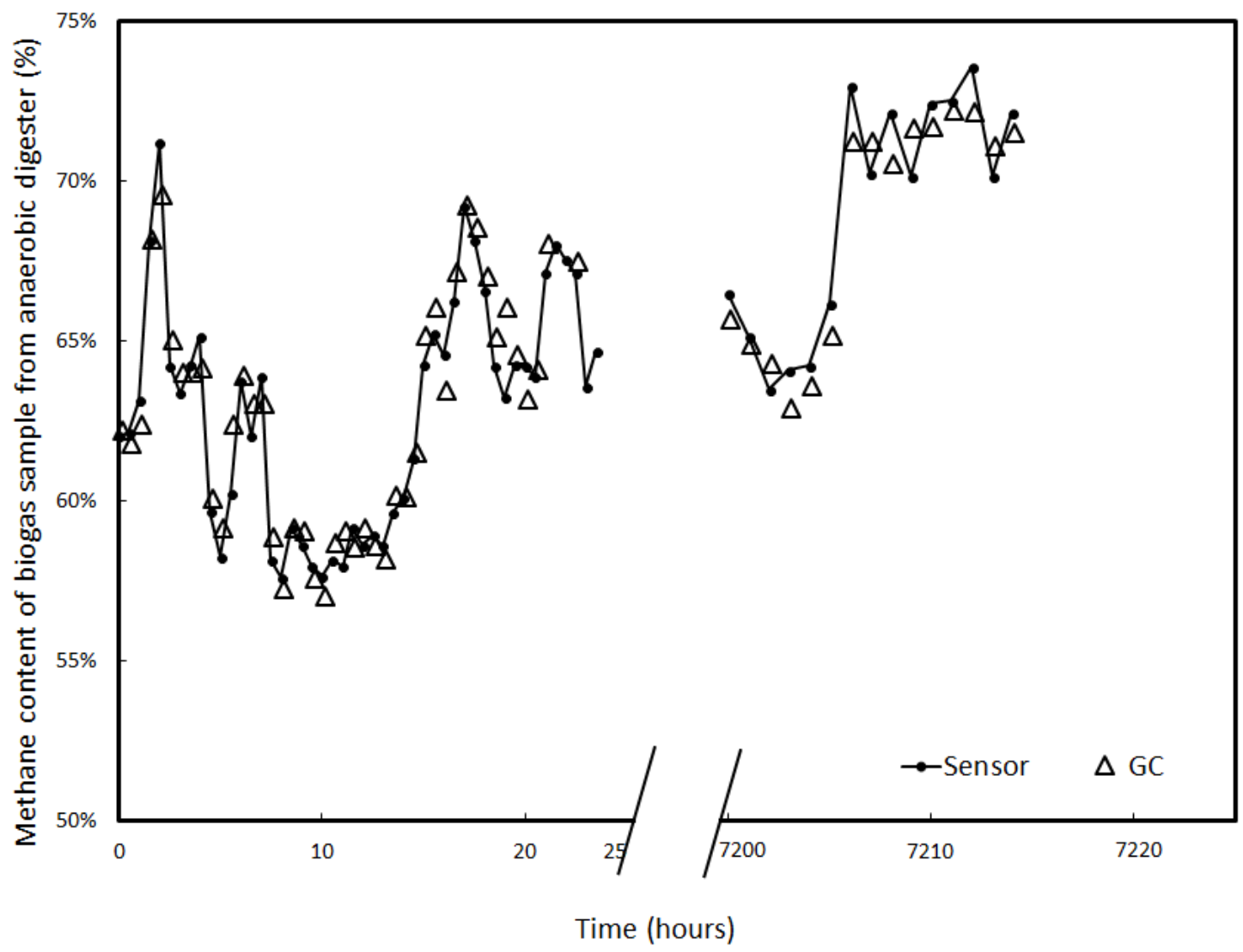

Fig 60: Comparison of methane measurements by device to measurements by GC of biogas samples from anaerobic digester, soon after the device was assembled and after ten months of device operation.

The above off-line measurement device was then modified for automatic and on-line measurement of methane content of biogas from anaerobic digester. The modifications included provision of two-way valves for automatic introduction of samples from anaerobic digester into device chamber and for evacuation of sample as well as an air pump to blow air into chamber to quickly vent the sample from chamber prior to next sample injection. These valves and air pump were controlled by an Arduino. This on-line measurement device was attached to anaerobic digester. Figure 61 shows the data collected by the device. Some measurements were compared to measurements made by a GC. The bars in the graph are instances of introducing feed into the digester. Figure 62 shows a detailed view of device measurements compared to that made using a GC over the duration of digester operation. Due to the dynamic nature of the process, only measurements made over a 
three hour window were compared. As can be seen the absolute error between measurements is about $1.1 \%$. The cost of the online device was about $\$ 107$.

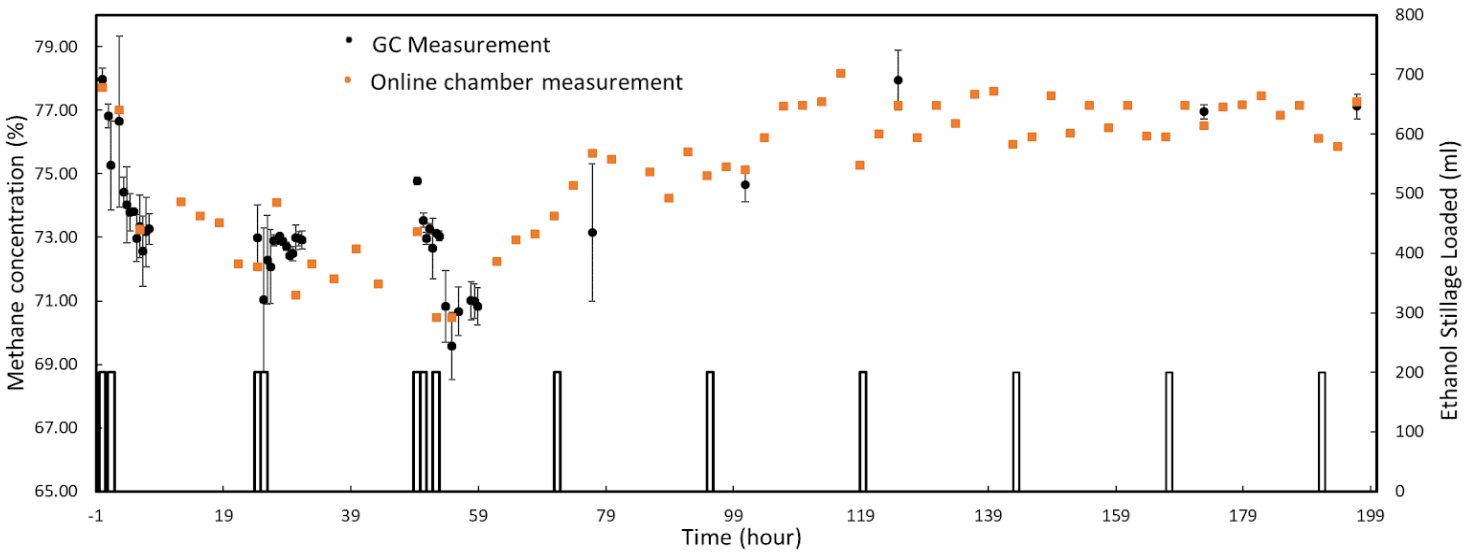

Fig 61: Comparison of online methane measurements by device to measurements by GC of biogas samples.

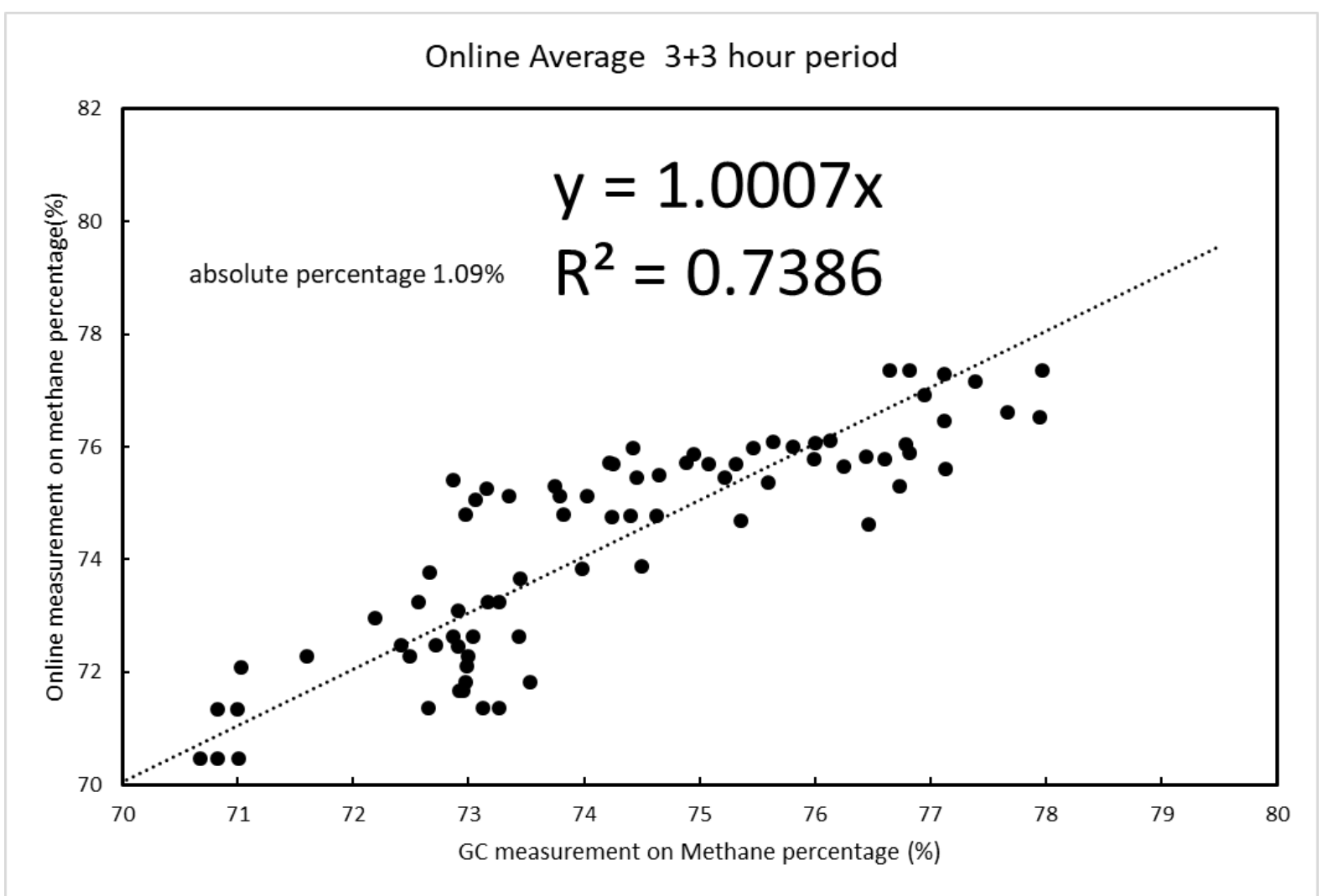

Fig 62: Comparison of inline methane measurements by sensor to measurements by GC of biogas samples in 3 hour-window. 


\section{References}

1. S. Aman, J. Tomas and H. Kalman, Breakage Probability of Irregularly Shaped Particles, Chemical Engineering Science 65 (2010) 1503-1512.

2. E. Rozenblat, D. Portnikov, A. Levy, H. Kalman, S. Aman and J. Tomas, Strength Distribution of Particles under Compression, Powder Technology 208 (2011) 215-224.

3. D. Portnikov, H. Kalman, S. Aman and J. Tomas, Investigating the Testing Procedure Limits for Measuring Particle Strength Distribution, Powder Technology 237 (2013) 489-496.

4. D. Portnikov and H. Kalman, Determination of Elastic Properties of Particles Using Single Particle Compression Test, Powder Technology 268 (2014) 244-252.

5. D. Portnikov and H. Kalman, The Effect of Temperature on the Mechanical Characteristics of Individual Particles, Powder Technology 336 (2018) 393-405.

6. D. Portnikov and H. Kalman, Material Comminution Functions of Wet Particles, Powder Technology, submitted, 2018.

7. M.I. Ahmad, C.D. Sinclair, A. Werritty, Log-logistic flood frequency analysis, J. Hydrol. 98 (1988) 205-224.

\section{COLLABORATION}

Kevin Buettner (Ph D student) worked in Dr. Kalman's laboratory at Ben-Gurion University collecting data on flow properties of biomass particles towards the end of Year 1 of this project. He then continued to work closely with Dr. Kalman's lab analysing data and simulating the flow behaviour of the particles. Joint publications are expected from this work.

\section{PUBLICATIONS}

\section{Referred journal publications}

1. K. Buettner, Y. Guo, and J. Curtis, "Using the Discrete Element Method to Develop Collisional Dissipation Rate Models that Incorporate Particle Shape", AIChE Journal, 63, 5384-5395 (2017)

2. Y. Guo, K. Buettner, G. Lane, C. Wassgren, B. Hancock, W. Ketterhagen and J. Curtis, "Computational and Experimental Studies of Flexible Fiber Flows in a Normal-StressFixed Shear Cell”, AIChE J., doi: 10.1002/aic.16397 (2018)

3. Y. Guo, C. Wassgren, B. Hancock, W. Ketterhagen and J. Curtis, "Discrete Element Simulation Studies of Angle of Repose and Shear Flow of Wet, Flexible Fibers", Soft Matter, 14, 2923-2937 doi: 10.1039/C7SM02135F (2018)

4. K.E. Buettner, Y. Guo and J.S. Curtis, Development of a collisional dissipation rate model for frictional cylinders, Powder Technology, Accepted https://doi.org/10.1016/j.powtec.2019.01.068

5. K. Buettner, Y. Guo and J. Curtis, "Some Considerations for Measuring the Collisional Dissipation Rate of Flexible Fibers, Powder Technology, In review (2018). 
6. Buettner, K., Sarkar, A. and J. Curtis, "Fluid-particle drag force measurements from particle-resolved CFD simulations of flow past random arrays of ellipsoidal particles", Chemical Engineering Science, in review (2018)

7. Yang, Shunchang; Liu, Yikan; Wu, Na; Zhang, Yingxiu; Svoronos, Spyros;

Pullammanappallil, Pratap. Low-cost. Arduino-based, portable device for measurement of methane composition in biogas. Renewable Energy. 138, pp224-229 (2019)

https://doi.org/10.1016/j.renene.2019.01.083 


\section{Future Publications}

There are a number of topics which are new innovative and will certainly be published soon:

1. Compression stress of biomass in air and in liquid.

2. Shear tests of biomass in air and in liquid.

3. Fluidization curves of biomass with air and with liquid.

4. On-line measurement of methane in biogas

5. Effect of bulk density on rate and extent of degradation during anaerobic digestion of biomass feedstocks. 